Serviço de Pós-Gradução EESC/USP

EXEMPLAR REVISADO

Data de entrada no Serviço:..07.../... $7 . . / .03$.

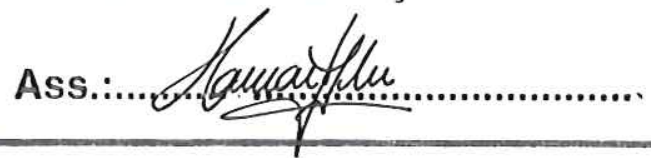

RICARDO TOSHIYUKI IRITA

\title{
TÉCNICA DE COLIMAÇÃO PARA OTIMIZAR A AQUISIÇÃO E O PROCESSAMENTO DE IMAGENS MAMOGRÁFICAS
}
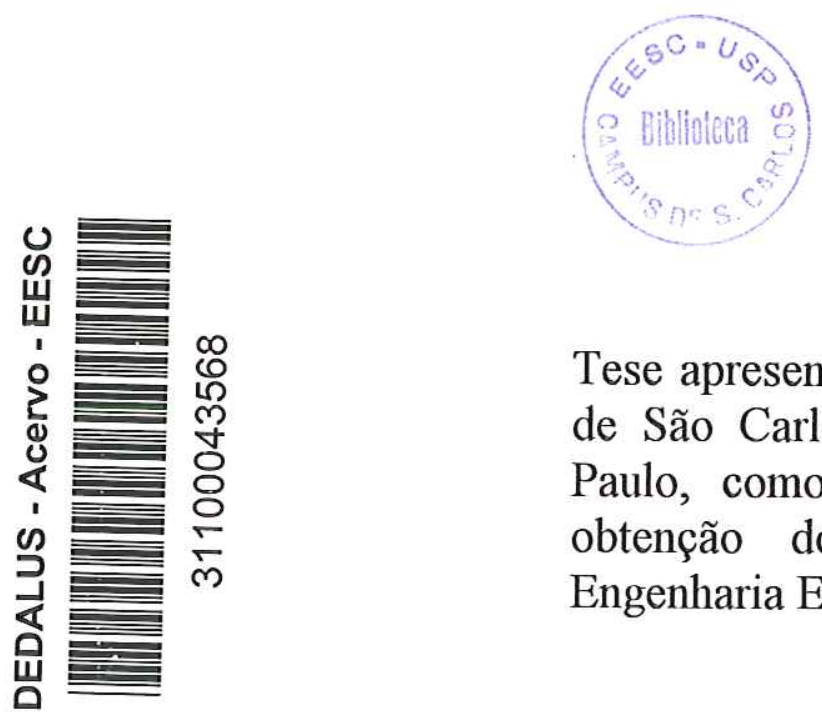

Tese apresentada à Escola de Engenharia de São Carlos da Universidade de São Paulo, como parte dos requisitos para obtenção do Título de Doutor em Engenharia Elétrica.

Orientadora: Prof ${ }^{-} \mathrm{Dr}^{\mathrm{a}}$ Annie France Frère Slaets 


\section{ERRATA}

\begin{tabular}{|l|l|l|l|}
\hline Página & Figura & Onde se lê & Leia-se \\
\hline 23 & 3.3 & $\begin{array}{l}\text { Proporção de gordura ou lucite } \\
\text { Coeficientes de atenuação }\end{array}$ & $\begin{array}{l}\text { Proporção de gordura ou lucite } \\
\text { Espectro de energia de raios -X; } \\
\text { Coeficientes de atenuação e } \\
\text { espalhamento; } \\
\text { kVp, mAs, espessura, dff, dfo; } \\
\text { n. de fótons total = 10^5 }\end{array}$ \\
\hline 32 & 4.3 & $\begin{array}{l}\text { Espectro de raios -X e } \\
\text { Coeficientes de atenuação e } \\
\text { espalhamento }\end{array}$ & $\begin{array}{l}\text { Espectro de raios -X; } \\
\text { Coeficientes de atenuação e } \\
\text { espalhamento; } \\
\text { kVp, mAs, espessura, dff, dfo. }\end{array}$ \\
\hline 32 & 4.3 & $\begin{array}{l}\text { Configuração da geometria e } \\
\text { parâmetros de exposição }\end{array}$ & $\begin{array}{l}\text { Configuração geométrica e } \\
\text { parâmetros de exposição } \\
\text { Pixel no início da matriz filme }\end{array}$ \\
\hline 32 & 4.3 & $\begin{array}{l}\text { Faça para cada ponto da matriz } \\
\text { filme }\end{array}$ & próximo pixel da matriz filme \\
\hline 32 & 4.3 & posição>matriz filme & percorreu matriz filme? \\
\hline
\end{tabular}

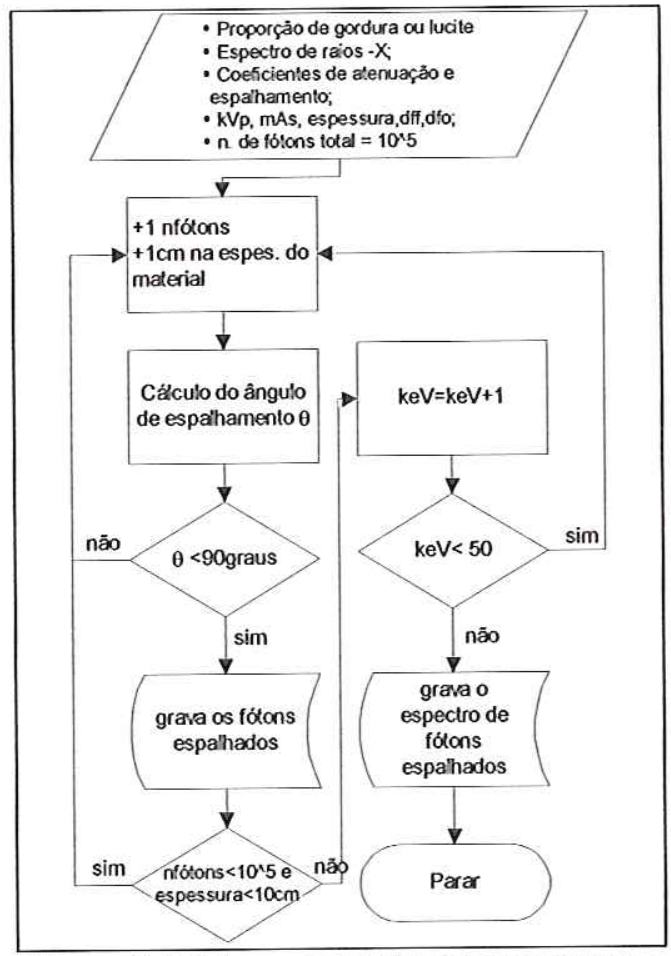

Figura 3.3. Fluxograma do programa para cálculo de espalhamento até $90^{\circ}$.

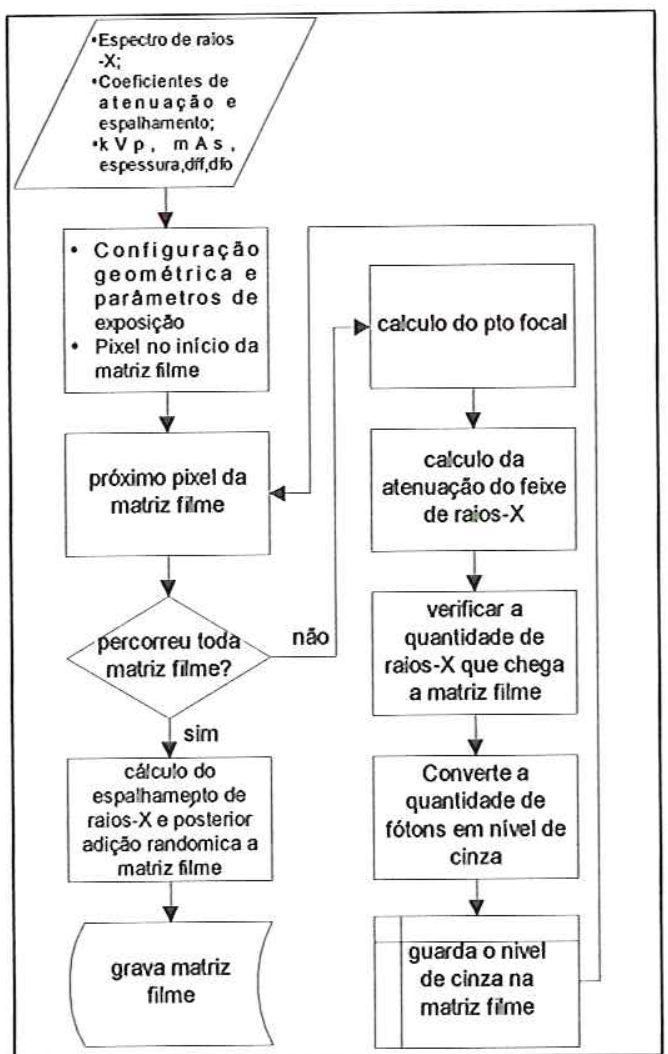

Figura 4.3. Fluxograma para obtenção de imagem de matriz de esferas. 
FOLHA DE JULGAMENTO

Candidato: Engenheiro RICARDO TOSHIYUKI IRITA

Tese defendida e julgada em 16-05-2003 perante a Comissão Julgadora:

Profa. Tit. ANNIE FRANCE FRËRE SLAETS (Orientadora)

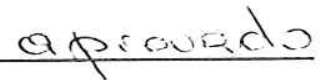

(Escola de Engenharia de São Carlos/USP)

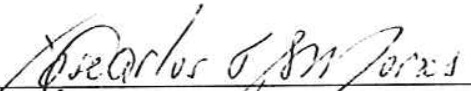

$A, P, 01 A .10$

Prof. Assoc. JOSÉ CARLOSTEIXEIRA DE BARROS MORAES (Escola Politécnica/USP)

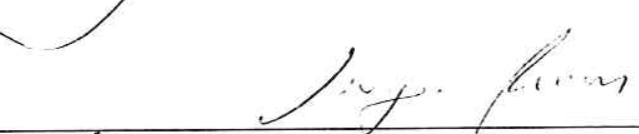

Dr. SÉRGIO SHIGLEMI FURUIE

(Instituto do Coraç $\tilde{g} / \mathrm{SP}$ )

Prof. Dr. ANTONIO CARLOS ROQUE DA SILVA FILHO

APROVADO

(Faculdade de Filosofia, Ciências e Letras de Ribeirão Preto/USP)

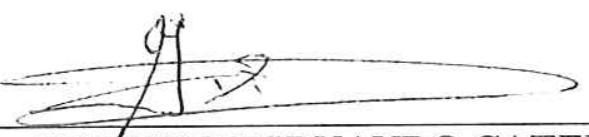

APRQVAR

Prof. Dr. ANTONIO FERNANDO CATELLI INFANTOSI

(COPPE/Universidade Federal do Rio de Janeiro/UFRJ)

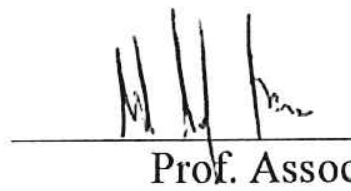

Prot. Assoc. MURILO ARAUJO ROMERO

Coordenador do Programa de Pós-Graduação

Em Engenharia Elétrica

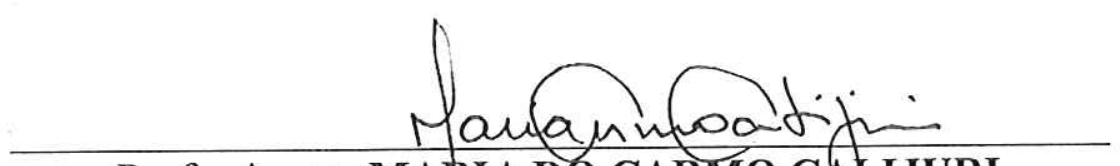

Profa. Assoc. MARIA DO CARMO CALIJURI

Presidente da Comissão de Pós-Graduação 
Este trabalho foi financiado pela Fundação de Amparo a Pesquisa do Estado de São Paulo - FAPESP. 
Dedico este trabalho a duas pessoas especiais: a minha esposa Nana pelo amor e paciência demonstrada antes, durante e após o término deste trabalho; e para o mais novo membro da família, o bebê, que cresce em segurança no ventre materno e que me reacende a vontade de viver e lutar por um mundo melhor. 


\section{AGRADECIMENTOS}

À minha querida companheira e incentivadora, Nana, pelo carinho e dedicação.

Aos meus pais e irmãos por me colocarem neste mundo e me ajudarem a crescer e a tornar a pessoa que sou.

Às famílias Ebisawa, Watanabe e Terauchi por acreditarem e me incentivarem sempre.

À Prof. $\mathrm{Dr}^{\mathrm{a}}$ Annie pela orientação no trabalho e na vida, sempre demonstrando carisma, sabedoria e principalmente paciência.

Aos amigos do laboratório @ladim pela amizade e companheirismo.

Aos professores e funcionários do Depto de Engenharia Elétrica.

Ao grupo do Fujita Laboratory da Universidade de Gifu pelas imagens e o sistema CAD cedidos.

$\mathrm{E}$ a todos que direta e indiretamente participaram deste trabalho.

À Fundação de Amparo a Pesquisa do Estado de São Paulo (Fapesp) pelo apoio financeiro. 


\section{RESUMO}

IRITA, R. T. (2003). Técnica de Colimação para Otimizar a Aquisição e o Processamento de Imagens Mamográficas. Tese (Doutorado) - Escola de Engenharia de São Carlos, Universidade de São Paulo, São Carlos, 2003.

Para melhorar a visualização das pequenas estruturas anatômicas importantes para o diagnóstico do câncer de mama e otimizar o processamento das mamografias pelos sistemas computadorizados de auxílio ao diagnóstico (CAD), foi desenvolvido um dispositivo, baseado na tecnologia slit, que melhora a aquisição dos mamogramas. Este dispositivo reduz a radiação espalhada e o tamanho do foco e foi projetado a partir de um modelo computacional. O modelo adotado permite quantificar o valor desses parâmetros para qualquer sistema radiológico, qualquer espessura de tecidos moles radiografada e qualquer tensão aplicada ao tubo de raios-X. O dispositivo foi implementado e testado, quantificando as melhorias obtidas. As imagens geradas foram comparadas com as fornecidas pelos sistemas mamográficos convencionais. O modelo serviu para estudar também a interferência do espalhamento sobre o desempenho dos algoritmos usados nos sistemas de diagnóstico auxiliado por computador (CAD).

Palavras-chaves: slit mamográfico modificado, simulação da radiação $X$, modelagem, quantificação da radiação $\mathrm{X}$, espalhamento, raios-X. 


\section{ABSTRACT}

IRITA, R. T. (2003). Collimation Techniques for Optimization of Mammography Image Acquisition and Processing. Ph.D Thesis - Escola de Engenharia de São Carlos, Universidade de São Paulo, São Carlos, 2003.

In order to improve the visualization of the small and important anatomical structures for breast cancer diagnosis and to optimize the image processing of mammograms by the computer aided diagnosis systems (CAD), a device that comes from slit technology was developed to improve the acquisition of mammograms. This device reduces the amount of scattered radiation and the focus size and it can be projected from a computational model. This model allows quantifying the value of those parameters, scattered radiation and the focus size, for any radiological system, any x-rayed soft tissue thickness and any tension applied to the $\mathrm{x}$-ray tube. The device was implemented and tested quantifying the obtained improvements. The generated images were compared to the supplied for conventional mammography systems. The model was also good for studying the scattering interference on the algorithms used in the computer aided diagnosis systems (CAD).

Keywords: modified mammography slit, x-ray simulation, computer modeling, $\mathrm{x}$-ray quantification, scatter radiation, $\mathrm{x}$-ray. 


\section{LISTA DE FIGURAS}

FIGURA 1. 1. DiSPOSIÇÃo DOS SLITS NOS SISTEMAS DIGITAIS (TESIC ET AL.,1983). 3

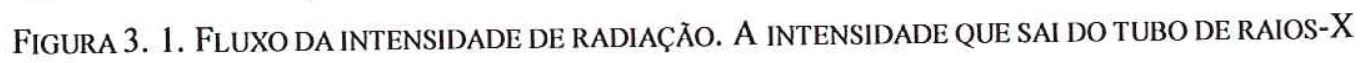

(Io) PASSA POR VÁRIAS ETAPAS ATÉ CHEGAR AO FILME EM FORMA DE INTENSIDADE DA RADIAÇÃO PRIMÁRIA (IPE) E RADIAÇÃO ESPALHADA (ISE) .................................................... 16

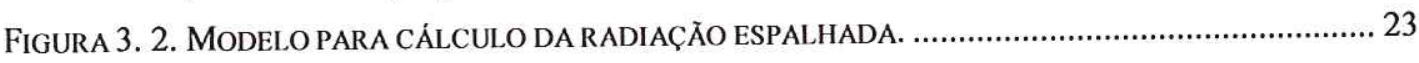

FIGURA 3. 3. FluXOGRAMA DO PROGRAMA PARA CÁLCULO DE ESPALHAMENTO ATÉ $90^{\circ}$.................... 23

FIGURA 3. 4. REPRESENTAÇ̃̃o DA PROJEÇão DO FOCO PARA UM ÂNGULO DE INCLINAÇÃO $\gamma$ EM RELAÇÃO AO EIXO CATODO ANODO. 25

FigURA 3. 5. MÉTOdO DE SUBTRAÇÃo ENTRE OBJETO E FONTE UTILIZADO POR OLIVEIRA

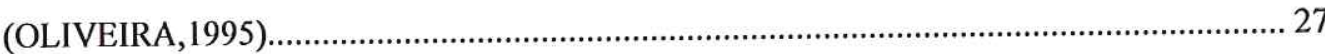

(4.2) 29

Figura 4. 1. MODELO DE FEIXE COLIMAdO PARA OTIMIZAR A AQUISIÇÃo DAS IMAGENS. .................... 29

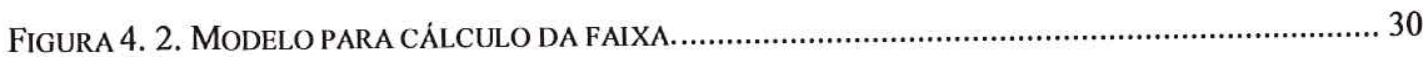

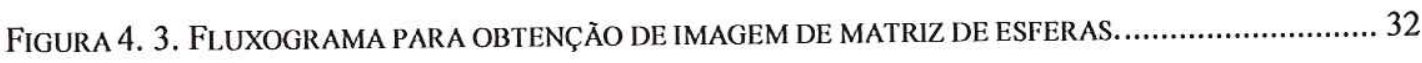

FigurA 4. 4. ESPALHAMENTO QUE ATRAVESSA A FENDA COM ÂNGULO LIMITE DE ESPALHAMENTO $\left(\theta_{\mathrm{M}}\right)$. 33

FIGURA 4. 5. FlUXXGRAMA PARA SIMULAR RADIOGRAFIAS POR FEIXE COLIMADO.............................. 34

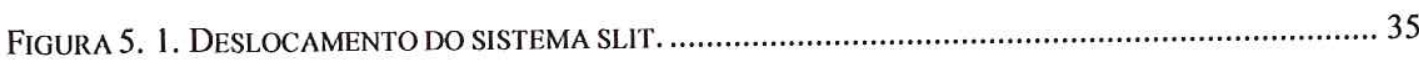

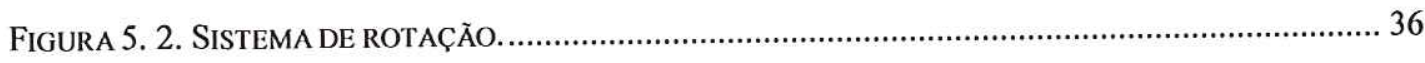

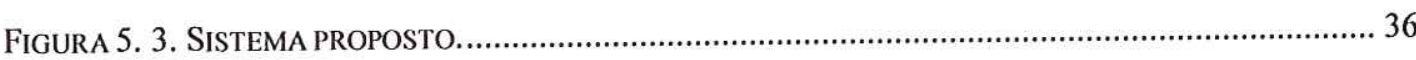

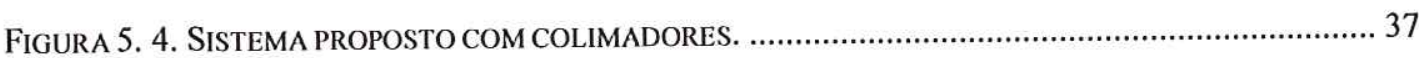

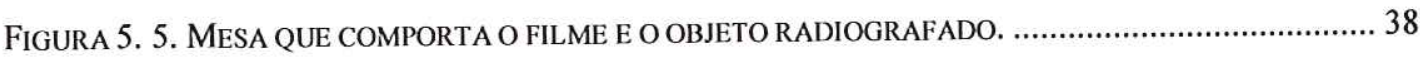

FIGURA 5. 6. CARRO COM EIXOS-GUIAS DE AÇO............................................................................. 39

FigURA 5. 7. GUIAS PARA CONTROLE DE ÂNGULO DE ROTAÇÃo DA MESA-FILME.................................. 40

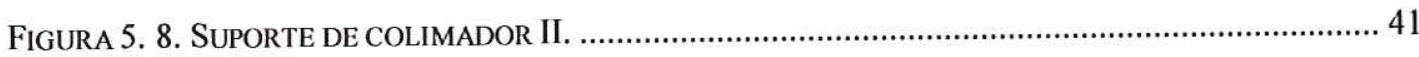

FIGURA 5. 9. SISTEMA COMPLETO COM COLIMADORES.................................................................. 41

FigURA 5. 10. POSICIONAMENTO dos COLIMADORES PARA LIMITAR O FEIXE. ...................................... 42

Figura 5. 11. ESQUEMA ELÉTrico(A) E MONTAGEM FINAL (B) DO CIRCUITO TRANSFORMADOR COM

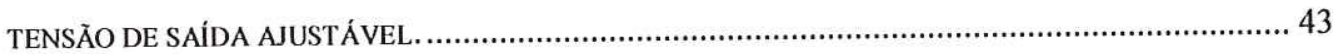

FigURA 5. 12. ESQUEMA (A) E MONTAGEM FINAL DA CAIXA DE CONTROLE PARA ACIONAMENTOE

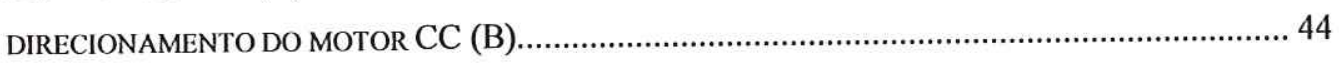

FIGURA 5. 13. ESQUEMA DE MEDIDA COM O USO DO BLOQUEADOR DE FEIXE. ...................................... 45

FIGURA 5. 14. O BLOQUEADOR DO FEIXE TEORICAMENTE NÃO DEIXA PASSAR RADIAÇÃO (A), PORÉM A RADIAÇ̃̃o ESPALHADA PELO OBJETO ACABA SENSIBILIZANDO O FILME LOGO ABAIXO DELE (B).46

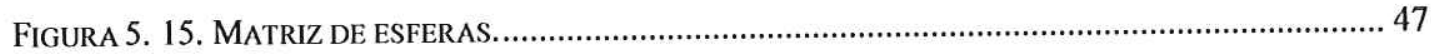

FigURA 6. 1. FLUXOGRAMA PARA ADICIONAR ESPALHAMENTO A UMA IMAGEM RADIOGRÁFICA.......... 51 
FIGURA 7. 1. ESQUEMA DO SISTEMA COM UM COLIMADOR. 53

FIGURA 7. 2. VARIAÇÃO DA INTENSIDADE DE RADIAÇÃO AO LONGO DO EIXO CATODO-ANODO DEVIDO AO EFEITO HEEL EM FUNÇÃO DA DISTÂNCIA DC__I.

FIGURA 7. 3. VARIAÇÃO DA INTENSIDADE DE RADIAÇÃO AO LONGO DO EIXO CATODO-ANODO DEVIDO AO EFEITO HEEL E À LEI DO INVERSO AO QUADRADO DA DISTÂNCIA. 54

FIGURA 7. 4. VARIAÇÃO DA INTENSIDADE DE RADIAÇÃO PERPENDICULARMENTE AO EIXO CATODOANODO DEVIDO AO EFEITO HEEL E À LEI DO INVERSO AO QUADRADO DA DISTÂNCIA................. 55

FIGURA 7. 5. DENSIDADE ÓPTICA SIMULADA E MEDIDA PARA O ÂNGULO DCc_I................................. 56

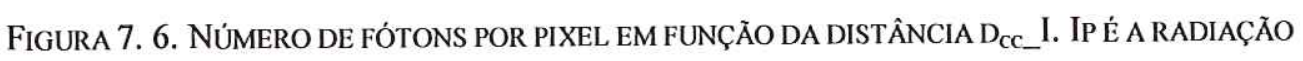
PRIMÁRIA E IS É A RADIAÇÃO ESPALHADA.

FIGURA 7. 7. RADIAÇÃO ESPALHADA SST EM FUNÇÃO DA ENERGIA (KEV) PARA MAMA SEM PRESENÇA DE TECIDO ADIPOSO.

FIGURA 7. 8. SST EM FUNÇÃO DA ENERGIA (KEV) PARA VÁRIAS ESPESSURAS DE MAMA COMPOSTA DE $70 \%$ DE TECIDO ADIPOSO

FIGURA 7. 9. SST EM FUNÇÃO DA ENERGIA (KEV) PARA VÁRIAS ESPESSURAS DE MAMA COMPOSTA

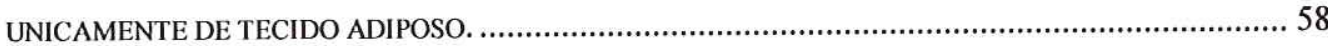

FIGURA 7. 10. SST EM FUNÇÃO DA ENERGIA (KEV) PARA VÁRIAS ESPESSURAS DE LUCITE................. 59

FIGURA 7. 11. SST $(\theta)$ PARA O LUCITE DE 5CM DE ESPESSURA A $25 \mathrm{~K}$ VP EM FUNÇÃO DO ÂNGULO DE ESPALHAMENTO DOS FÓTONS.

FiguRA 7. 12. ESPALHAMENTO SST( $\theta)$ PROVOCADO POR $1 \mathrm{MM}^{2}$ DO LUCITE DE 5 CM DE ESPESSURA COM $25 \mathrm{KVP}$.

Figura 7. 13. TAXA DE ESPALHAMENTO EM RELAÇÃO AO PRIMÁRIO(SP) MEDIDA FEITA POR BARNES E BREZOVICH (BARNES\&BREZOVICH,1978) E SIMULADA PARA ESPESSURAS DE LUCITE DE ATE 6 См СОм о тUво А $32 \mathrm{KVP}$.

FIGURA 7. 14. MODELO DE FEIXE COLIMADO PARA OTIMIZAR A AQUISIÇÃO DAS IMAGENS. 63

FIGURA 7. 15. TAMANHO DO PONTO FOCAL EM FUNÇÃO DA LARGURA DA FAIXA DE RADIAÇÃO PARA $\beta_{1}$ $\mathrm{E} \beta_{2}$ 65

FIGURA 7. 16. RADIAÇÃO PRIMÁRIA EM FUNÇÃO DA LARGURA DA FAIXA DE RADIAÇÃO PARA A PLACA DE LUCITE DE 2,5CM DE ESPESSURA EM $\beta_{1}$ E $\beta_{2}$

FIGURA 7. 17. RADIAÇÃO ESPALHADA EM FUNÇÃO DO TAMANHO DA FAIXA DE RADIAÇÃO PARA A PLACA DE LUCITE DE 2,5CM DE ESPESSURA.

FIGURA 7. 18. TAXA DE ESPALHAMENTO EM FUNÇÃO DO TAMANHO DA FAIXA DE RADIAÇÃO PARA ESPESSURAS DE LUCITE DE 2,5; 4,5 E 6,5 cM.

FIGURA 7. 19. TAXA DE ESPALHAMENTO EM FUNÇÃO DO TAMANHO DO FOCO A_SLIT.

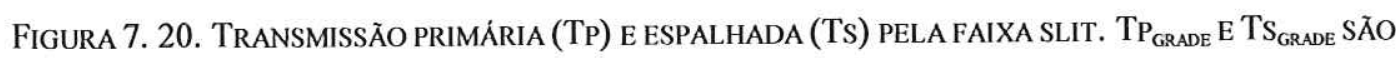
AS TRANSMISSÕES DA GRADE LINEAR VIBRATÓRIA. 
FiguRA 7. 21. TAXAS DE ESPALHAMENTO PARA O MODO CONVENCIONAL SEM GRADE, PARA O MODO SLIT E PARA O MODO SLIT MODIFICADO EM FUNÇÃO DA ESPESSURA DO OBJETO (LUCITE) A $25 \mathrm{KVP}$ E ABERTURA DE FEIXE DE 10MM NOS MODOS SLIT.

FigURA 7. 22. SimULAÇ̃̃o DA RADIOGRAFIA NO MODO CONVENCIONAL DE UMA MATRIZ DE ESFERAS

(A) E IMAGEM DA ESFERA POSICIONADA A $3,0^{\circ}$ DO CENTRO DO CAMPO (B). 72

FigURA 7. 23. SiMULAÇÃo de RADIOGRAFIA NO MODO SLIT MODIFICADO (A) E E IMAGEM DA ESFERA POSICIONADA A $3,0^{\circ}$ DO CENTRO DO CAMPO (B). 72

FIGURA 7. 24. DIÂMETROS E NIVEIS DE CINZA MÁXIMOS DAS IMAGENS DAS ESFERAS EM FUNÇÃO DA

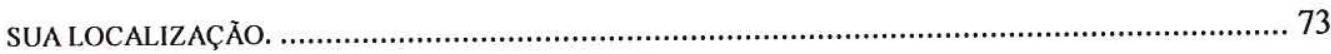

FIGURA 7. 25. SISTEMA COMPLETO COM COLIMADORES NO MAMÓGRAFO........................................... 74

FIGURA 7. 26. IMAGEM DA MATRIZ COM DISPOSITIVO MAMOGRÁFICO CONVENCIONAL. ....................... 75

FIGURA 7. 27. IMAGEM DA MATRIZ COM O DISPOSITIVO SLIT MODIFICADO.......................................... 75

FigURA 7. 28. AUMENTO DA RADIAÇ̃̃o ESPALHADA NA IMAGEM SIMULADA EM FUNÇÃO DA

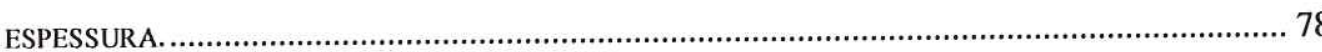

Figura 7. 29. DETECÇÃo de MiCRoCALCIFICAÇões E "CLUSTER" DE MiCROCALCIFICAÇÕES NA IMAGEM ORIGINAL (1,8CM DE ESPESSURA). AS MICROCALCIFICAÇÕES SÃO IDENTIFICADAS PELOS PEQUENOS CÍRCULOS E O “CLUSTER” PELO CIRCULO MAIOR. ..................................................... 79

FigurA 7. 30. DETECÇÃo DE MICROCALCIFICAÇÕES E “CLUSTER” DE MICROCALCIFICAÇÕES NA

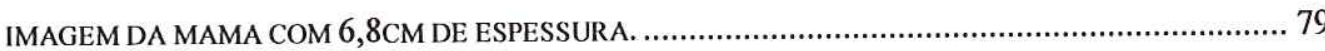

Figura 7. 31. DETECÇÃo DE MICROCALCIFICAÇÕES E “CLUSTER” DE MICROCALCIFICAÇÕES NA IMAGEM DA MAMA COM MAIS DE 8CM DE ESPESSURA.

FIGURA 7. 32. TAXA DE DETECÇÃO DE MICROCALCIFICAÇÕES EM FUNÇÃO DO AUMENTO DA ESPESSURA DA MAMA. 80

FiguRA 7. 33. VARIAÇÃo DA TAXA DE ESPALHAMENTO EM FUNÇÃO DA ESPESSURA DA MAMA PARA AS DIVERSAS PROPORÇÕES DE TECIDO ADIPOSO

FigURA 7. 34. DETECÇÃO RELATIVA EM FUNÇÃO DA ESPESSURA E PROPORÇÕES DE TECIDO ADIPOSO. 82 


\section{LISTA DE TABELAS}

TABELA 7. 1. COEFICIENTES A, XC, K DA EQUAÇÃO DE SGOMPEZ PARA OS TECIDOS DA MAMA.......... 59

TABELA 7. 2. COEFICIENTES A, XC, K DA EQUAÇÃO DE SGOMPEZ PARA O LUCITE..............................60

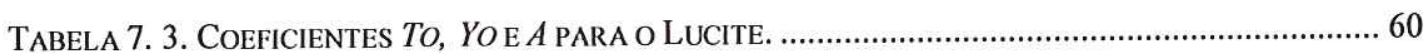

TABELA 8. 1. TABELA COMPARATIVA ENTRE OS MÉTODOS SLIT ORIGINAL E MODIFICADO COM MÉTODO

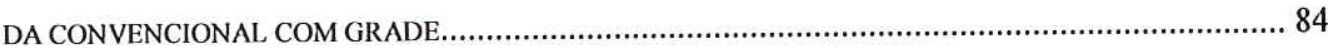




\section{LISTA DE TERMOS}

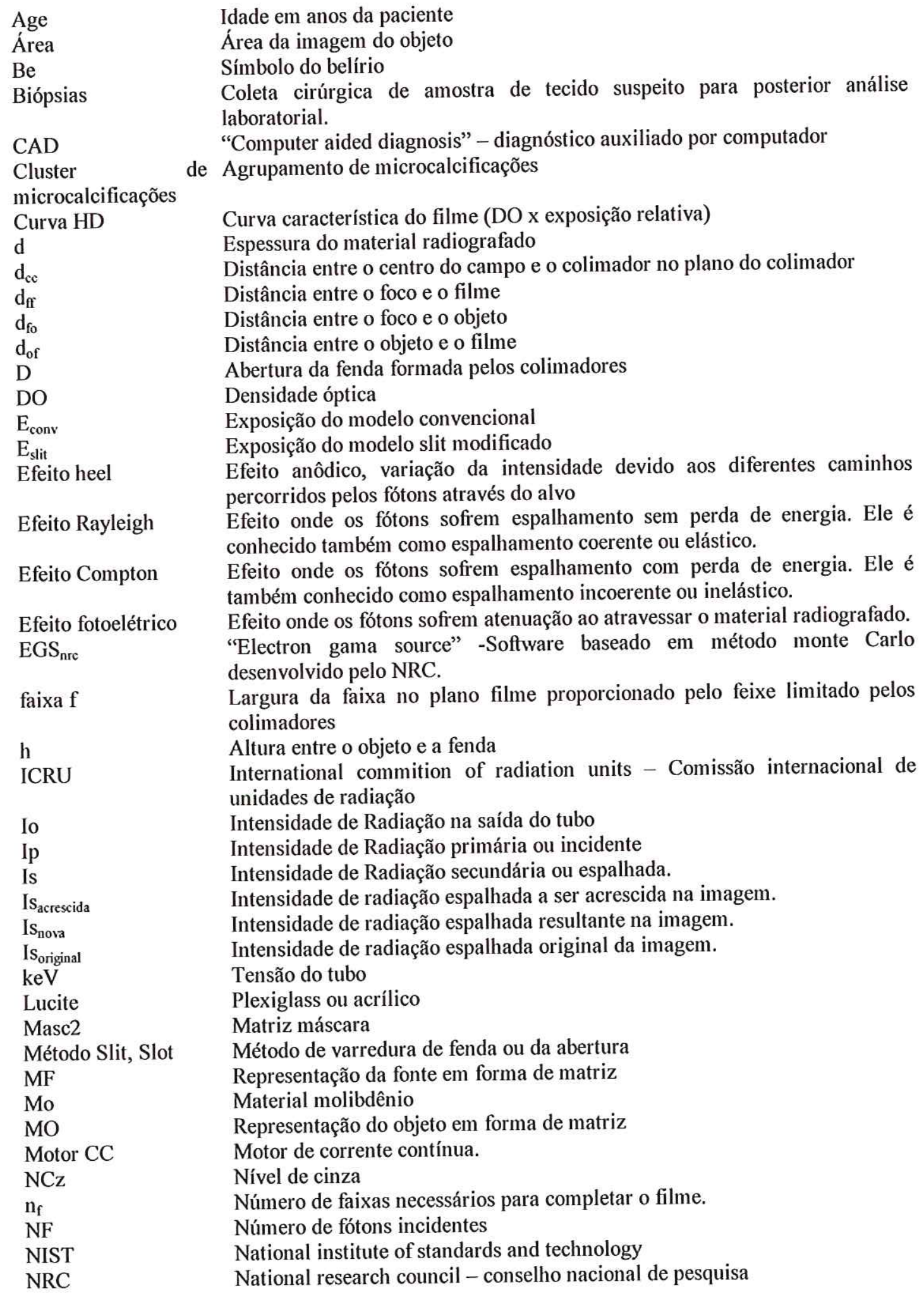


Origin ${ }^{\circledR}$

Prop $_{\text {adipose }}$

Q

$\theta$

$\rho$

$\sigma$

S/P

SST

$\mathrm{t}$

$t_{\text {conv }}$

$t_{\text {slit }}$

Threshold

Tp e Ts

$\mathrm{W}$

XCOM
Software para manipulação e visualização de dados da empresa Microcal Software, Inc - Microcal ${ }^{\mathrm{TM}}$

Proporção de tecido adiposo em relação ao tecido fibro-glandular

Corrente do tubo

Angulo de espalhamento

Densidade

Seção de choque atômica

Taxa de espalhamento

Porcentagem de fótons espalhados

Tempo de exposição

Tempo de exposição no modo convencional

Tempo de exposição pelo modo slit modificado

Valor usado para binarização

Transmissão da radiação primária e espalhada através da grade

Tamanho do ponto focal, será a na direção catodo-anodo e b na direção perpendicular ao mesmo

Software desenvolvido pelo NIST para obter os coeficientes de atenuação de massa para os diversos tecidos 


\section{SUMÁRIO}

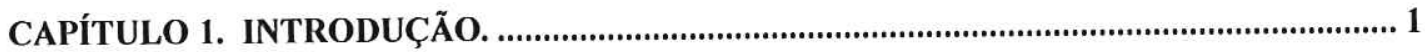

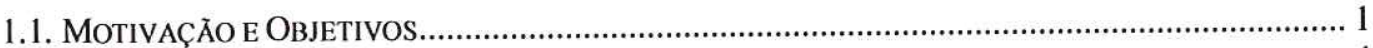

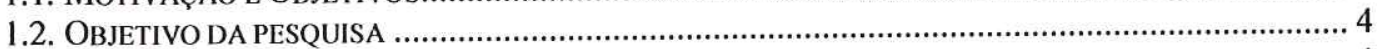

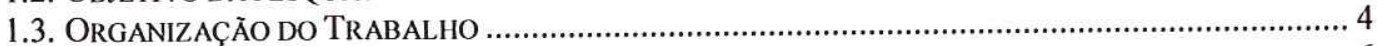

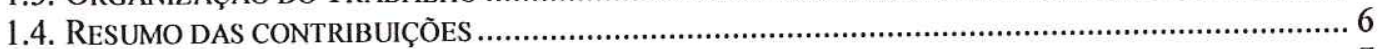

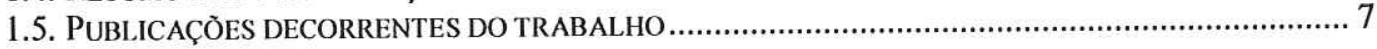

CAPÍTULO 2. CONTEXTUALIZAÇÃO DO TRABALHO.......................................................... 8

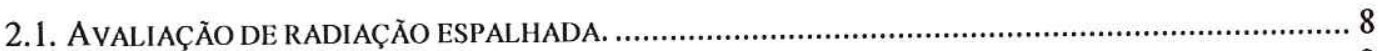

2.2. EFICIÊNCIA DOS MÉTODOS SLITS PARA A REDUÇÃO DE ESPALHAMENTO .................................. 9

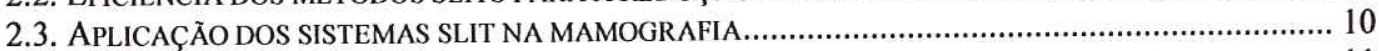

2.4. AVALIAÇÃo DA EFICIÊNCIA DOS SISTEMAS SLIT POR SIMULAÇÃO COMPUTACIONAL..................... 11

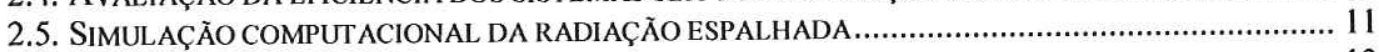

2.6. CONCLUSÕES DA REVISÃO …………………………...................................................... 13

CAPÍTULO 3. METODOLOGIA - ALGORITMOS PARA CALCULAR AS RADIAÇÕES PRIMÁRIAS E ESPALHADAS E O TAMANHO DO FOCO....................................................... 15

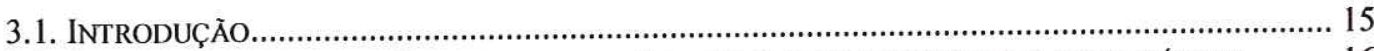

3.2. SiMULAÇÃO DA RADIAÇÃo PARA FORMAÇ̃̃o DE IMAGENS DE ESTRUTURAS MAMÁRIAS............ 16

3.2.1. Modelo para o cálculo das radiações transmitidas e espalhadas pela mama ................. 16

3.2.2. Determinação da composição e das proporções entre os tecidos mamários................... 19

3.2.3. Cálculo da quantidade de fótons espalhados SST que chega no detector: ...................... 20

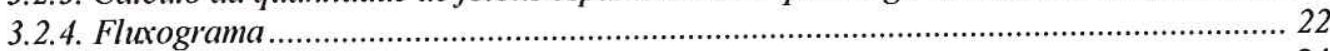

3.3. CÁLCULO DO TAMANHO E DA FORMA DO PONTO FOCAL ......................................................... 24

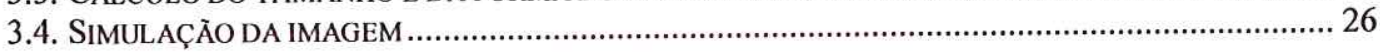

CAPÍTULO 4. APLICAÇÃO 1 - PROJETO DO SISTEMA PARA OTIMIZAR A AQUISIÇÃO DAS MAMOGRAFIAS. .................................................................................. 28

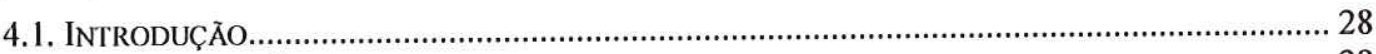

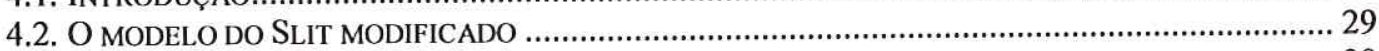

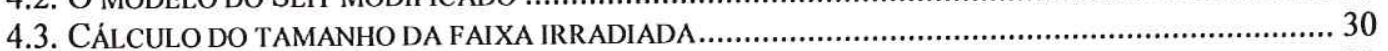

4.4. CÁLCULO DA EXPOSIÇÃO COM O SLIT MODIFICADO ………………………………………....... 31

4.5. FluXXograma Da SIMULAÇÃo DA IMAGEM CONSIDERANDO ESPALHAMENTO E TAMANHO DO

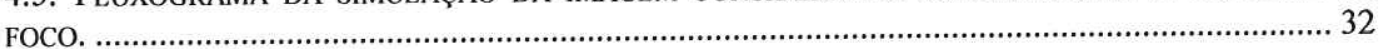

4.6. FluXograma da simulação COMPUTACIONAL do ESPALHAMENTO PROVOCADO PELO

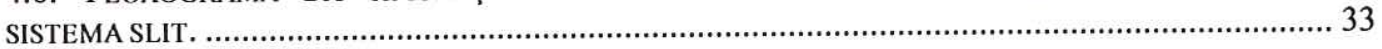

CAPÍTULO 5. PROTÓTIPO DO SISTEMA SLIT MODIFICADO E DISPOSITIVOS

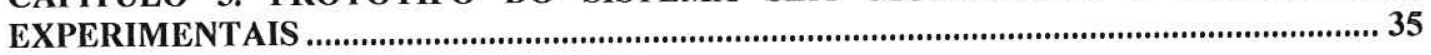

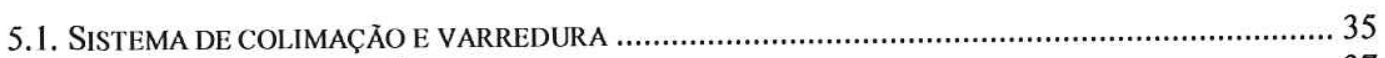

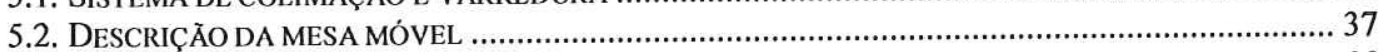

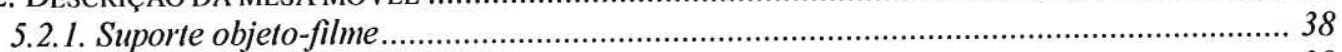

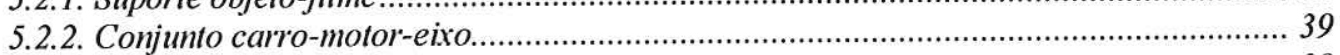

5.2.3. Guias para ajuste do ângulo de rotação ...................................................................... 39

5.2.4. Suporte ajustável para o colimador II........................................................................ 40

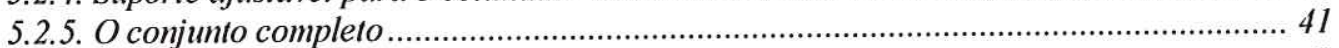

5.2.6. Colocação dos colimadores...................................................................................... 42

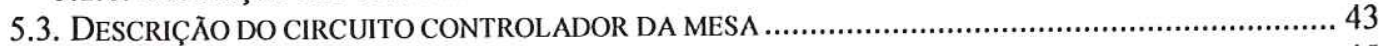

5.4. DISPOSITIVOS EXPERIMENTAIS PARA AVALIAÇÃO DO MODELO..................................................... 45

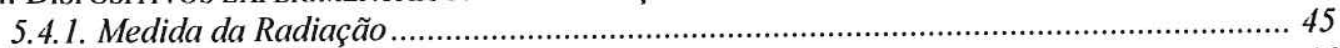

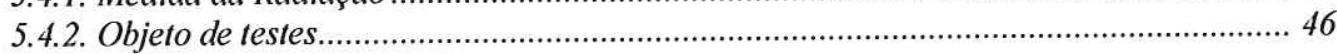


CAPÍTULO 6. APLICAÇÃO 2 - ESTUDO DA INTERFERÊNCIA DA RADIAÇÃO ESPALHADA SOBRE O DESEMPENHO DOS ALGORITMOS USADOS NOS SISTEMAS CAD.

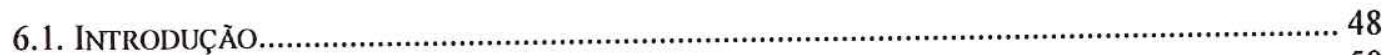

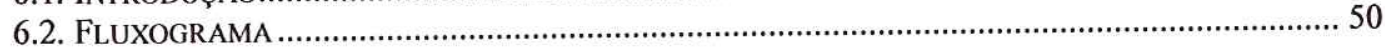

CAPÍTULO 7. RESULTADOS E DISCUSSÕES................................................................... 52

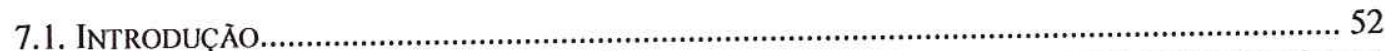

7.2. QUANTIFICAÇÃo DA RADIAÇÃo PRIMÁRIA PARA O SISTEMA CONVENCIONAL E VALIDAÇÃO DO

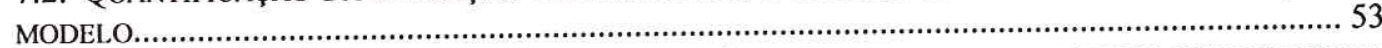

7.3. QUANTIFICAÇÃO COMPUTACIONAL DA RADIAÇÃO ESPALHADA PARA O SISTEMA CONVENCIONAL

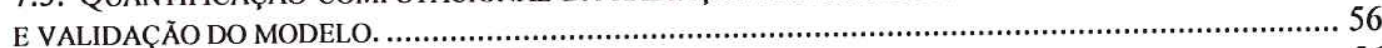

7.3.1. Cálculo da radiação espalhada ............................................................................. 56

7.3.2. Determinação dos coeficientes necessários para o cálculo do SST em função do ângulo

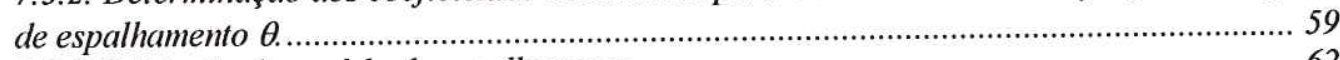

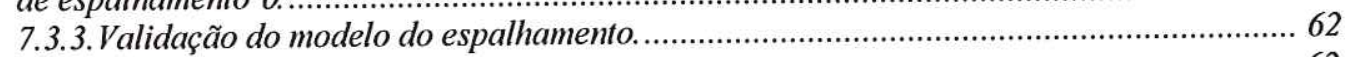

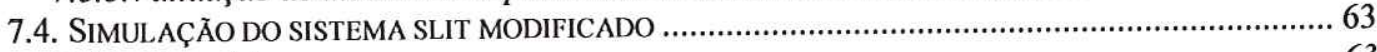

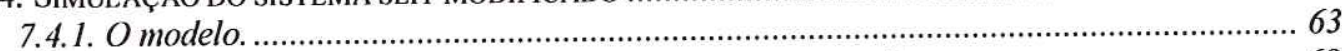

7.5. DIMENSIONAMENTO DO PROTÓTIPO PARA OTIMIZAR A AQUISIÇÃO DOS MAMOGRAMAS.............69

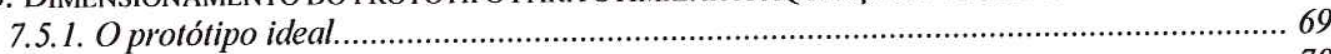

7.5.2. Simulação da exposição ....................................................................................... 70

7.5.3. Simulação das imagens produzidas pela radiografia convencional e pelo modo slit. .... 71

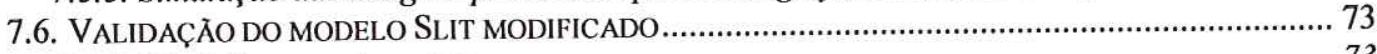

7.6.1. Mediçôes experimentais ............................................................................................ 73

7.6.2. Medições do espalhamento e da radiação total.......................................................... 75

7.7. QUANTIFICAÇÃO DA INFLUÊNCIA DA RADIAÇÃo ESPALHADA SOBRE O DESEMPENHO DOS

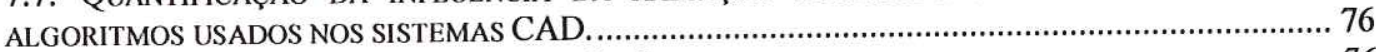

7.7.1. Determinação da radiação espalhada por um mamograma ............................................. 76

7.7.2 Analisando os resultados do CAD com imagens modificadas ........................................ 78

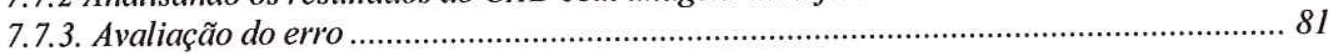

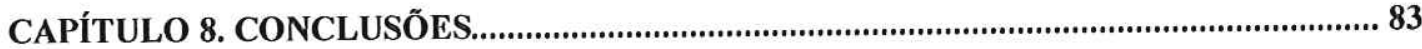

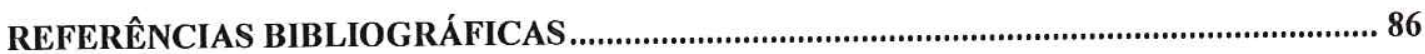




\section{CAPÍTULO 1. INTRODUÇÃO.}

\subsection{MOTIVAÇÃO E OBJETIVOS}

O tamanho do foco que emite os raios-X, assim como as radiações espalhadas pelas estruturas anatômicas, são os maiores responsáveis pela falta de nitidez das imagens radiográficas. Quanto maior o foco, maior é a penumbra formada na imagem. Para se obter imagens ideais, sem deformações geométricas, o foco ou ponto focal, deve ser igual a um ponto, o que não acontece na realidade apesar do nome. Além disso, devido à chamada característica de campo, as projeções do foco variam ao longo do campo de radiação, aumentando em direção ao catodo, dificultando ainda mais a obtenção de uma imagem uniforme e nítida, e conseqüentemente o diagnóstico do médico.

No caso dos mamógrafos a nitidez da imagem é prejudicada pelo fato de se utilizar, para posicionar a mama, o lado do catodo onde o foco é maior, mas onde a intensidade do feixe de radiação é também mais intensa devido ao efeito "heel". Esta posição é escolhida porque a espessura da mama é maior junto ao tórax (mesmo com a mama comprimida) e receberá mais radiação nesta extremidade. Esta opção para casar o aumento da intensidade dos raios$\mathrm{X}$ com o aumento da espessura da mama tem, como contrapartida, a localização das possíveis lesões na região do campo onde o foco é maior e, portanto, onde a deteç̧ão de estruturas pequenas como microcalcificações é a menos favorecida. 
Por outro lado, como a deteç̧ão das microcalcificações associadas aos tumores vem nos últimos anos se mostrando cada vez mais importante para o diagnóstico precoce do câncer de mama, os fabricantes lançaram no mercado tubos para mamografia com duas opções para focos, $0,3 \mathrm{~mm}$ e $0,7 \mathrm{~mm}$. Entretanto o que se verifica na prática é que os microfocos de $0,3 \mathrm{~mm}$ nem sempre são utilizados porque muitos usuários escolhem trabalhar somente com a segunda opção para não danificar o tubo. Isto acontece porque a redução do tamanho do foco é obtida pela diminuição da área de impacto do feixe de elétrons no anodo, concentrando, numa área reduzida, a dissipação da energia térmica resultante da transformação da energia cinética dos elétrons em fótons. Quando se lembrar que $90 \%$ da energia do feixe de elétrons são transformados em calor, se entende o temor dos usuários pela durabilidade dos tubos. Desse modo, a redução do tamanho do foco por procedimentos externos ao tubo de raios-X que não diminuam a área de impacto do feixe de elétrons sobre o ânodo, é relevante para os usuários.

A radiação espalhada é outro fator que compromete a nitidez da imagem mamográfica. Devido à sua característica aleatória, ela sensibiliza locais não desejados, deformando as imagens e, apesar da existência de várias técnicas de eliminação, ela pode ser até o dobro da radiação primária que chega ao sistema detector. Entre os ruídos, a radiação espalhada devida à interação dos fótons de raios-X com a estrutura radiografada, é um dos mais importantes e sua influência sobre a eficiência na inspeção visual já foi estudada por vários autores que propuseram métodos de grades ou de câmera slit para reduzir a quantidade de fótons espalhados que chegam ao detector (BARNES et al., 1993). Com o avanço dos mamógrafos digitais, a técnica de eliminação do espalhamento através do uso de fenda ou "slit" foi introduzida e se mostrou eficiente.

Nos métodos "slit", que também são chamados de "slot" ou "scanográfico", o feixe de raios-X é limitado por duas fendas feitas de material radiopaco, colocadas uma antes e outra logo após o objeto 
radiografado (TESIC et al., 1983) formando um feixe de radiação colimado. Este feixe é então utilizado para varrer o paciente e formar a imagem de interesse como mostra a Figura 1.1.

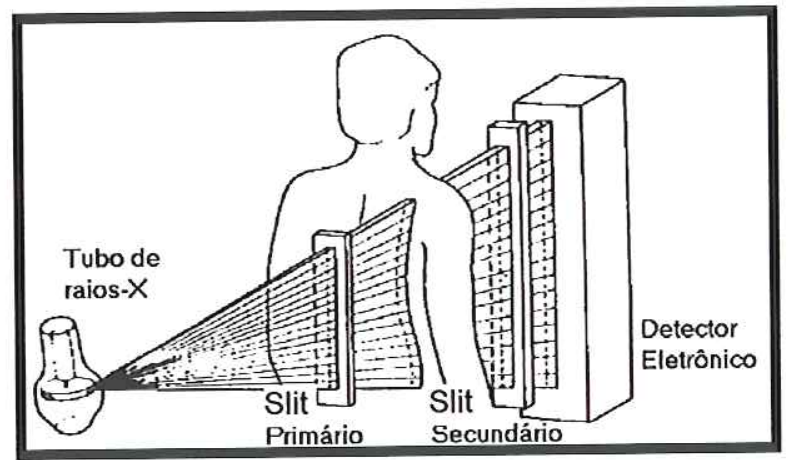

Figura 1. 1. Disposição dos slits nos sistemas digitais (TESIC et al.,1983).

Este método, quando acoplado a um mamógrafo, pode reduzir a radiação espalhada, melhorando na aquisição das imagens, o contraste e a nitidez das microcalcificações importantes para o diagnóstico precoce de câncer de mama. Entretanto a redução do espalhamento nunca foi quantificada. Os trabalhos relacionados ao método slit apresentaram apenas resultados de estudos experimentais. Por exemplo, BARNES et al. (BARNES et al., 1993) e JING et al. (JING et al., 1998), quando propuseram o uso de conjuntos slits, avaliaram a redução do espalhamento medindo experimentalmente o contraste da imagem.

Alguns autores simularam computacionalmente o efeito espalhamento para quantificar o ruído produzido \{(BOONE et al., 1999), (PEPLOW \& VERGHESE, 1998)\}. O método que estamos apresentando permite, além de calcular e simular o espalhamento, o superpor às imagens preservando, portanto, as características das mamografias relevantes para o processamento.

Atualmente, devido a pouca definição fornecida pelos mamógrafos dos detalhes importantes para o diagnóstico, começam a ser adotados sistemas que permitem complementar o exame mamográfico por um processamento computacional eficiente (ANASTASIO et al., 1998) o que permitirá reduzir o 
número de biópsias (70\% das biópsias são negativas). A detecção precoce do câncer de mama, que aumenta a probabilidade de cura, é facilitada pelo realce das pequenas estruturas e realizada por sistemas de auxílio computadorizado ao diagnóstico (CAD) (DOI, 1999). Entretanto o desempenho destes sistemas varia drasticamente em função das imagens que eles analisam (KALLERGI et al., 1999). Embora não exista uma relação clara entre a qualidade das imagens e os resultados apresentados pelos CAD há suspeitas que o ruído seja o fator fundamental para o mau funcionamento dos algoritmos (NISHIKAWA et al., 1994). De fato, o "gargalo" do processamento é a segmentação que, quando aplicada a estruturas de contornos não muito nítidos, não consegue separar adequadamente o ruído das microcalcificações. Portanto, a redução da radiação espalhada, favorecendo a deteç̧ão das estruturas pequenas mais importantes para o diagnóstico, desenvolvida neste trabalho, facilitará tanto o exame visual quanto o diagnóstico auxiliado por processamento computacional (CAD).

\subsection{OBJETIVO DA PESQUISA}

Melhorar a aquisição das imagens mamográficas, projetando, implementando e testando um dispositivo que reduz o tamanho do ponto focal e a radiação espalhada.

\subsection{ORGANIZAÇÃO DO TRABALHO}

Para realizar este trabalho levantamos o estado da arte a respeito das técnicas "slit" e grades desenvolvidas até agora para reduzir o espalhamento. Estudamos também, os conceitos teóricos que descrevem o espalhamento, assim como os modelos que o simulam e são apresentados na literatura. 
Analisamos estes tópicos e os apresentamos numa monografia para qualificação no programa de doutorado de engenharia elétrica USP São Carlos. Apenas a conclusão desta revisão foi utilizada e é apresentada no Capítulo 2 deste trabalho. Para maior detalhamento acessar a página da internet http://www.sel.eesc.sc.usp.br/aladim/index.htm.

Realizamos o estudo por simulação computacional de quanto um colimador e uma máscara podem melhorar a nitidez das imagens sem atenuar demais a intensidade da radiação. Apresentamos no Capítulo 3 o modelo e as equações desenvolvidas para calcular as radiações primárias e espalhadas, o tamanho e a forma do foco. Consideramos para os cálculos a influência destes fatores sobre um pixel do plano imagem localizado no eixo catodo anodo a uma distância variável do centro do campo.

Apresentamos no Capítulo 4 um modelo que permite calcular estes mesmos parâmetros para sistemas radiológicos com geometrias de exposição diferentes como o sistema slit ou slit modificado. No Capítulo 5 apresentamos o protótipo do sistema slit modificado e os dispositivos experimentais utilizados na validação do novo sistema.

No Capítulo 6 apresentamos um método que permite analisar o desempenho dos sistemas $\mathrm{CAD}$ em função da radiação espalhada.

No Capítulo 7 apresentamos os resultados obtidos a saber: quantificação da radiação primária e do espalhamento para o sistema convencional; quantificação das radiações primárias e espalhadas e da redução do tamanho do ponto focal para o sistema slit modificado; o protótipo para otimizar a aquisição das mamografias; as medições experimentais para comprovação do modelo.

No Capítulo 8 apresentamos as conclusões do trabalho e as propostas de trabalhos futuros. 


\subsection{RESUMO DAS CONTRIBUIÇÕES}

- Desenvolvimento de algoritmos que simulam e quantificam o espalhamento possibilitando:

- Projetar novos dispositivos para redução da radiação espalhada;

- Avaliar os métodos de redução de radiação espalhada;

- Simular as imagens produzidas com e sem espalhamento;

- Analisar a influência da radiação espalhada em sistemas de diagnóstico computadorizado (CAD);

- Projeto e implementação de um método slit modificado que melhora a qualidade das imagens mamográficas (foco e espalhamento);

- Determinação dos coeficientes relativos a composição da mama e do Lucite utilizados para calcular a taxa de espalhamento em função da tensão, espessura, composição dos tecidos (no caso da mama) e ângulo de espalhamento. 


\subsection{PUBLICAÇÕES DECORRENTES DO TRABALHO}

- IRITA, R.T.; FRÉRE, A.F.; OLIVEIRA, H.J.Q.; AZEVEDO MARQUES, P.M. Simulation of external collimator to enhancement of mammographic image sharpness. Journal IFMBE - MEDICAL \& BIOLOGICAL ENGINEERING \& COMPUTING, v.2, p1250-1251,Viena, Nov., 04-07, 1999.

- IRITA, R.T., FRERE, A.F., FUJITA, H. (2002). Simulation model to analyze the scatter radiation effects on breast cancer diagnosis by CAD system. Proc. of SPIE -The International Society for Optical Engineering, Medical Imaging, v.4682, p.782 - 791.

- IRITA, R.T.; FRÉRE, A.F. Scattered radiation in the slit mammography systems. Journal IFMBE - MEDICAL \& BIOLOGICAL ENGINEERING \& COMPUTING, v.3, p1270-1271,Viena, Dez., 04-07, 2002. 


\section{CAPÍTULO 2. CONTEXTUALIZAÇÃO DO TRABALHO.}

\subsection{AVALIAÇÃO DE RADIAÇÃO ESPALHADA.}

$\mathrm{Na}$ revisão da literatura que apresentamos na monografia para qualificação, mostramos que a radiação espalhada é um dos fatores que mais afetam a qualidade de imagem radiográfica. Quanto maior a sua quantidade, pior é o contraste da imagem. Na mamografia, onde a visualização de pequenos detalhes é muito importante para a deteç̧ão precoce do câncer, o método slit começou a ser utilizado para formar esta imagem, devido à suas propriedades de reduzir o espalhamento tanto incoerente como coerente.

Concluímos da revisão bibliográfica que a análise dos métodos de redução do espalhamento deve considerar a distribuição angular, as distribuições espectrais e a intensidade das radiações primárias e espalhadas nas condições normais de formação de imagem mamográfica. A avaliação experimental, como feita até agora, não possibilita essa análise devido ao grande número de fatores envolvidos, mas ela é viável com uma simulação computacional. 


\subsection{EFICIÊNCIA DOS MÉTODOS SLITS PARA A} REDUÇÃO DE ESPALHAMENTO.

O método slit foi proposto por Pasche em 1903, mas não se popularizou devido tanto ao longo tempo de exposição exigido, quanto ao sucesso da técnica de grade proposta por Potter e Bucky em 1913. O método somente despertou de novo o interesse dos pesquisadores quando foi apresentada uma ampliação utilizando múltiplos slits (JAFFE \& WEBSTER, 1975) que permitiu reduzir o tempo de exposição e a sobrecarga do tubo. Aos múltiplos slits foram acrescentados movimentos síncronos lineares e rotativos que proporcionaram resultados melhores que os obtidos com a técnica de grade.

Em destaque o sistema de Moore et al (1977) que reduziu o espalhamento significativamente. Os autores compararam um sistema com grade, com um sistema sem nenhuma redução, com um sistema slit e com um sistema composto grade-slit. O sistema grade melhora o contraste em $40 \%$ em relação ao sistema convencional sem nenhum dispositivo de redução de radiação espalhada, o sistema slit melhora o contraste em $80 \%$ e os autores conseguiram um resultado melhor ainda (95\%) com um sistema conjunto grade e slit. A revisão da literatura mostrou que além de reduzir o espalhamento, o sistema de varredura slit (CASTANEDA-ZUNIGA et al., 1980) proporciona uma uniformidade da imagem radiográfica pela eliminação do efeito "heel". Por sua vez Korbuly et al. (1980) destacaram que a dose absorvida é sempre menor no sistema slit que no sistema com grade.

Dos sistemas de múltiplos slit lineares (BARNES et al., 1993) e slit rotativos (YAFFE, 1993) propostos, os primeiros, que utilizam sistema telafilme, ainda não são produzidos comercialmente, mas os segundos, que utilizam detectores digitais, são produzidos pela Fischer Imaging unidade "Senoscan" desde 1996 (BOYLE et al., 1999). 


\subsection{APLICAÇÃO DOS SISTEMAS SLIT NA MAMOGRAFIA}

Na mamografia o sistema de múltiplos slits lineares de Barnes et al. (1993) e o sistema slit rotativo de Yaffe (1993) apresentaram excelentes resultados para remoção da radiação espalhada. O primeiro possui a vantagem de utilizar um conjunto de slits, que reduz o tempo de exposição do paciente, assim como um sistema tela filme que apresenta uma boa resolução espacial, mas possui uma mecânica de alinhamento complexa. O sistema de Yaffe é rotativo com um único par de slits que facilita o alinhamento e elimina o efeito heel. Porém o seu sistema gasta mais tempo que o sistema de Barnes e é acoplado a detectores digitais.

Nenhum dos dois sistemas leva em consideração a redução do tamanho do ponto focal. Na literatura somente o sistema slit de Amplatz et al. (1978) se preocupa em diminuí-lo tanto lateralmente através de colimadores eletrônicos dentro do tubo de raios-X quanto longitudinalmente inclinando o tubo em direção ao lado do ânodo.

Desde o início da década de 80 até hoje os detectores digitais sofreram um grande desenvolvimento e são acoplados e testados em conjunto com o sistema slit, principalmente com movimento rotativo. Porém eles ainda apresentam uma resolução espacial pior que o sistema tela-filme. Enquanto que o tamanho dos detectores está na ordem de $50 \mu \mathrm{m}$, o grão do sistema telafilme possui $3 \mu \mathrm{m}$. Isto nos leva a concluir que até o momento o uso de sistema tela filme é o mais indicado na mamografia para a visualização de pequenos detalhes. 


\subsection{AVALIAÇÃO DA EFICIÊNCIA DOS SISTEMAS SLIT POR SIMULAÇÃO COMPUTACIONAL}

A maioria dos trabalhos relacionada ao método slit apresentou apenas resultados de estudos experimentais. Somente Vuorinen e King \{(VUORINEN, 1959), (KING \& BARNES, 1983)\} fizeram um estudo matemático. Os outros autores avaliaram experimentalmente a redução do espalhamento quantificando o contraste da imagem.

Vuorinen (VUORINEN, 1959) equacionou parâmetros como largura do feixe, abertura e espessura do slit. Ele pretendia relacionar também a distribuição de intensidade do feixe, mas infelizmente ele não considerou a distribuição de intensidade do ponto focal nos seus cálculos, o que resultou em algumas conclusões equivocadas como a "sobreposição" das áreas de penumbra para explicar a intensidade maior nas bordas do que no centro dos feixes colimados.

King e Barnes em (KING \& BARNES, 1983) apresentaram um estudo em termos de função de transferência de sistema com somente um slit e também com múltiplos slits. Eles utilizaram a descrição matemática da transmitância do slit em convolução com a saída do tubo de raios-X para avaliar a exposição resultante no filme.

\subsection{SIMULAÇÃO COMPUTACIONAL DA RADIAÇÃO} ESPALHADA

Para reduzir a quantidade de espalhamento que chega ao detector, é necessário conhecer a distribuição angular e energética da radiação espalhada. Porém, devido à natureza estocástica do processo, onde não é possível fazer uma previsão exata do que acontecerá a cada fóton que atravessa o material 
espalhador, o estudo por meios analíticos torna-se muito complexo. Em função disto o método de modelagem utilizando Monte Carlo é quase unanimidade entre os pesquisadores para simular o espalhamento. Entre as vantagens deste método está a possibilidade de classificar os fótons em função do número de interações e dos tipos de processos que sofrem (coerente, incoerente, etc.). $\mathrm{O}$ método permite mudar facilmente vários parâmetros físicos como energia do feixe, geometria de irradiação, material espalhador, etc. Ele possibilita ainda estudar o comportamento de fótons monoenergéticos e suas características mudando determinados parâmetros como espessura e composição do material, etc.

Neste intuito a técnica de simulação de Monte Carlo foi utilizada por diversos pesquisadores da área de Radiologia. Em particular, estudos detalhados foram apresentados por Chan e Doi \{(CHAN \& DOI, 1983a), (CHAN \& DOI, 1983b), (CHAN \& DOI, 1985)\} e por Neitzel et al. (NEITZEL et al., 1985) que verificaram a validade de sua aplicação para o estudo da radiação espalhada. Os coeficientes de espalhamento foram dados por Hubbel (HUBBEL, 1975).

Dance (DANCE, 1980) aplicou o método Monte Carlo para prever a dose total de radiação na mama em xeromamografia. Porém, este autor preocupa-se somente em determinar a distribuição de dose no órgão durante o exame radiográfico e não considera outra importante característica como a radiação espalhada. Kalender em (KALENDER, 1981) empregou a simulação Monte Carlo para calcular o espalhamento para algumas condições de formação de imagem diagnóstica; porém, ele enfatizou as frações de espalhamento sem fornecer informações sobre outras propriedades importantes como a radiação espalhada por efeito Rayleigh em baixas energias.

As propriedades da formação da imagem com radiação espalhada na radiologia diagnóstica foram apresentadas detalhadamente por Chan e Doi em (CHAN \& DOI, 1983a). Os autores utilizam o método Monte Carlo para 
descrever os processos de interações dos fótons, incluindo a simulação do espalhamento, em um fantoma de tecido equivalente homogêneo. Eles aplicaram o programa para determinar as frações de espalhamento e sua distribuição no espaço quando os fótons emergem de um fantoma de Lucite sobre o plano da imagem. Esta simulação é a mais detalhada e específica para radiologia diagnóstica encontrada na literatura, sendo sempre referenciada. No entanto esta referência foi apresentada para a geometria de exposição da radiografia convencional, onde portanto, está limitada à entrada de parâmetros para tal geometria e somente para o material Lucite ou água, disposto em forma cúbica logo abaixo do tubo de raios-X.

Na simulação do sistema slit, apenas Barnes et al. (BARNES et al., 1994) utilizou o método Monte Carlo para comprovar a eficiência da eliminação do espalhamento por um dispositivo de varredura do pulmão. Ele mostrou a geometria de exposição adotada, porém não descreveu o algoritmo utilizado dificultando a reprodução da simulação.

\subsection{CONCLUSÕES DA REVISÃO}

Sem dúvida alguma, os sistemas atuais com grades e os métodos de redução do ponto focal, são muito melhores que no passado recente. No entanto, eles possuem limitações, provocam o aquecimento do tubo, a remoção da radiação espalhada é incompleta, a radiação primária no campo é muito atenuada, além de não eliminar o efeito heel.

Através desta revisão observamos que o sistema slit possui uma maior capacidade de redução da radiação espalhada do que os outros métodos. Contudo ele depende do ajuste preciso dos seus parâmetros para que não haja uma diminuição significativa da intensidade dos raios-X. Parâmetros como espessura e abertura de cada slit, distâncias foco-slit e foco-filme, além do alinhamento e movimento síncrono entre o slit primário e secundário devem 
ser ajustados com grande precisão. O tempo de exposição também é outro fator crítico que deve ser otimizado. Como a análise destes sistemas foi feita, na maioria dos casos, de modo experimental, a multiplicidade dos parâmetros envolvidos não permitiu propor sistemas eficientes tanto para reduzir o espalhamento e diminuir o tamanho do ponto focal quanto para otimizar a exposição e o tempo de varredura.

Portanto, desenvolvemos neste trabalho um método que permite modelar e quantificar esses parâmetros para que o sistema slit seja realmente utilizado. 


\section{CAPÍTULO 3. METODOLOGIA - ALGORITMOS PARA CALCULAR AS RADIAÇÕES PRIMÁRIAS E ESPALHADAS E O TAMANHO DO FOCO.}

\subsection{INTRODUÇÃO}

Neste capítulo apresentamos o modelo e as equações desenvolvidos para calcular: as radiações primárias e espalhadas; os coeficientes de espalhamento tanto para a mama quanto para o Lucite facilitando a utilização do método Monte Carlo para prever a quantidade de fótons espalhados que realmente chegam ao receptor (SST); o tamanho e a forma do foco. Consideramos para os cálculos a influência destes fatores sobre um pixel do plano imagem localizado no eixo catodo anodo a uma distância variável do centro do campo. 


\subsection{SIMULAÇÃO DA RADIAÇÃO PARA FORMAÇÃO DE IMAGENS DE ESTRUTURAS MAMÁRIAS.}

\subsubsection{Modelo para o cálculo das radiações transmitidas $\mathrm{e}$} espalhadas pela mama.

O modelo que adotamos para calcular o fluxo de raios-X que alcança $o$ sistema tela-filme é ilustrado na Figura 3.1, onde a radiação primária é a radiação que atravessa o material sem ser desviada de sua trajetória original e a radiação secundária é aquela que sofreu algum tipo de desvio.

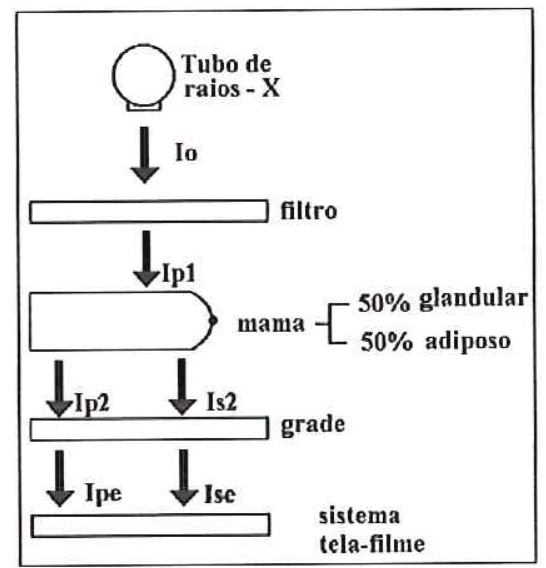

Figura 3. 1. Fluxo da intensidade de radiação. A intensidade que sai do tubo de raios-X (Io) passa por várias etapas até chegar ao filme em forma de intensidade da radiação primária (Ipe) e radiação espalhada (Ise).

Para simular as radiações transmitidas e espalhadas pela mama utilizamos a equação de Lambert_Bear (equação 3.1), que permite calcular a intensidade primária transmitida $I_{p}$ quando um feixe monoenergético com intensidade incidente $\boldsymbol{I} \boldsymbol{o}$ interage com o material de densidade de área $\boldsymbol{m}_{\boldsymbol{x}}$ (CURRY III et al, 1990). $\boldsymbol{m}_{\boldsymbol{x}}$ é o produto da espessura $\boldsymbol{d}$ pela densidade volumétrica $\rho$ do material e é dada pela equação $3.2 \mathrm{em}$ termos de massa por unidade de área. 


$$
\begin{aligned}
& I p=I o \cdot e^{-\mathrm{m}_{\mathrm{x}} \cdot \frac{\mu}{\rho}} \\
& \mathrm{m}_{\mathrm{x}}=d \cdot \rho
\end{aligned}
$$

O coeficiente de atenuação de massa $\mu \rho$ é relacionado pela equação 3.2 com a seção de choque total atômica $\sigma_{\text {tot }}$ que representa a probabilidade de encontro do fóton com partículas.

$$
\left(\frac{\mu}{\rho}\right)_{t o t}=\frac{\sigma_{t o t}}{(u \cdot A)}
$$

Onde $\boldsymbol{u}$ é a unidade de massa atômica $\left(\boldsymbol{u}=1.6605402 * 10^{-24} \mathrm{~g}\right)$ e $\boldsymbol{A}$ é a massa atômica relativa do material do alvo.

A seção de choque total $\sigma_{\text {tot }}$ pode ser escrita na equação 3.4 como a soma das contribuições das várias interações sofridas pelos fótons, onde $\sigma_{p e}$ é a seção de choque fotoelétrico, $\sigma_{c o}$ é a seção de choque de espalhamento coerente, $\sigma_{\text {inco }}$ é a seção de choque de espalhamento incoerente, $\sigma_{\text {pair }}$ e $\sigma_{\text {trip }}$ são as seções de choque para produção eletron-positron e $\sigma_{p l . n}$ é a seção de choque fotonuclear. Como os valores de $\sigma_{\text {pair, }}, \sigma_{\text {trip }}$ e $\sigma_{\text {pl.n }}$ para energias abaixo de $1 \mathrm{MeV}$ são próximos de zero, eles não são considerados nas baixas energias próprias das mamografias (HUBBELL, 1999). Portanto a expressão do coeficiente de atenuação de massa $(\mu \rho)$ total é dada pela equação 3.6.

$$
\begin{aligned}
& \sigma_{\text {tot }}=\left(\sigma_{p e}+\sigma_{c o}+\sigma_{\text {inco }}+\sigma_{\text {pair }}+\sigma_{\text {trip }}+\sigma_{\text {plun }}\right) \\
& \left(\frac{\mu}{\rho}\right)_{t o t}=\frac{\left(\sigma_{p e}+\sigma_{c o}+\sigma_{\text {inco }}\right)}{(u \cdot A)} \\
& \left(\frac{\mu}{\rho}\right)_{t o t}=\left(\frac{\mu}{\rho}\right)_{p e}+\left(\frac{\mu}{\rho}\right)_{c o}+\left(\frac{\mu}{\rho}\right)_{\text {inco }}
\end{aligned}
$$

Os fótons que incidem no material com intensidade (Io) são atenuados pelo efeito fotoelétrico, "Rayleigh" (coerente) e "Compton" (incoerente) 
(JONHS e CUNNINGHAM, 1983). Se a influência do efeito coerente e incoerente da equação 3.7 não fosse considerada, a equação 3.8 representaria a intensidade resultante (I $\left.\boldsymbol{p}^{\prime}\right)$ provocada apenas pelo processo fotoelétrico. Logo, por subtração, obtemos a intensidade dos fótons espalhados (I $\left.\boldsymbol{s}^{\prime}\right)$, como mostra a equação 3.9 .

$$
\begin{aligned}
& I p=I o \cdot \exp \left\{-d \cdot \rho \cdot\left[\left(\frac{\mu}{\rho}\right)_{R e}+\left(\frac{\mu}{\rho}\right)_{\omega}+\left(\frac{\mu}{\rho}\right)_{i n c o}\right]\right\} \\
& I p ` I o \cdot \exp \left\{-d \cdot \rho \cdot\left(\frac{\mu}{\rho}\right)_{\Gamma e}\right\} \\
& I s^{\prime}=I p-I p^{\prime}
\end{aligned}
$$

No modelo adotado da Figura 3.1, o feixe monoenergético Io, resultante da interação dos elétrons com o material do alvo, é atenuado por um material filtrador logo após a janela do tubo. A intensidade de radiação primária resultante da filtragem (Ip1), e calculada pela equação 3.10 , é atenuada e espalhada pela mama. A radiação primária (Ip2) e espalhada (Is2) são calculados pelas equações 3.11, 3.12 e 3.13. Essas radiações são também atenuadas e espalhadas pela grade, em função das taxas de transmissão das radiações primária $\left(\boldsymbol{T} \boldsymbol{p}_{\text {grade }}\right)$ e espalhada $\left(\boldsymbol{T} \boldsymbol{s}_{\text {grade }}\right)$ produzindo a radiação primária (Ipe) e espalhada (Ise) que chegam ao sistema tela-filme (equações 3.14 e 3.15 ).

$$
\begin{aligned}
& I p_{1}=I o \cdot \exp \left\{-d_{\text {fitr }} \cdot \rho_{\text {fithr }} \cdot\left[\left(\frac{\mu_{\text {fltro }}}{\rho_{\text {fitro }}}\right)_{F e}+\left(\frac{\mu_{\text {fitro }}}{\rho_{\text {fitro }}}\right)_{\omega}+\left(\frac{\mu_{\text {fitro }}}{\rho_{\text {fitro }}}\right)_{\text {inco }}\right]\right\}
\end{aligned}
$$

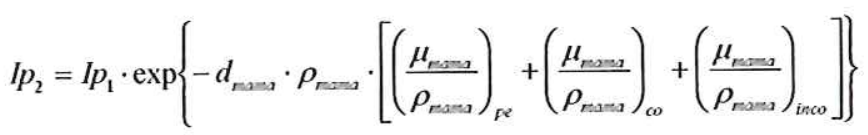

$$
\begin{aligned}
& I s_{2}{ }^{\prime}=I p_{1}-I p_{2} \\
& I s_{2}=S S T \cdot I s_{2}{ }^{\prime}
\end{aligned}
$$




$$
\begin{aligned}
& I p e=T p \cdot I p_{2} \\
& I s e=T s \cdot I s_{2}
\end{aligned}
$$

Encontramos os valores de $(\mu / \rho)_{\text {pe }},(\mu / \rho)_{\text {co }}$ e $(\mu / \rho)_{\text {inco }}$ para o filtro, para a mama e para o Lucite utilizando o software "XCOM" (BERGER et al., 1999) da "National Institute of Standards and Technology - NIST" disponível na página da internet http://physics.nist.gov/PhysRefData/.

\subsubsection{Determinação da composição e das proporções entre os} tecidos mamários.

Para calcular a quantidade de fótons espalhados pela mama é necessário conhecer a proporção entre os tecidos fibro-glandular e adiposo; a geometria da mama e os dados de exposição (número de fótons e energia incidente).

Adotamos para o tecido fibro-glandular a composição $(10,6 \mathrm{H}: 33,2 \mathrm{C}$ : $3 \mathrm{~N}: 52,7 \mathrm{O}: 0,1 \mathrm{Na}: 0,1 \mathrm{P}: 0,2 \mathrm{~S}: 0,1 \mathrm{Cl})$ e para o tecido adiposo $(11,4 \mathrm{H}:$ $59,8 \mathrm{C}: 0,7 \mathrm{~N}: 27,8 \mathrm{O}: 0,1 \mathrm{Na}: 0,1 \mathrm{~S}: 0,1 \mathrm{Cl})$. Estas composições são fornecidas pela Comissão Internacional de Unidades de Radiação ${ }^{1}$ (ICRU- Report 44) e as utilizamos para representar a mama respeitando sua geometria e espessura.

A proporção de tecido adiposo em relação ao tecido fibro-glandular (Prop $_{\text {alipose) }}$ foi fornecida por Lee et al. (LEE et al., 1997) que a relaciona com a idade (Age) pela equação 3.16. Utilizando exame de ressonância magnética, que capta melhor a quantidade de gordura que outros métodos de formação de imagens, o autor mostrou que o tecido adiposo varia de $48.5 \%$ a $84.5 \%$ da composição total da mama para pacientes com idade entre 20 a 83 anos.

1 ICRU (1989), "Tissue Substitutes in Radiation Dosimetry and Measurement", Report 44 of the International Commission on Radiation Units and Measurements (Bethesda, MD). 


$$
\text { Prop }_{\text {adipose }}=0.33248+0.00646 \cdot \text { Age }
$$

\subsubsection{Cálculo da quantidade de fótons espalhados SST que chega no detector.}

Como somente os fótons espalhados com ângulos entre $0^{\circ}$ e $90^{\circ}$ atingem o filme, já que os fótons fora deste intervalo são retro-espalhados, calculamos a quantidade de fótons espalhados (SST) que chega ao detector em relação ao número total de fótons espalhados pela mama, utilizando o programa de simulação por método de Monte Carlo fornecido pela NRCNational Research Council, o EGSnrc, disponível on-line via: "http://www.irs.inms.nrc.ca/irs/EGSnrc".

A partir da composição e da geometria do objeto, e dos dados de exposição (número de fótons e energia incidente) o programa Monte Carlo simula as interações dos fótons durante e após atravessarem o objeto (ROGERS et al., 2000). A este programa acrescentamos uma sub-rotina que calcula a $\operatorname{SST}(\theta)$ para cada ângulo estudado (equação 3.17), onde a $I \boldsymbol{S}(\theta)$ representa os fótons espalhados, $\boldsymbol{I} \boldsymbol{s}$, por um ângulo $\theta$ entre 0 a $90^{\circ}$ e $\boldsymbol{S T}$ o total de fótons espalhados.

$$
\operatorname{SST}(\theta)=\frac{I s(\theta)}{S T}
$$

SST depende ainda da composição e espessura do material radiografado e da $\mathrm{kVp}$ utilizada no tubo de raios-X. Por ser difícil a implementação e aumentar o tempo de simulação para cada composição, espessura e kVp requisitados, desenvolvemos um equacionamento simplificado, através de regressão, para variar estes parâmetros e poder utiliza-los posteriormente em qualquer programa de simulação de radiação espalhada. 
Por meio de regressão linear, equacionamos $\boldsymbol{S S T}(\theta)$ em função da proporção entre tecidos adiposo e fibro-glandular e da espessura do material radiografado para os pontos intermediários entre aqueles fornecidos pelo programa Monte Carlo. Para fazer a regressão, utilizamos as aproximações matemáticas fornecidas pelas equações de SGompez (equação 3.18), linear (equação 3.19), polinomial (equação 3.20) e de Harris (equação 3.21) via software Origin5® e, para avaliar o erro, a equação do qui-quadrado (equação 3.22), onde $\boldsymbol{A}, \boldsymbol{B}_{1}, \boldsymbol{B}_{2}, \boldsymbol{C}, \boldsymbol{k}, \boldsymbol{x c}$ são coeficientes; $\boldsymbol{x}$ representa os valores de entrada; $\boldsymbol{m}$ é a média; $\sigma_{\Delta}$ é o desvio padrão.

$$
\begin{aligned}
& Y=A^{*} e^{-\mathbf{k}(x-x c)} \\
& Y=A+B_{1}{ }^{*} x \\
& Y=A+B_{1}{ }^{*} x+B_{2}{ }^{*} x^{2} \\
& Y=\left(A+B_{1}{ }^{*} x^{C}\right)^{-1} \\
& \chi_{\Phi=n}^{2}=\sum\left(\frac{(x-m)}{\sigma_{\Delta}}\right)^{2}
\end{aligned}
$$

Adotamos como parâmetros: $\boldsymbol{x}$ quantidade de gordura na mama (0 a $100 \%)$ e $k e V$ energia do fóton.

Os coeficientes $\boldsymbol{a}, \boldsymbol{x} \boldsymbol{c}$ e $\boldsymbol{k}$ possuem valores aproximados pelas Equações (3.23), (3.24) e (3.25), respectivamente.

$$
\begin{aligned}
& a=A+B * k e V \\
& x c=A+B 1 * k e V+B 2 *(k e V)^{2} \\
& k=\left[A+B *(k e V)^{2}\right]^{-1}
\end{aligned}
$$

Equacionamos assim as porcentagens de fótons espalhados, $\boldsymbol{S S T}(\theta)$, para cada ângulo $\theta$ e para os coeficientes relativos a espessura do material radiografado ( $A$, To e $\mathbf{Y o}$ ) (Equação 3.26). Devido ao conjunto de dados possuir forma semelhante e com mínimo desvio, utilizamos para o cálculo a função exponencial (ExpDec1) do Origin5®. 


$$
\operatorname{SST}(\theta)=\mathrm{A} * \exp (-\theta / T o+Y o)
$$

Os coeficientes $\boldsymbol{A}, \boldsymbol{T o}$ e $\boldsymbol{Y o}$ foram aproximados novamente pela função exponencial do tipo $\mathrm{a}^{*} \exp (\mathrm{keV} / \mathrm{t})$.

Somamos a quantidade de fótons espalhados $\operatorname{SST}(\theta)$ para $\theta$ entre 1 e $90^{\circ}$ e encontramos o valor de $\boldsymbol{S S T}$ que utilizamos na equação 3.13 para calcular a radiação espalhada $\left(\boldsymbol{I} \boldsymbol{s}_{2}\right)$ a partir do $\boldsymbol{I} \boldsymbol{s}_{2}$ ' dado pela equação 3.12. No caso de sistema convencional com grade, antes de chegar ao receptor $I p_{2}$ e $I s_{2}$ são atenuados pela grade, fornecendo Ipe e Ise pelas equações 3.14 e 3.15 .

Ipe e Ise são dados em função de número de fótons transmitidos, do tempo de exposição, da corrente do tubo e da área medida no filme (n. de fótons $\left./\left(\mathrm{mA}^{*} \mathrm{~s} * \mathrm{~mm}^{2}\right)\right)$. Para encontrar o número de fótons da radiação primária total $I \boldsymbol{p}_{\text {total }}$ e espalhada total $\boldsymbol{I} \boldsymbol{s}_{\text {total }}$ que formam a imagem no filme radiográfico, consideramos o tempo de exposição $(t)$ e a corrente do tubo $(Q)$, equações 3.27 e 3.28 .

$$
\begin{aligned}
& I p_{\text {total }}=t \cdot Q \cdot \sum_{E=0}^{k p_{p}} I p e(E) \\
& I s_{\text {total }}=t \cdot Q \cdot \sum_{E=0}^{k V_{p}} I \operatorname{se}(E)
\end{aligned}
$$

\subsubsection{Fluxograma}

Utilizạmos para o modelo, feixes de radiação incidẹtes paralelos e um objeto radiografado com espessura uniforme como mostra a Figura 3.2. 


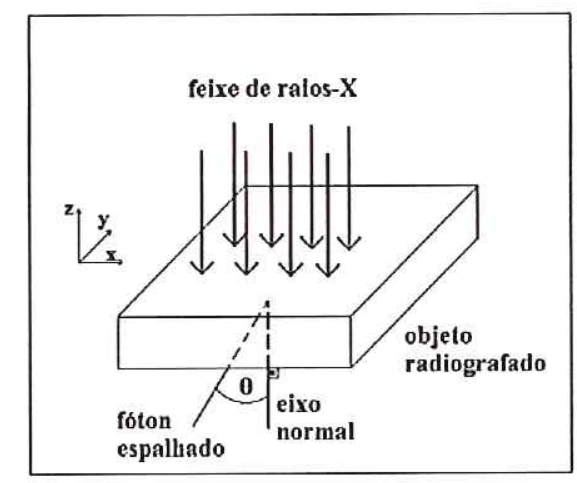

Figura 3. 2. Modelo para cálculo da radiação espalhada.

O programa em linguagem mortran (Fortran modificado), seguiu o fluxograma da Figura 3.3. Fornecemos a energia e o número de fótons, assim como os coeficientes de atenuação do material radiografado e, no caso da mama, a proporção de tecido adiposo em relação ao tecido fibro-glandular. Incrementamos a espessura ou a tensão do tubo (keV) e calculamos o ângulo de espalhamento $\theta$. Se o ângulo $\theta$ for menor que $90^{\circ}$ o armazenamos, se não, voltamos ao início com outro fóton. Realizamos este processo para espessura de 0 até $10 \mathrm{~cm}$, a energia do elétron de 0 até $50 \mathrm{keV}$ e o número de fótons ser igual a $10^{5}$.

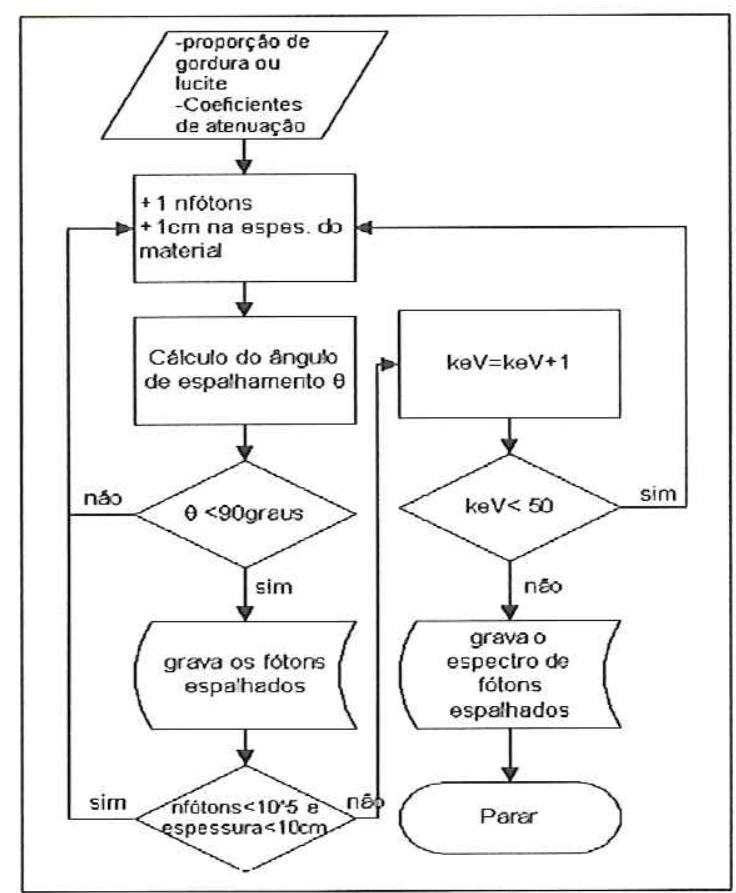

Figura 3. 3. Fluxograma do programa para cálculo de espalhamento até $90^{\circ}$. 


\subsection{CÁlCULO DO TAMANHO E DA FORMA DO PONTO FOCAL.}

As equações 3.29, 3.30, 3.31 apresentadas por Doi em (DOI, 1977), permitem calcular o tamanho das projeções do ponto focal sobre qualquer pixel do plano da imagem.

$$
\begin{aligned}
& \beta=\arctan \left(\frac{P_{y}}{d f f}\right) \\
& \gamma=\arctan \left[\frac{P_{x}}{\left(P_{y}+d f f \cdot \tan \alpha\right)}\right] \\
& a=a_{o} \cdot \frac{(1+\cot \alpha \cdot \tan \beta)}{\cos \gamma}
\end{aligned}
$$

onde $\beta$ é o ângulo formado pela reta pixel-foco e a reta normal ao plano da imagem no eixo catodo-anodo; $\gamma$ é o ângulo formado por essa normal e o eixo catodo anodo no plano da imagem; $\boldsymbol{a}$ é o tamanho do lado do ponto focal ao longo do eixo catodo-anodo e $\boldsymbol{a}_{\boldsymbol{o}}$ é este tamanho no centro do campo de radiação; $\boldsymbol{P}_{\boldsymbol{y}}$ é a coordenada de um pixel no plano filme na direção perpendicular ao eixo catodo-anodo; $\boldsymbol{P}_{\boldsymbol{x}}$ é a coordenada do mesmo pixel no plano filme no eixo catodo-anodo, com origem no centro do campo e $\boldsymbol{d}_{f f}$ é a distância entre o plano do foco e o plano do filme.

No trabalho de mestrado (IRITA, 1999a), analisamos a influência do colimador sobre a projeção do foco no plano da imagem. Dependendo da posição do pixel, a forma desta projeção sofre uma deformação (apenas o lado a sofre uma deformação, Figura 3.4).

Verificamos se o pixel está ou não na região de exposição. Se estiver além, ele não receberá radiação direta e, neste caso, atribuímos a cada pixel da matriz imagem um valor relacionado à cor branca. Na realidade, o filme para 
esta posição é transparente mas, na imagem, para efeito representativo, estabelecemos a cor branca. Caso o pixel estiver dentro da zona de exposição calculamos a área do paralelogramo de projeção do foco que o irradia com as equações 3.32 e 3.33 (IRITA et al., 1999b).

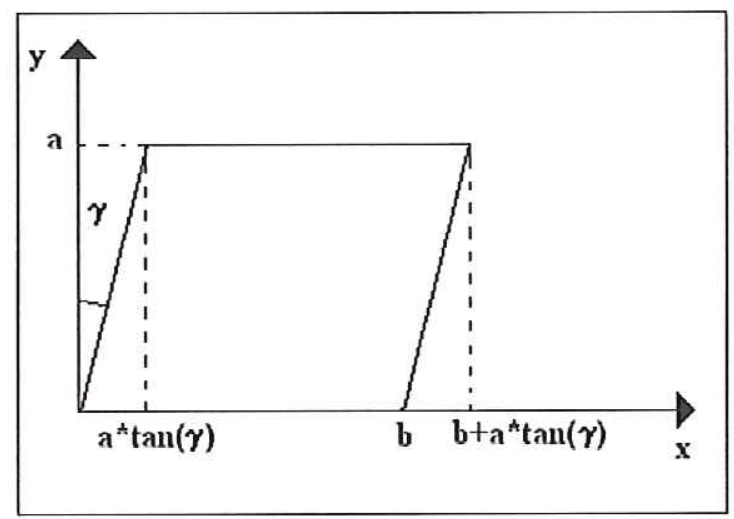

Figura 3. 4. Representação da projeção do foco para um ângulo de inclinação $\gamma$ em relação ao eixo catodo anodo.

- para deslocamento do pixel na coordenada x (longitudinal):

$$
\text { area }=\int_{0}^{a \tan (\lambda)}(1 / 2) \tan (90-\gamma) d x+\int_{a \tan (\gamma)}^{b+a \tan (\gamma)} a d x-\int_{b}^{b+a \tan (\gamma)}(1-b / x)(1 / 2) \tan (90-\gamma) d x
$$

- para deslocamento na coordenada y (lateral):

$$
\text { area }=\int_{0}^{a} b d y
$$

$\gamma$ é o ângulo formado pela reta que liga o pixel ao centro do campo e a reta que representa o eixo catodo-anodo no plano do filme; $\boldsymbol{a}$ é o valor do foco na direção catodo-anodo; $\boldsymbol{b}$ é o valor do foco na direção perpendicular ao eixo catodo-anodo . 
O tamanho do lado $\boldsymbol{a}$ da projeção geométrica do foco na direção catodo-anodo (lateral) é o próprio a enquanto que o lado $\boldsymbol{b}$ na direção perpendicular o eixo catodo-anodo (longitudinal) é dada pela equação 3.34:

$$
\operatorname{proj} b=b+a \cdot \tan (\gamma)
$$

Para a quantidade de radiação que o pixel recebe (proporcional à área da projeção do foco - projeção de a x projeção de b) é atribuído um nível de cinza, que é então, armazenado em uma matriz que representa o filme (IRITA et al., 1999b).

\subsection{SIMULAÇÃO DA IMAGEM}

Utilizamos o algoritmo proposto por Oliveira em (OLIVEIRA,1995) para simular a imagem de um objeto radiopaco colocado em qualquer posição do campo de radiação quando irradiado por uma fonte de intensidade uniforme e unitária.

A imagem do objeto é simulada calculando para cada pixel do filme a área do ponto focal resultante da subtração da projeção do objeto sobre o plano da fonte. O ponto focal é representado pela matriz fonte (MF) e a projeção do objeto pela matriz objeto (MO) (ver Figura 3.5). Para obter o valor do nível de cinza de um pixel qualquer no plano da imagem, é feita uma sobreposição das duas matrizes. O valor da intensidade irradiada é proporcional à área da fonte não coberta pela projeção do objeto. 

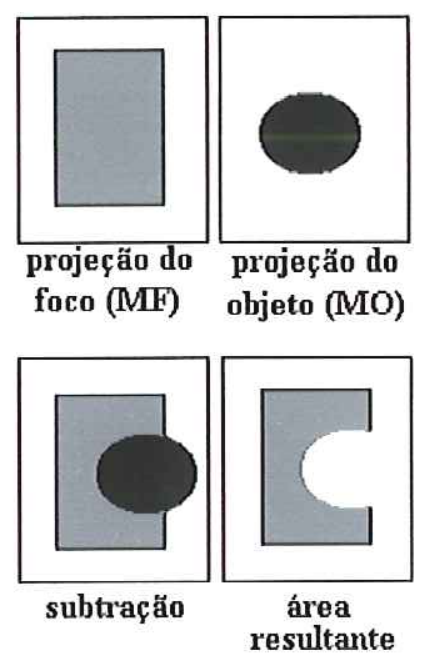

Figura 3. 5. Método de subtração entre objeto e fonte utilizado por Oliveira (OLIVEIRA,1995).

Esse processo é realizado para todos os pixels da imagem do objeto que sofrem a influência do ponto focal. 


\section{CAPÍTULO 4. APLICAÇÃO 1 - PROJETO DO SISTEMA PARA OTIMIZAR A AQUISIÇÃO DAS MAMOGRAFIAS.}

\subsection{INTRODUÇÃO}

Como o modelo desenvolvido nesta pesquisa permite a quantificação da radiação espalhada para qualquer sistema radiológico, para qualquer espessura radiografada e qualquer tensão aplicada ao tubo de raios-X, assim como calcular a projeção do ponto focal limitado por um colimador, propomos uma variação da técnica slit que melhora a qualidade da imagem mamográfica reduzindo o ponto focal, a radiação espalhada e uniformizando o campo de radiação. $\mathrm{O}$ modelo permite quantificar estas melhorias e calcular o espalhamento que uma matriz de esferas totalmente radiopacas produz quando irradiada por sistemas radiológicos com geometrias diversas. Escolhemos uma matriz de esferas de $0,7 \mathrm{~mm}$ de diâmetro, fixadas em uma base de Lucite de 2,5 $\mathrm{cm}$ de espessura porque ela permite uma comparação fácil com o modelo real.

Consideramos o filme MinR2000 da Kodak $®$ e utilizamos o equacionamento da curva característica dado por Silva e Frère (SILVA \& FRERE, 2001) que relaciona a densidade óptica (D) em função do número de fótons incidentes $(N F)$, equação (4.1). Como o nível de cinza $(N C z)$ é diretamente proporcional a densidade óptica, o valor máximo, 4, corresponde a 4095 níveis de cinza para uma escala de 12 bits (equação 4.2). 


$$
\begin{aligned}
& D=4\left\lfloor\left[-e^{-3,12 \cdot 10^{-7} \cdot N F}\right]\right. \\
& N C z=4095\left[1-e^{-3,12 \cdot 10^{-7} \cdot N F}\right]
\end{aligned}
$$

\subsection{O MODELO DO SLIT MODIFICADO}

Após o desenvolvimento dos algoritmos para simulação da radiação para formação de imagens (item 3.2) e do cálculo do ponto focal (item 3.3) acrescentamos no modelo, dois colimadores que permitem gerar e quantificar um feixe colimado sobre qualquer posição do plano filme como mostrado pela Figura 4.1.

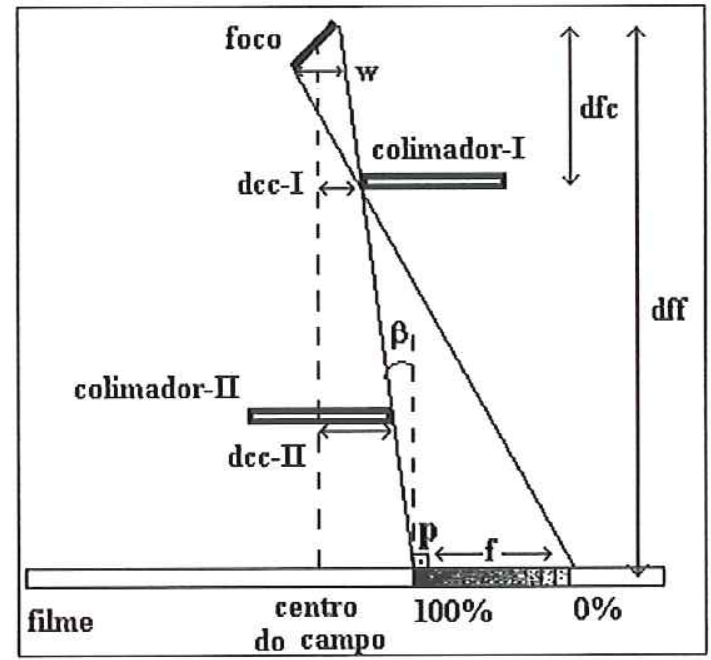

Figura 4. 1. Modelo de feixe colimado para otimizar a aquisição das imagens. 


\subsection{CÁLCULO DO TAMANHO DA FAIXA IRRADIADA}

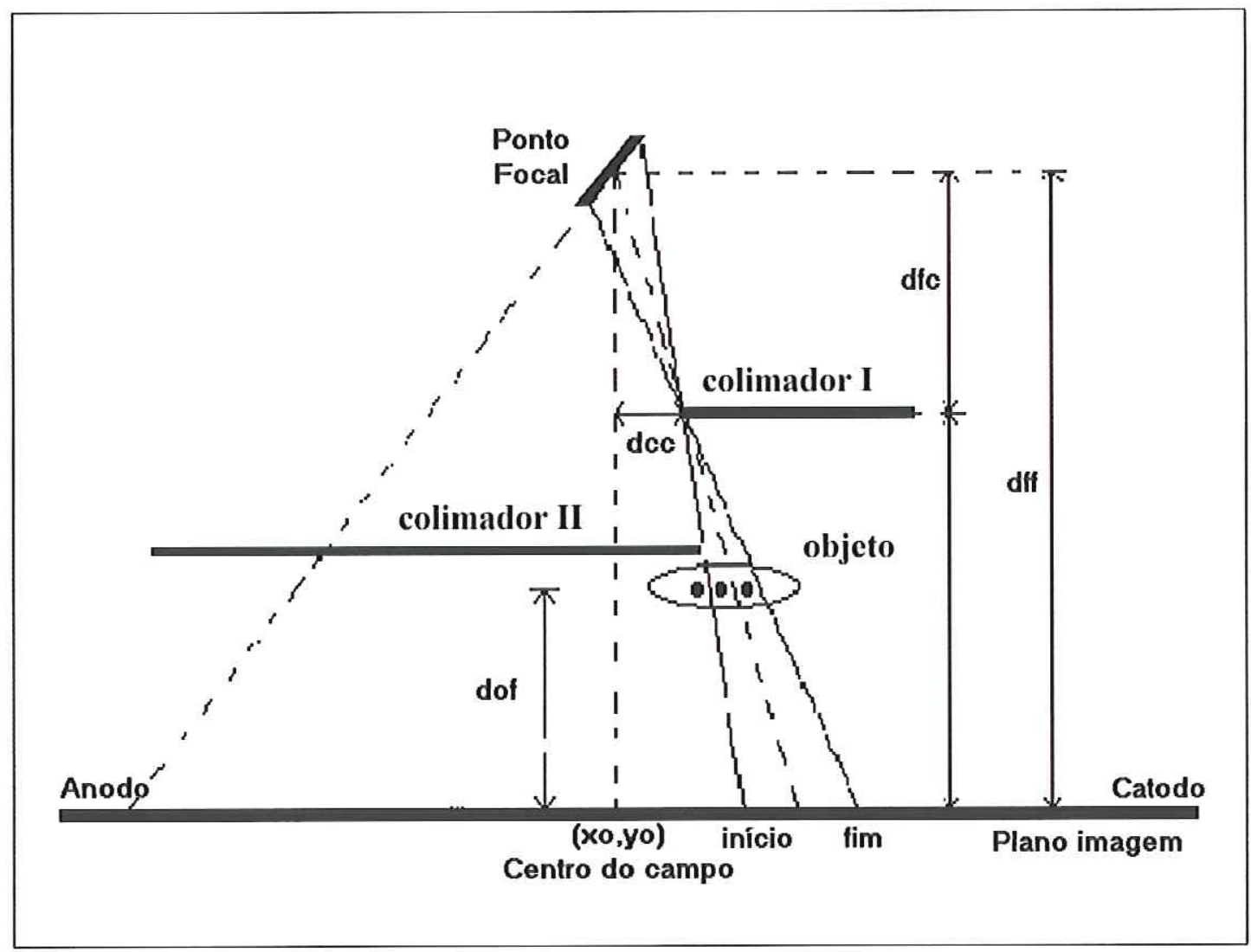

Figura 4. 2. Modelo para cálculo da faixa.

A faixa irradiada é a região do filme sensibilizada pelo feixe de raios- $X$ colimado. Fisicamente, esta faixa é limitada por um colimador externo colocado no lado do catodo e por uma máscara de chumbo do lado do anodo. Definimos como faixa $f$, a faixa onde a projeção do foco é mascarada pelo colimador externo. O tamanho da faixa $\boldsymbol{f}$ depende do tamanho do ponto focal $(\boldsymbol{a} \times \boldsymbol{b})$, da distância do colimador do centro do campo $\left(\boldsymbol{d}_{\boldsymbol{c}}\right)$, da relação entre a distância foco-colimador $\left(\boldsymbol{d}_{f c}\right)$, da distância foco-filme $\left(\boldsymbol{d}_{f f}\right)$ e da distribuição de intensidade de raios-X no ponto focal. Considerando a distribuição de intensidade no foco uniforme, o aumento dessas distâncias implica no aumento da faixa $f$. 
A faixa $\boldsymbol{f}$ é determinada pela equação 4.3 estabelecida por relações geométricas como mostra a Figura 4.2, sendo que na direção do eixo catodoanodo $w$ é a projeção lateral do tamanho do ponto focal (lado $a$ ), e na direção perpendicular ao eixo catodo-anodo $w$ é a projeção longitudinal do tamanho do foco (lado $b$ ), ou seja, $w$ representa a projeção do ponto focal no plano do objeto e esta diretamente relacionada com $\boldsymbol{d}_{c c}$, uma vez que este determina a posição no campo de radiação onde será calculada a projeção do foco.

$$
\text { faixa }=w *(d f f / d f c-1)
$$

\subsection{CÁlCULO DA EXPOSIÇÃo COM O SLIT MODIFICADO}

Para relacionar a exposição do sistema slit $\boldsymbol{E}_{\text {slit }}$ com a exposição convencional $\boldsymbol{E}_{\text {conv }}$ utilizamos a taxa de transmissão primária $\boldsymbol{T}_{p}$ e o número de faixas $\boldsymbol{n}_{\boldsymbol{f}}$ como mostra a equação 4.4 .

Da mesma forma, o tempo de exposição com o sistema slit, $\boldsymbol{t}_{\text {slit, }}$ depende de $\boldsymbol{T}_{\boldsymbol{p}}$ e de $\boldsymbol{n}_{\boldsymbol{f}}$ como mostra a equação 4.5. $\boldsymbol{n}_{\boldsymbol{f}}$ é o número de faixas de largura $f$ contido na largura do filme $\boldsymbol{L}_{\text {filme }}$ (equação 4.6).

$$
\begin{aligned}
& E_{\text {slit }}=E_{\text {conv }} \cdot \frac{n_{f}}{T_{p}} \\
& t_{\text {slit }}=t_{\text {conv }} \cdot \frac{n_{f}}{T_{p}} \\
& n_{f}=\frac{L_{\text {filme }}}{f}
\end{aligned}
$$




\subsection{FLUXOGRAMA DA SIMULAÇÃO DA IMAGEM CONSIDERANDO ESPALHAMENTO E TAMANHO DO FOCO.}

O algoritmo desenvolvido é ilustrado no fluxograma da Figura 4.3. Após registrar nos arquivos o espectro de energia e os coeficientes de atenuação, iniciamos a configuração da geometria e dos parâmetros de exposição do aparelho de raios-X que desejamos simular.

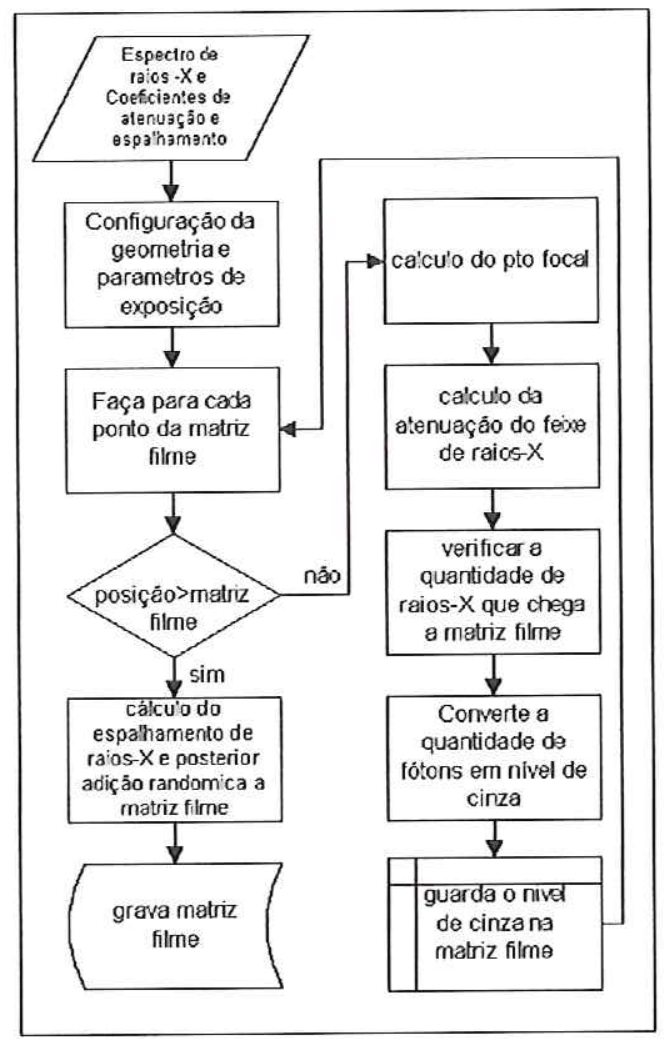

Figura 4. 3. Fluxograma para obtenção de imagem de matriz de esferas.

O resultado final da configuração da geometria é armazenado internamente na matriz filme. Calculamos para cada ponto desta matriz o ponto focal e a atenuação do feixe e convertemos o número de fótons resultantes em níveis de cinza que armazenamos na matriz filme. Após esta etapa calculamos o espalhamento para o objeto inteiro, obtemos a quantidade 
de radiação que adicionamos randomicamente à matriz filme, que é visualizada e gravada em um arquivo binário com extensão “.cut".

\subsection{FLUXOGRAMA DA SIMULAÇÃO COMPUTACIONAL DO ESPALHAMENTO PROVOCADO PELO SISTEMA SLIT.}

Neste modelo utilizamos a abertura da fenda $(\boldsymbol{D})$, a espessura do objeto (d) e a distância entre o objeto e a fenda $(\boldsymbol{h})$ para calcular o ângulo limite de espalhamento $\left(\theta_{m}\right)$ relativo a cada ponto da superfície do objeto onde incidiram os raios-X (Figura 4.4). A radiação espalhada que atravessa a fenda e chega ao pixel é produzida pelos fótons incidentes na superfície do objeto.

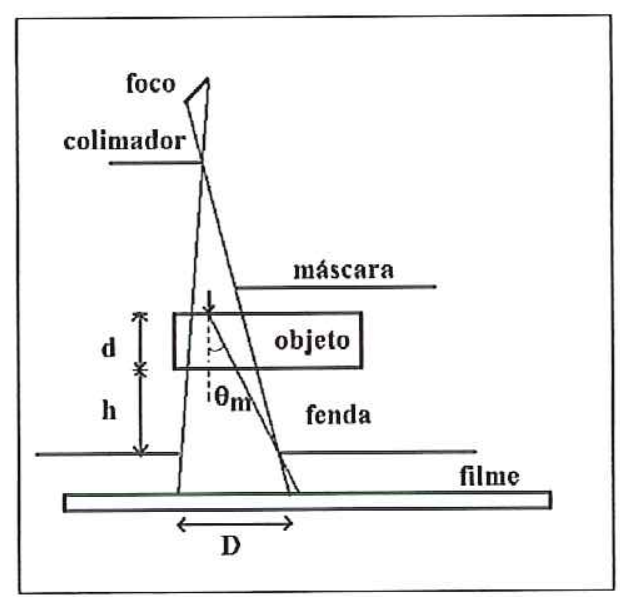

Figura 4. 4. Espalhamento que atravessa a fenda com ângulo limite de espalhamento $\left(\theta_{\mathrm{m}}\right)$.

Percorrendo cada ponto do objeto radiografado nas coordenadas $\mathrm{X}$ (largura) e Y (comprimento), armazenamos os valores de espalhamento referentes à faixa do objeto irradiado na matriz máscara Masc2 quando o feixe é limitado pelo conjunto colimador-anteparo. Sobrepomos essa matriz Masc2 à matriz que representa o filme Matriz-filme como mostra o fluxograma da Figura 4.5. 


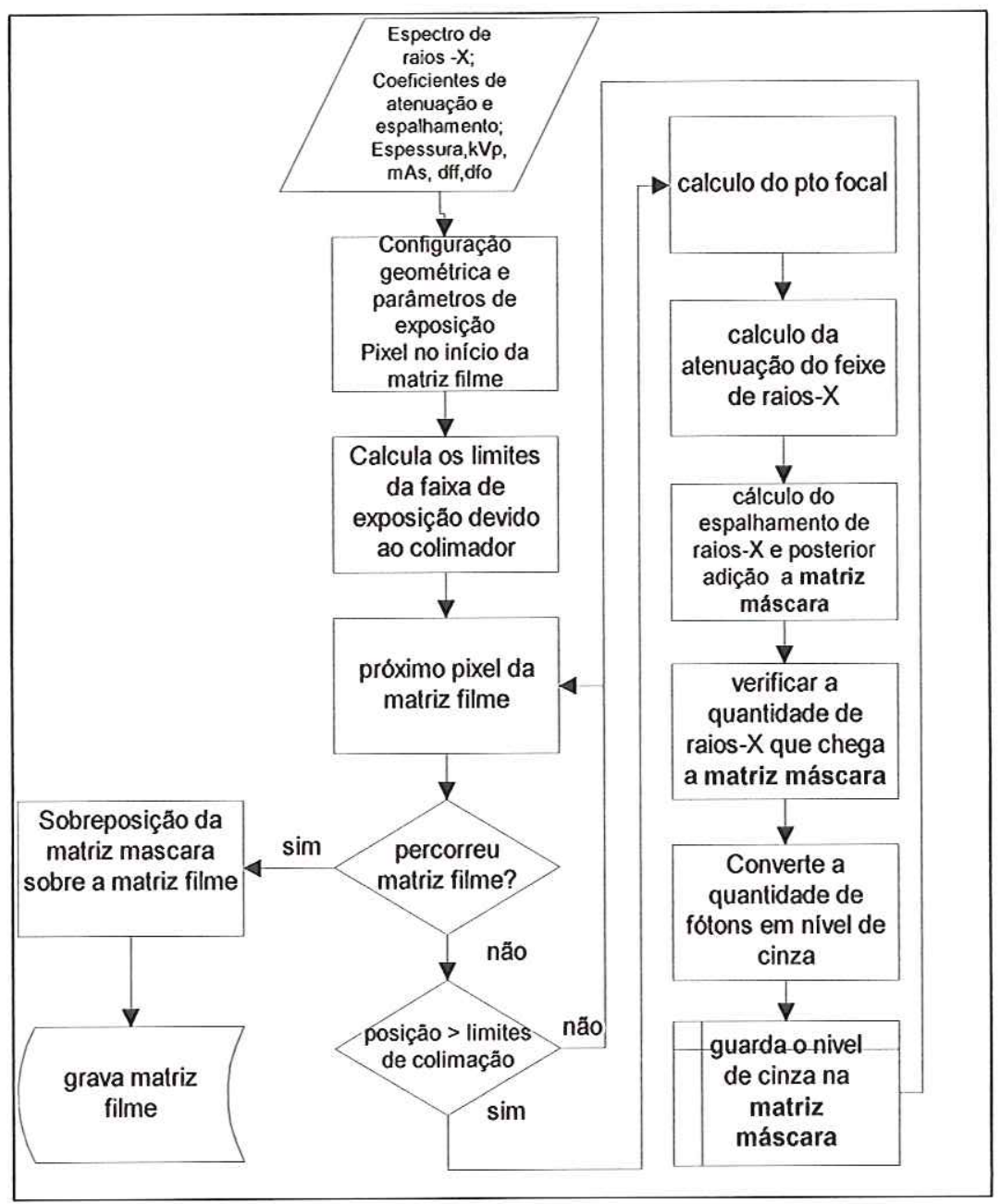

Figura 4. 5. Fluxograma para simular radiografias por feixe colimado. 


\section{CAPÍTULO 5. PROTÓTIPO DO SISTEMA SLIT MODIFICADO E DISPOSITIVOS EXPERIMENTAIS}

\subsection{SISTEMA DE COLIMAÇÃO E VARREDURA}

Neste Capítulo descrevemos o sistema slit modificado projetado a partir dos algoritmos descritos anteriormente.

No sistema slit, o tubo de raios-X deve girar em torno de seu eixo para que o feixe de radiação varra o objeto com velocidade angular constante $(\omega)$. Na nossa pesquisa propomos deslocar o tubo paralelamente ao objeto como mostra a Figura 5.1. Como nesta pesquisa utilizamos um sistema radiográfico comercial, para realizar a varredura, deslocamos o objeto e o filme numa trajetória em forma de arco (Figura 5.2) ajustada em função da distância focoobjeto $\left(\boldsymbol{d}_{\boldsymbol{f} f}\right)$. Desta maneira obtemos o mesmo efeito que se estivéssemos deslocando o tubo lateralmente. É claro que esta substituição não seria viável para radiografar estruturas anatômicas, mas serve para avaliar o modelo.

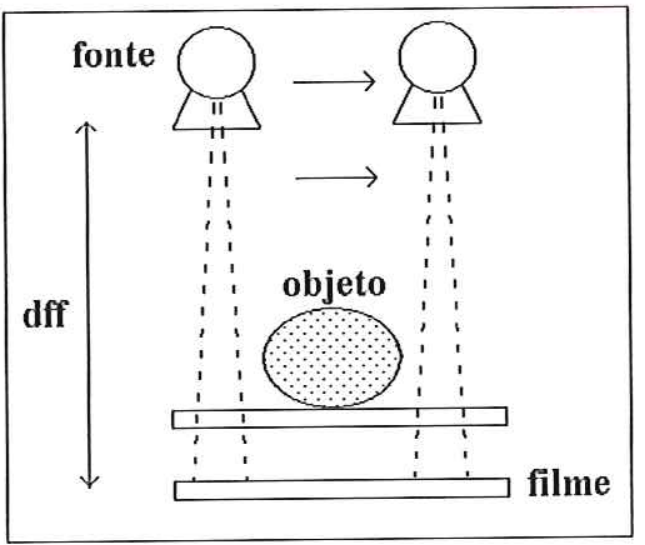

Figura 5. 1. Deslocamento do sistema slit. 


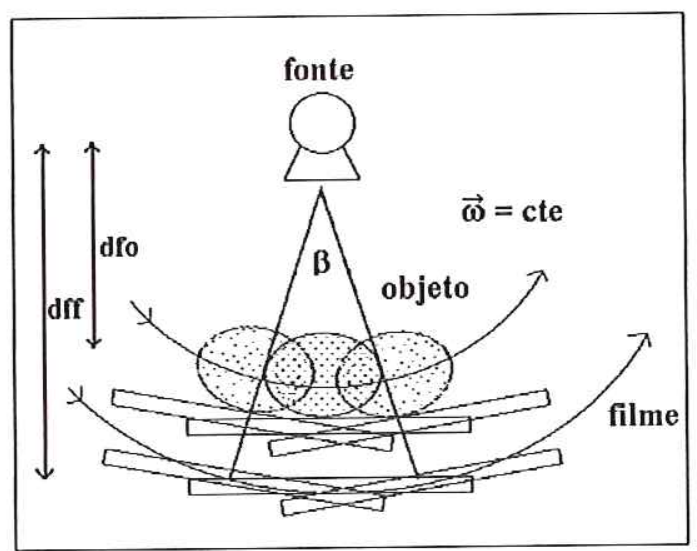

Figura 5. 2. Sistema de rotação.

Para realizar os movimentos, fixamos o objeto e o filme radiográfico em uma base movimentada por uma régua direcionadora ligada a um motor como mostra o esboço da Figura 5.3. A régua direcionadora determina o ângulo de rotação do tubo e o movimento rotatório é controlado pelo motor. Acrescentamos um conjunto de colimadores, o colimador 1 é fixado ao tubo e o colimador 2 é preso à base da mesa móvel (Figura 5.4).

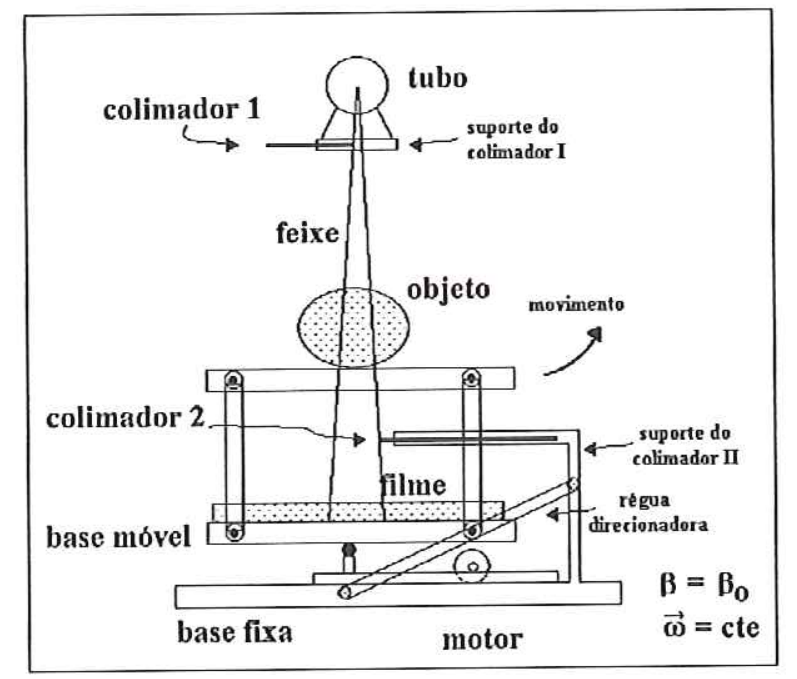

Figura 5. 3. Sistema proposto. 


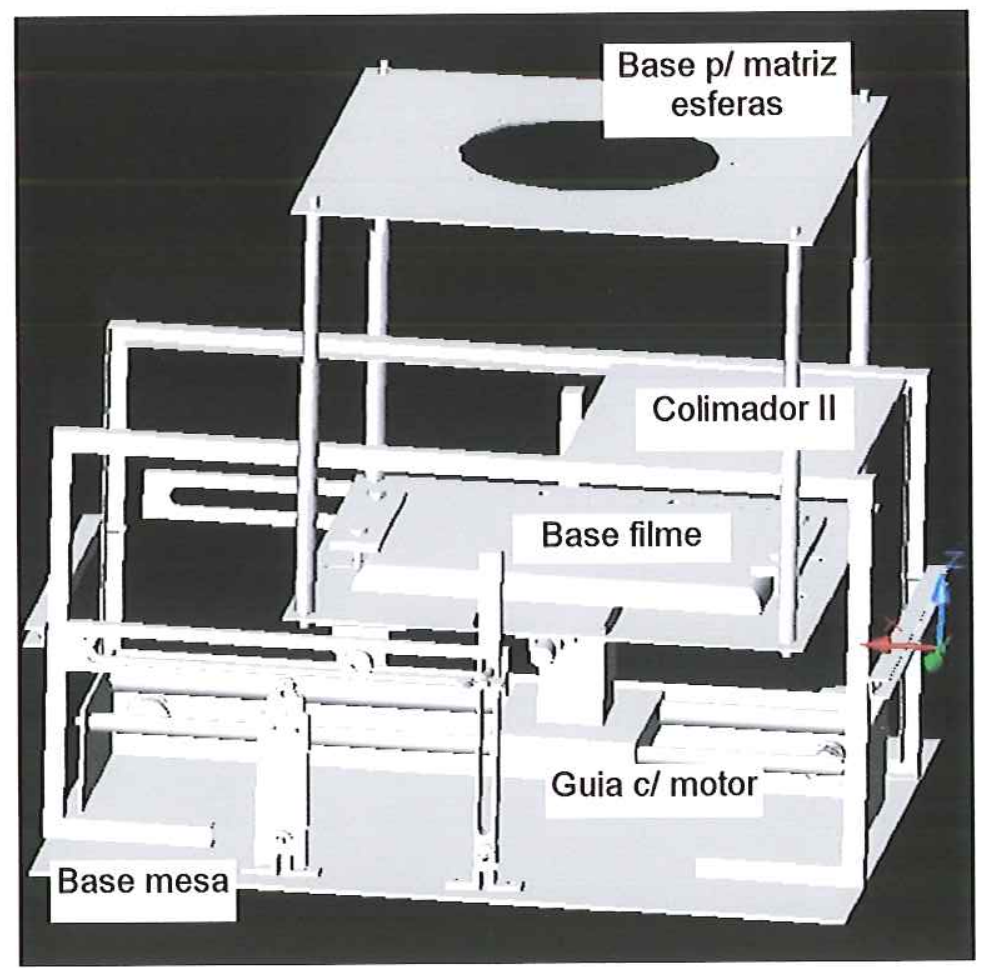

Figura 5. 4. Sistema proposto com colimadores.

O deslocamento foi realizado por um motor de corrente contínua (CC). Como o motor CC necessita de um tempo para produzir um movimento constante, usamos redutores para tornar este efeito inicial praticamente desprezível. Ajustamos o controle de velocidade através de um potenciômetro que controla a tensão e a corrente do motor CC. Sincronizamos o disparo do tubo de raios-X e o movimento do motor com uma chave dupla.

\subsection{DESCRIÇÃO DA MESA MÓVEL}

Utilizamos o alumínio para implementar a mesa móvel, devido a sua leveza e maleabilidade, e latão para os eixos. A mesa é composta do suporte objeto-filme onde são posicionados o chassi radiográfico e o objeto; do 
conjunto carro-motor-eixo para deslocar o suporte; de guias para ajustar o ângulo de rotação do conjunto; e do suporte ajustável do colimador II.

\subsubsection{Suporte objeto-filme}

Este suporte (Figura 5.5) permite o ajuste da distância entre o objeto e o filme através de 4 hastes de $8 \mathrm{~mm}$ de diâmetro e de 4 hastes de $12 \mathrm{~mm}$ de diâmetro todas com $150 \mathrm{~mm}$ de altura. Estas hastes são rosqueadas entre si para fornecerem a altura desejada. $\mathrm{Na}$ base da mesa existem sulcos que permitem o uso de pinos para a fixação do cassete. Na parte inferior da base estão fixados dois rolos para guiar o movimento de rotação do conjunto ao redor de um pino preso no centro da base.

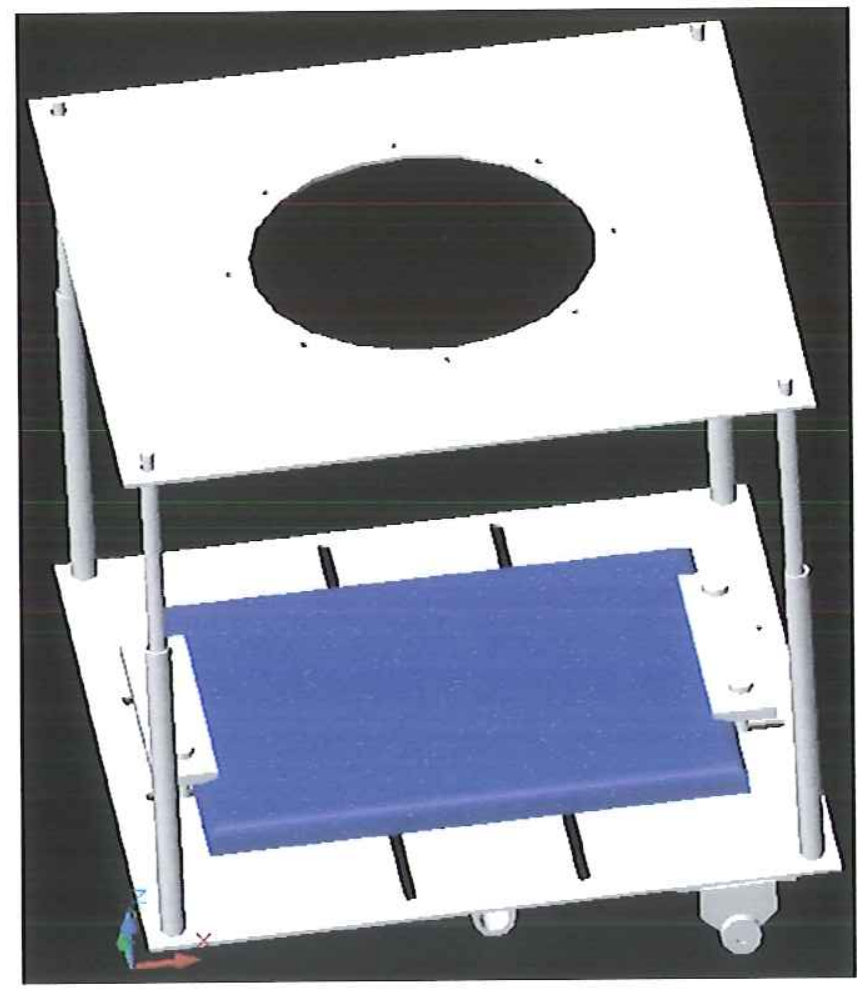

Figura 5. 5. Mesa que comporta o filme e objeto radiografado. 


\subsubsection{Conjunto carro-motor-eixo}

Este conjunto permite deslocar o suporte objeto-filme, Figura 5.6. Ele é constituído de dois eixos de aço, um de 12 e outro de $16 \mathrm{~mm}$ de diâmetro e $480 \mathrm{~mm}$ de comprimento, que guiam um carro de plástico puxado por uma correia ligada ao motor. Em cima do carro é fixo o suporte com o objeto e o filme. A velocidade do carrinho é controlada pelo motor que gira uma engrenagem com 25 dentes de $1,92 \mathrm{~mm} /$ dente. Uma rotação do motor corresponde a $48 \mathrm{~mm}$ de deslocamento do carro.

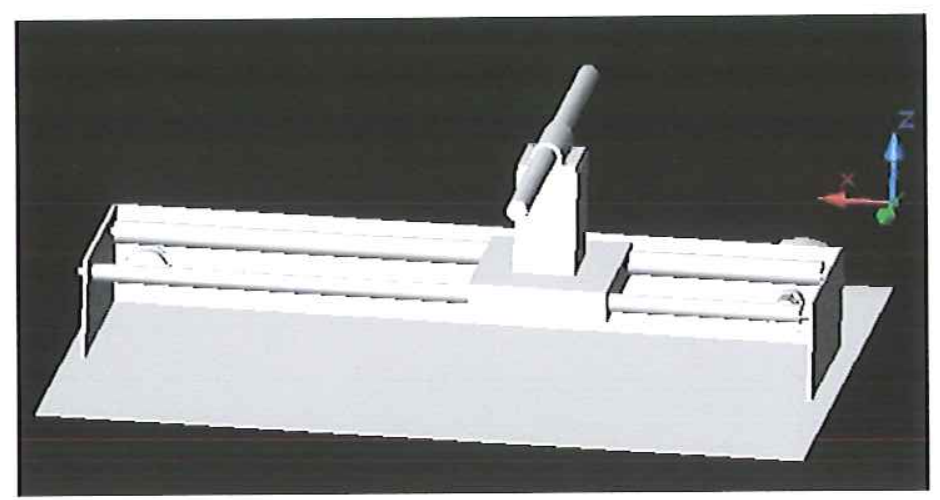

Figura 5. 6. Carro com eixos-guias de aço.

\subsubsection{Guias para ajuste do ângulo de rotação}

Estas guias (Figura 5.7) determinam o ângulo de giro do conjunto objeto-filme que pode ser ajustado em função da distância foco-filme e calculado pela equação 5.1. Onde $\mathbf{l}$ é a distancia entre o centro da mesa (posição do pino) e a roldana; $\theta_{1}$ é o ângulo da guia; $\mathbf{h}$ é a distância do centro da guia até o ponto de deslocamento; e $\theta_{2}$ é o ângulo formado pela mesa.

A guia de alumínio possui $6 \mathrm{~mm}$ de espessura e $31 \mathrm{~mm} \times 269 \mathrm{~mm}$ de lados com uma abertura de $12 \mathrm{~mm}$ x $239 \mathrm{~mm}$ no centro. A inclinação é ajustada com o movimento sobre uma abertura de 7,2 $\times 99,5 \mathrm{~mm}^{2}$ feita na 
barra flexível, também de alumínio, de $12,5 \times 12,5 \mathrm{~mm}^{2}$ e $275 \mathrm{~mm}$ de comprimento.

Utilizando relações geométricas estabelecemos a equação 5.1 que relaciona o ângulo de inclinação $\theta_{2}$ da mesa em relação à base. Derivando este ângulo pelas distâncias $\mathbf{I}$ e $\mathbf{h}$ calculamos a velocidade angular $\mathbf{w}\left(\theta_{2}\right)$ que multiplicado pela distância foco-filme $\left(\mathbf{d}_{\mathbf{f f}}\right)$ fornece a velocidade de deslocamento do tubo (equação 5.2).

$$
\begin{aligned}
& \theta_{2}=\arccos \left(\frac{l-h \cdot \cos \left(\theta_{1}\right)}{l}\right) \\
& v=d f f \cdot \bar{\omega}\left(\theta_{2}\right)
\end{aligned}
$$

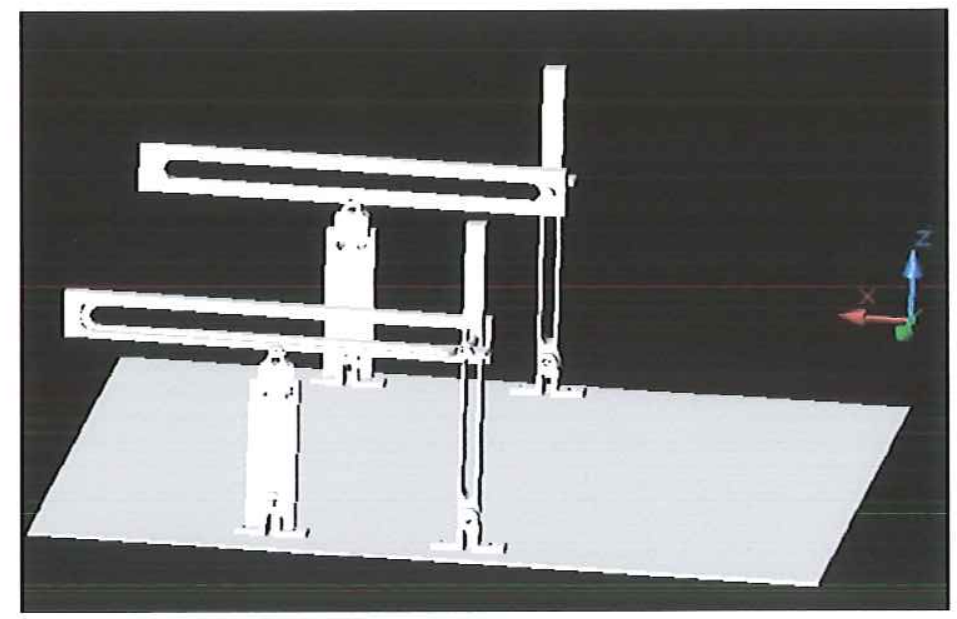

Figura 5. 7. Guias para controle de ângulo de rotação da mesa-filme.

\subsubsection{Suporte ajustável para o colimador II}

Confeccionamos este suporte utilizando duas cantoneiras de alumínio em forma de "U" de $23 \mathrm{~mm}$ de lado e $900 \mathrm{~mm}$ de comprimento. Dobramos cada cantoneira em $150 \mathrm{~mm}, 500 \mathrm{~mm}$ e $250 \mathrm{~mm}$ e as fixamos na base do dispositivo 
final, como mostra a Figura 5.8. Fixamos uma chapa de chumbo de $2 \mathrm{~mm}$ de espessura na placa de alumínio de $240 \times 180 \mathrm{~mm}$, formando o colimador II.

Duas barras adicionais de $250 \mathrm{~mm}$ fortalecem e estabilizam o suporte.

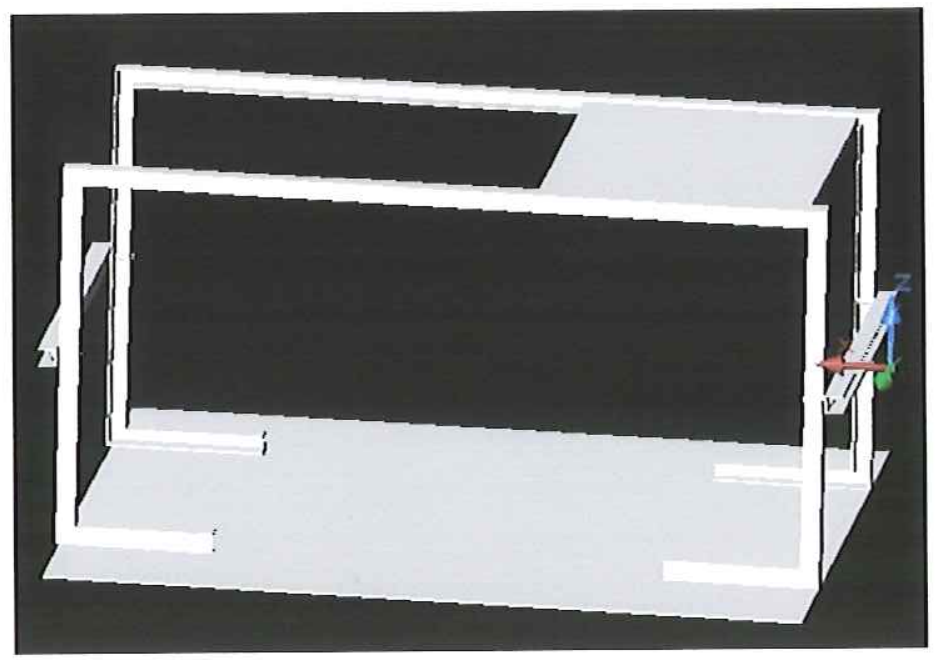

Figura 5. 8. Suporte de colimador II.

\subsubsection{O conjunto completo}

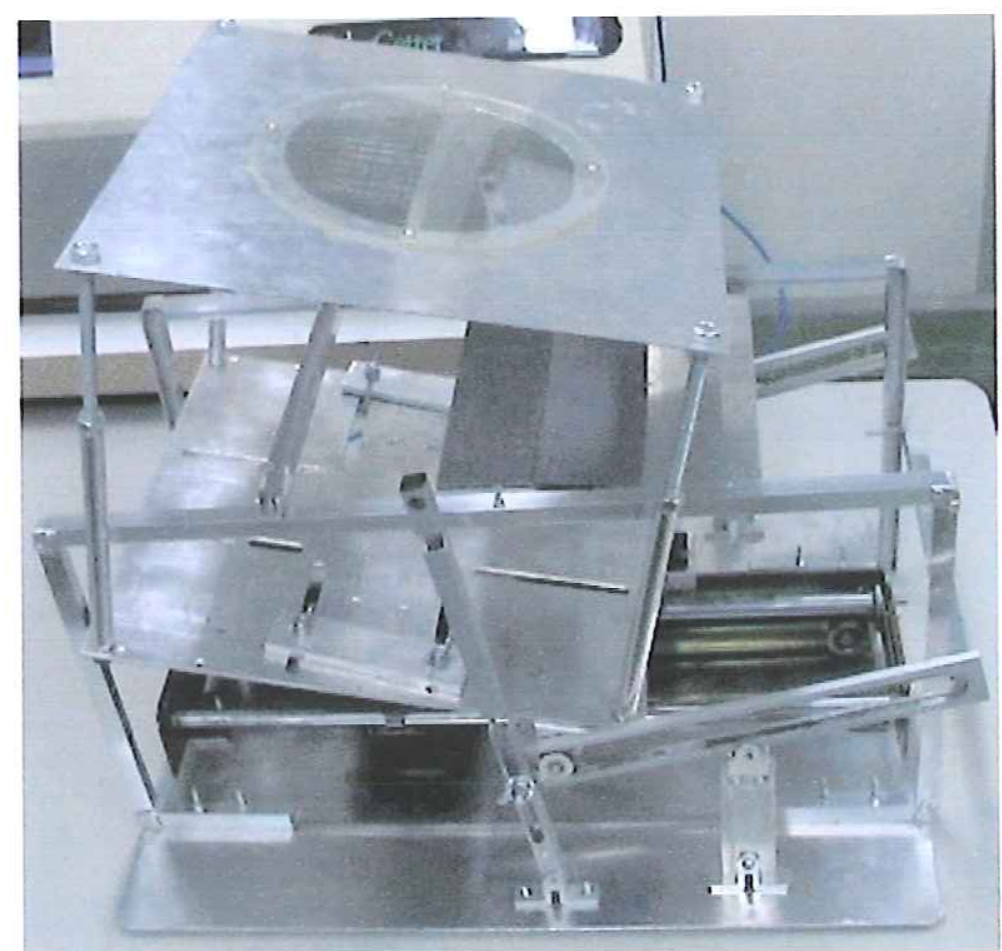

Figura 5. 9. Sistema completo com colimadores. 
O suporte objeto-filme, o conjunto carro-motor-eixo, as guias de ajuste e o suporte colimador II formam o dispositivo da Figura 5.9. Os ângulos do movimento de rotação da mesa em torno do seu eixo podem variar de 0 a 30 graus e o deslocamento da mesa de 0 a $235 \mathrm{~mm}$ é limitado por 2 sensores fím de curso.

\subsubsection{Colocação dos colimadores}

Dispomos os colimadores como mostra a Figura 5.10: o colimador I logo abaixo do tubo de raios-X e o colimador II logo acima do objeto. Esta configuração deixa passar um feixe estreito com intensidade suficiente para formar a imagem, mas com um ponto focal menor que o original.

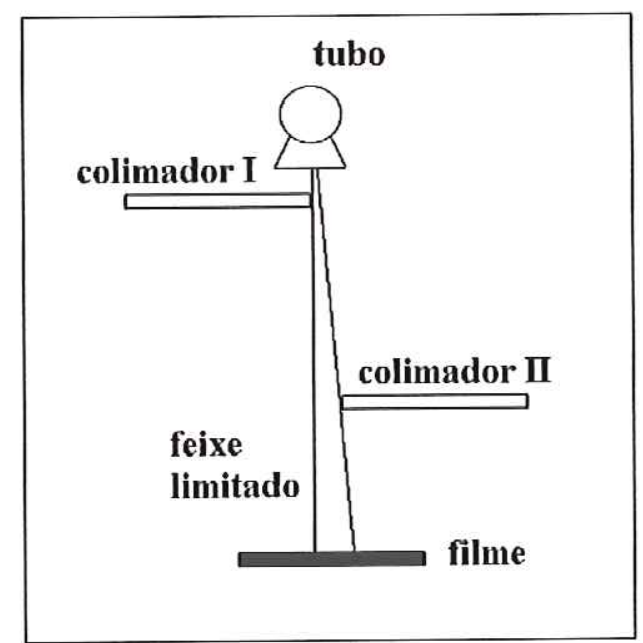

Figura 5. 10. Posicionamento dos colimadores para limitar o feixe.

Colimador I - utilizamos o colimador que acompanha o aparelho mamográfico CGR Senographe 500T. Ele é composto de aço denso e suas dimensões são de $125 \times 120 \times 2 \mathrm{~mm}^{3}$. 
Colimador II - fixamos uma chapa de chumbo de $2 \mathrm{~mm}$ de espessura, entre 2 placas de alumínio de $240 \times 180 \times 2 \mathrm{~mm}$.

\subsection{DESCRIÇÃO DO CIRCUITO CONTROLADOR DA} MESA

Controlamos a velocidade do motor variando a tensão produzida por uma fonte regulável de 1.5 a $24 \mathrm{~V}$. Para a sua confecção utilizamos um transformador de 12 volts (2A) com "center-tap", retificador de 2 A, capacitores de $2200 \mu \mathrm{F}$ e $1000 \mu \mathrm{F}$, regulador LM367, potenciômetro de $5 \mathrm{k} \Omega$. O circuito elétrico é mostrado na Figura 5.11A e a montagem final é mostrada na Figura 5.11B.
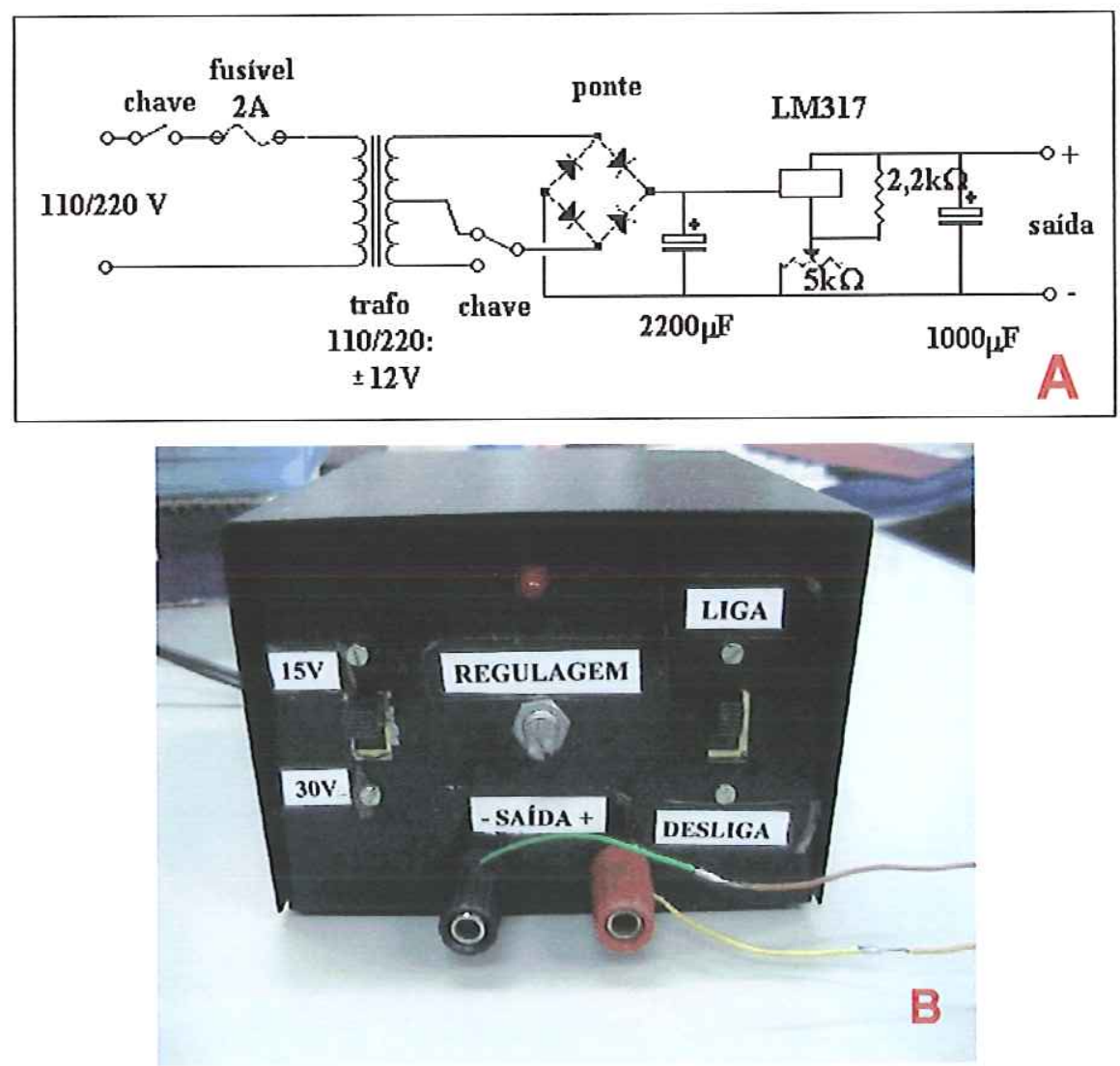

Figura 5. 11. Esquema elétrico(A) e montagem final (B) do circuito Transformador com tensão de saída ajustável. 
A chave $\mathrm{H}-\mathrm{H}$ e dois sensores fim-de-curso controlam a direção do deslocamento. Acrescentamos um botão "push-button" para iniciar o movimento do motor e sair da ação do sensor fim-de-curso e mais um botão para ligar-desligar o dispositivo. O esquema do circuito é mostrado na Figura 5.12A e a caixa do controle com $80 \times 90 \times 30 \mathrm{~mm}$ na Figura 5.12B.
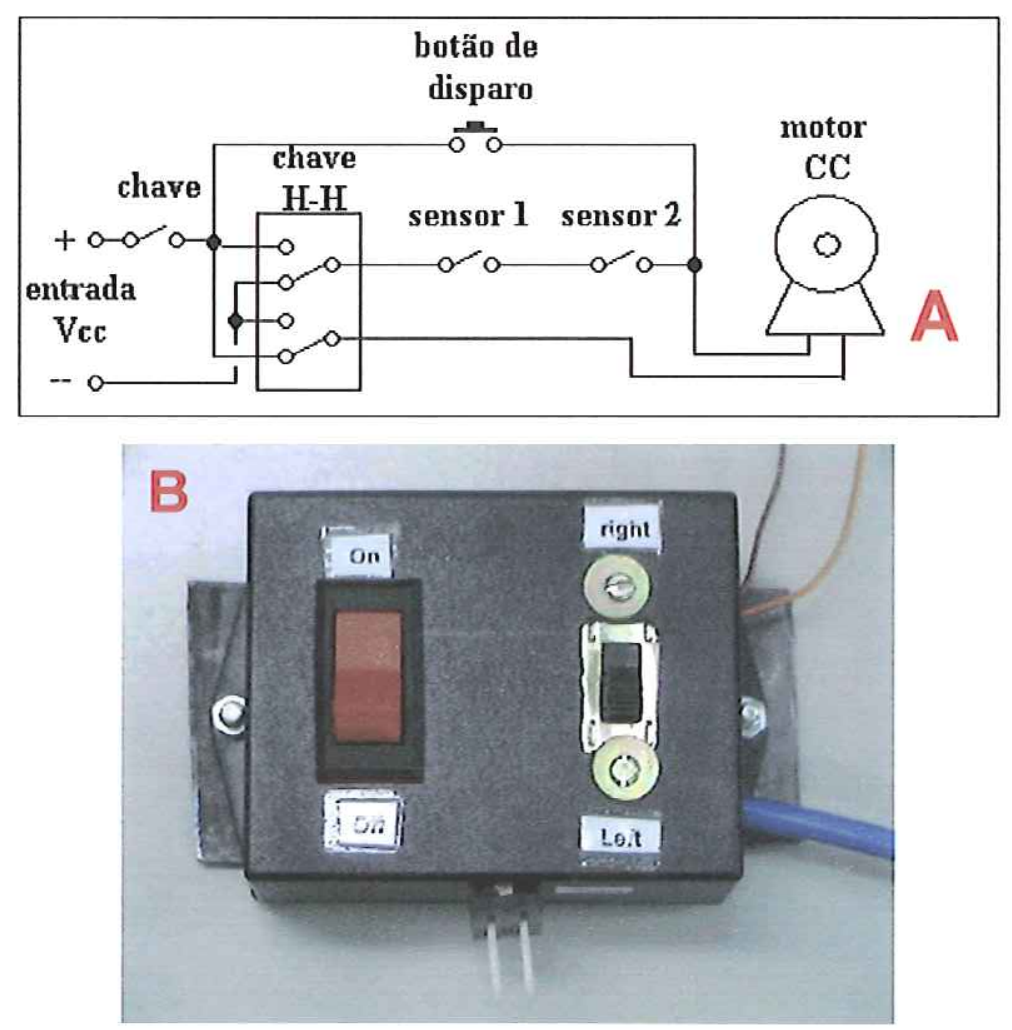

Figura 5. 12. Esquema (A) e montagem final da caixa de controle para acionamento e direcionamento do motor $\mathrm{CC}(\mathrm{B})$. 


\subsection{DISPOSITIVOS EXPERIMENTAIS PARA}

\section{AVALIAÇÃO DO MODELO}

\subsubsection{Medida da Radiação}

Para realizarmos as medições de radiação que chega ao filme utilizamos um kit da Innovision®: o kit TRIAD 10100A, que contêm a câmara de ionização e o display de visualização.

Realizamos as medições com e sem a presença da matriz de esferas na mesa-objeto. Medimos também a radiação espalhada com e sem presença dos colimadores, utilizando a técnica do bloqueador de feixe. Colocamos uma chapa esférica de chumbo de $2 \mathrm{~mm}$ de diâmetro logo acima do objeto e posicionamos a câmera de ionização no plano filme como mostra Figura 5.13.

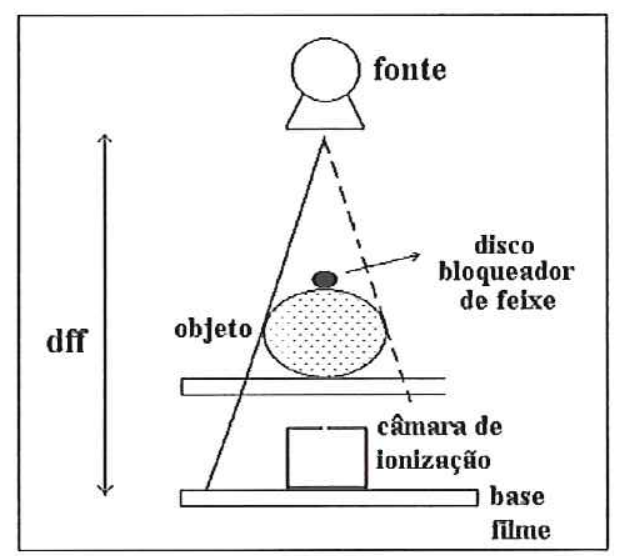

Figura 5. 13. Esquema de medida com o uso do bloqueador de feixe.

A área do filme abaixo do chumbo não recebe radiação primária (Figura 5.14A), somente radiação espalhada (Figura 5.14B). 


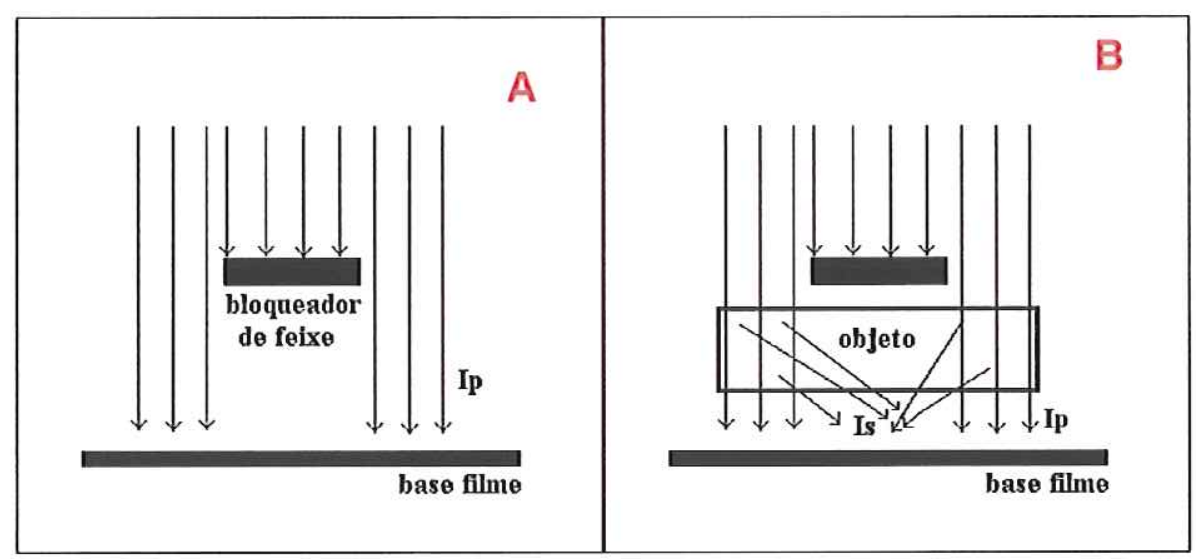

Figura 5. 14. O bloqueador do feixe teoricamente não deixa passar radiação (A), porém a radiação espalhada pelo objeto acaba sensibilizando o filme logo abaixo dele (B).

\subsubsection{Objeto de testes}

O objeto de teste deve ser capaz de mostrar a falta de nitidez provocada pelo tamanho do ponto focal. Utilizamos uma matriz de esferas radiopacas com formas perfeitamente regulares e disposições conhecidas sobre uma placa de acrílico. A placa circular de acrílico com 3,0 mm de espessura e $140 \mathrm{~mm}$ de diâmetro suporta esferas de $0,7 \mathrm{~mm}$ dispostas em colunas espaçadas de $10 \mathrm{~mm}$. No hemisfério inferior as linhas são separadas por $2,5 \mathrm{~mm}$ e no hemisfério superior por $10 \mathrm{~mm}$ (Figura 5.15). O centro das três colunas deste último hemisfério foi preenchido com esferas espaçadas de $1,25 \mathrm{~mm}$. 


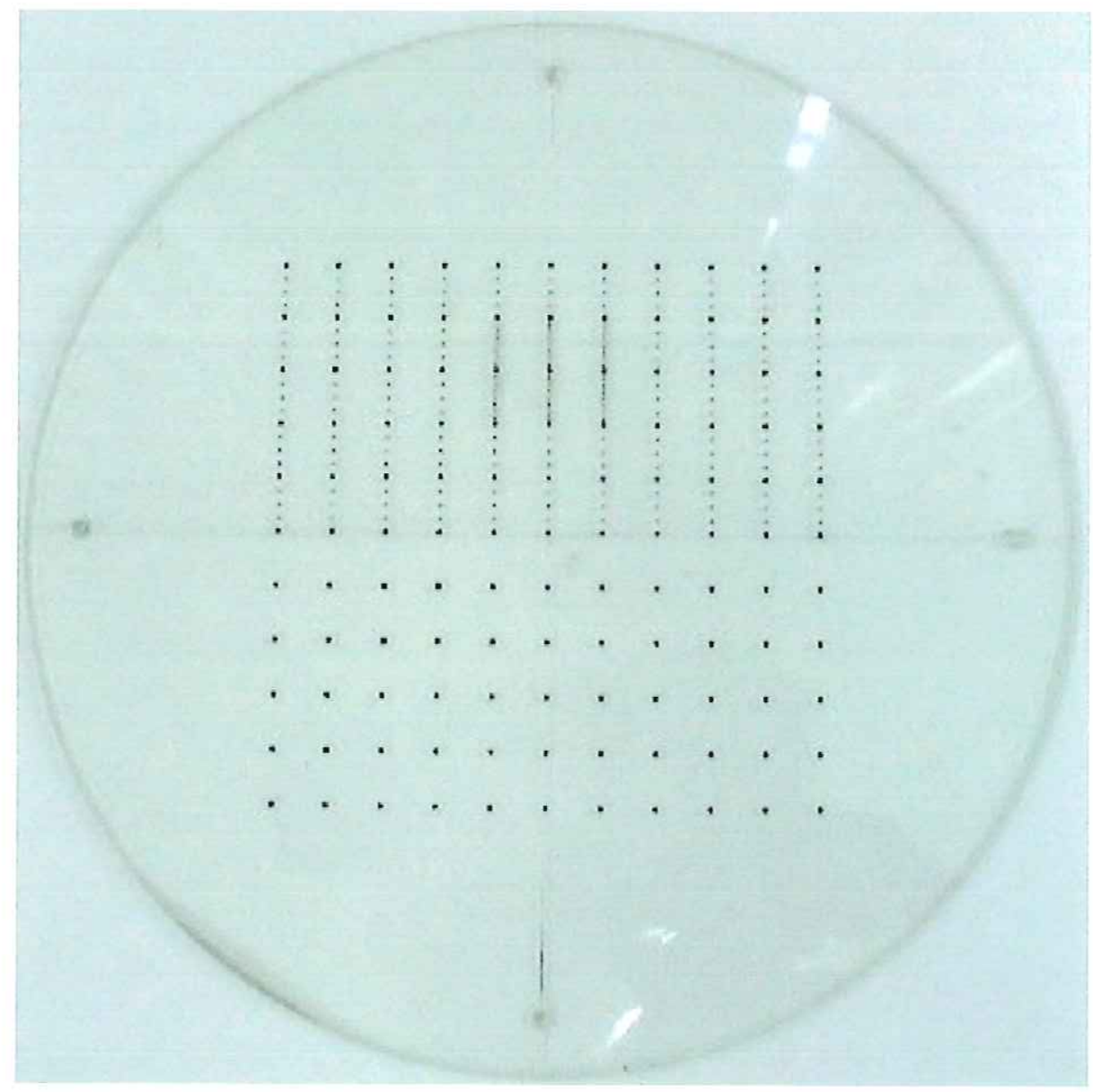

Figura 5. 15. Matriz de esferas. 


\section{CAPÍTULO 6. APLICAÇÃO 2 - ESTUDO DA INTERFERÊNCIA DA RADIAÇÃO ESPALHADA SOBRE O DESEMPENHO DOS ALGORITMOS USADOS NOS SISTEMAS CAD.}

\subsection{INTRODUÇÃO}

Para analisar o desempenho dos sistemas CAD nesta aplicação, simulamos a radiação espalhada utilizando mamografias como base. Utilizamos esta técnica para conservar as informações das estruturas anatômicas reais. Analisamos o efeito provocado sobre o desempenho do $\mathrm{CAD}$ após acrescentar computacionalmente a radiação espalhada à imagem.

Para estudar a interferência do espalhamento sobre o desempenho dos algoritmos usados nos sistemas CAD, adotamos o modelo geométrico da exposição radiográfica convencional. Selecionamos a imagem de uma mama com a menor espessura possível devido ao espalhamento ser menor e pouco influente na qualidade da imagem nestes casos, pois o espalhamento é diretamente proporcional à espessura. A simulação levou também em consideração a tensão aplicada no tubo e a espessura da mama, ambas fornecidas pelo radiologista. Calculamos a área da mama a partir da própria mamografia com a aplicação de um "threshold" simples. Como as imagens do banco do Fujita Lab já são recortadas (FUJITA et al.,1995), a área de fundo das imagens (background) é mais escura que a área que representa a mama $\mathrm{e}$ um threshold simples consegue separá-la. Assim, considerando exposição de contato e conhecendo a resolução espacial utilizada para digitalizar as imagens calculamos a área aproximada da mama. 
Obviamente o filtro também induz a produção de radiação espalhada, porém como a mama é posicionada relativamente longe dele, aproximadamente $50 \mathrm{~cm}$, a maioria desta radiação espalhada não a atinge. Portanto a desconsideramos devido a sua pouca influência na formação da imagem.

Como o coeficiente de atenuação, as seções de choque de interação do fóton e o fluxo de fótons são funções da energia, consideramos um feixe polienergético. Portanto, calculamos a atenuação e o espalhamento da radiação dentro do percurso ilustrado na Figura 3.1 para cada nível de energia (E) utilizando os espectros de radiação dados por Boone em 1997 (BOONE,1997) para um tubo de raios-X com alvo de Molibdênio $(\boldsymbol{M o})$ e filtro inerente de Belírio $(\boldsymbol{B e})$ e realizamos a somatória dos fótons para todas as energias referentes à tensão do tubo.

Ipe e Ise são dados em função de número de fótons transmitidos, do tempo de exposição, da corrente do tubo e da área da medida no filme (n. de fótons $\left./\left(\mathrm{mA}^{*} \mathrm{~s}^{*} \mathrm{~mm}^{2}\right)\right)$. Para encontrar o número de fótons da radiação primária total Ip_total e da radiação espalhada total Is_total que formam a imagem no filme radiográfico consideramos o tempo de exposição $(t)$, a corrente do tubo $(Q)$ e a área da mama no filme (Area).

Calculamos a área da mama no filme (Area) contando quantos pixels na imagem digitalizada têm valores $10 \%$ maior que o menor nível de cinza (threshold). O valor $10 \%$ foi escolhido para diminuir a influência do ruído.

Com esse procedimento calculamos a intensidade de radiação espalhada que chegou ao filme considerando a espessura da mama e a tensão utilizada para gerar a imagem original (Is_original). Utilizamos o mesmo processo para calcular a intensidade de radiação espalhada que seria produzida para outras espessuras de mama ou para tensões do tubo diferentes (Is_nova).

Feito isso, calculamos a variação de intensidade de radiação espalhada (Is_acrescida) subtraindo do Is_nova o valor do Is_original (equação 6.1): 


$$
I s_{\text {acrescida }}=I s_{\text {now }}-I s_{\text {original }}
$$

Distribuímos uniformemente essa intensidade suplementar à imagem original utilizando um gerador de números pseudo-randômico que, de acordo com a semente ou numero inicial ("seed") e do gerador de frequiência da máquina utilizada (clock), gera as coordenadas da imagem para cada fótons de radiação acrescentada.

$\mathrm{O}$ resultado final é uma imagem da mama com a radiação espalhada suplementar.

\subsection{FLUXOGRAMA}

O funcionamento do programa principal é mostrado na Figura 6.1. Os parâmetros de entrada, são de um lado, uma mamografia digitalizada com condições de exposição conhecidas ( $\mathrm{kVp}$ aplicado, taxa de grade, espessura da mama, idade da paciente) e do outro são os acréscimos de espessura ou da $\mathrm{kVp}$ que se pretendem avaliar. A seguir é calculada a área da mama.

Após isso o programa se divide em duas partes: cálculo do espalhamento presente na imagem de entrada e cálculo do espalhamento gerado por diversas espessuras ou $\mathrm{kVp}$, o que determina a intensidade de radiação espalhada devida somente ao acréscimo estipulado na entrada do programa. Estas intensidades são convertidas em níveis de cinza e armazenadas randomicamente em uma matriz máscara que é acrescentada à entrada para produzir a imagem com radiação espalhada suplementar. 


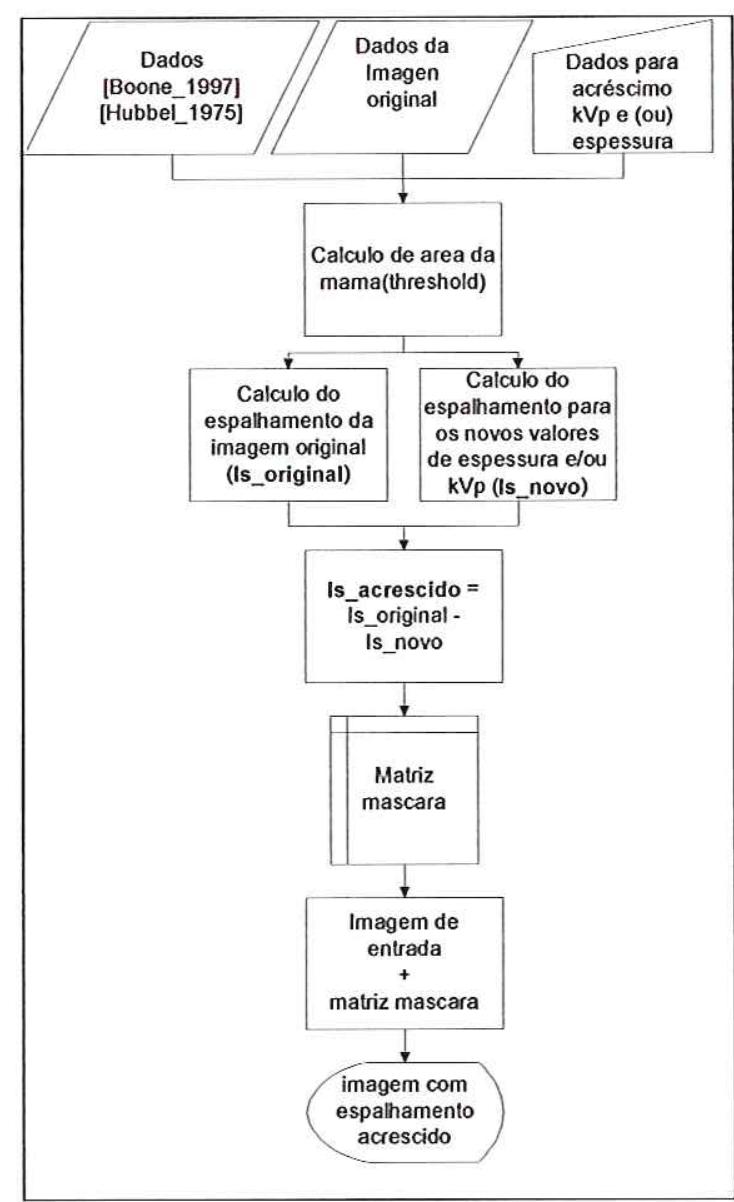

Figura 6. 1. Fluxograma para adicionar espalhamento a uma imagem radiográfica.

Estas imagens foram processadas pelo sistema de detecção CAD desenvolvido no laboratório de imagens médicas, Fujita Lab, da Universidade de Gifu - Japão \{(HIRAKO et al.,1995), (IBRAHIM et al.,1997), (KATO et al., 1998)\}. 


\section{CAPÍTULO 7. RESULTADOS E DISCUSSÕES.}

\subsection{INTRODUÇÃO}

Neste capítulo apresentamos os resultados obtidos a saber: quantificação da radiação primária e do espalhamento para o sistema convencional e validação dos modelos adotados; quantificação das radiações primárias e espalhadas e da redução do tamanho do ponto focal para o sistema slit modificado; o protótipo para otimizar a aquisição das mamografias; as medidas experimentais para comprovação do modelo.

Para as simulações e os experimentos estabelecemos como parâmetros físicos do sistema radiográfico: $25 \mathrm{kVp}$, distância foco-filme $\left(\boldsymbol{d}_{f f}\right)$ de $470 \mathrm{~mm}$, distância foco-colimador $\left(\boldsymbol{d}_{\boldsymbol{f}}\right)$ de $150 \mathrm{~mm}$, ponto focal de $1,86 \times 0,97 \mathrm{~mm}^{2}$, anodo de molibdênio com inclinação de $25,4^{\circ}$, filtro de molibdênio e resolução espacial da matriz que representa a imagem de $0,1 \mathrm{~mm} /$ pixel. Adotamos a distância objeto-filme $\left(\boldsymbol{d}_{o f}\right)$ de $235 \mathrm{~mm}$ quando consideramos como objeto a matriz de esferas. O sistema tela-filme utilizado foi $o$ MinR/MinR2000 da Kodak®. O sistema mamográfico é o CGR Senographe $500 \mathrm{~T}$. 


\subsection{QUANTIFICAÇÃO DA RADIAÇÃO PRIMÁRIA PARA O SISTEMA CONVENCIONAL E VALIDAÇÃO DO MODELO.}

Para estes cálculos adotamos o esquema da Figura 7.1, onde $\boldsymbol{d}_{c c \_} \boldsymbol{I}$ é a distância entre o centro do campo e a extremidade do colimador-I, e analisamos os resultados para um pixel do filme, $\boldsymbol{p}$, situado no limite do campo totalmente irradiado.

Deslocamos o colimador-I, modificando $\boldsymbol{d}_{c c_{-}} \boldsymbol{I}$ e portanto a posição do ponto $\boldsymbol{p}$. A intensidade de radiação primária considerando o efeito heel, recebida pelo ponto $p$, varia ao longo do eixo catodo-anodo em função de $\boldsymbol{d}_{c \_} \boldsymbol{I}$ como mostrado na Figura 7.2. Quando consideramos também o efeito da distância entre o pixel e o foco, que reduz a radiação proporcionalmente ao inverso do quadrado da distância, a intensidade primária decai para as distâncias $\mathbf{d}_{\mathbf{c c} \_} \mathbf{I}$ superiores a $44,7 \mathrm{~mm}$, como mostra a Figura 7.3 .

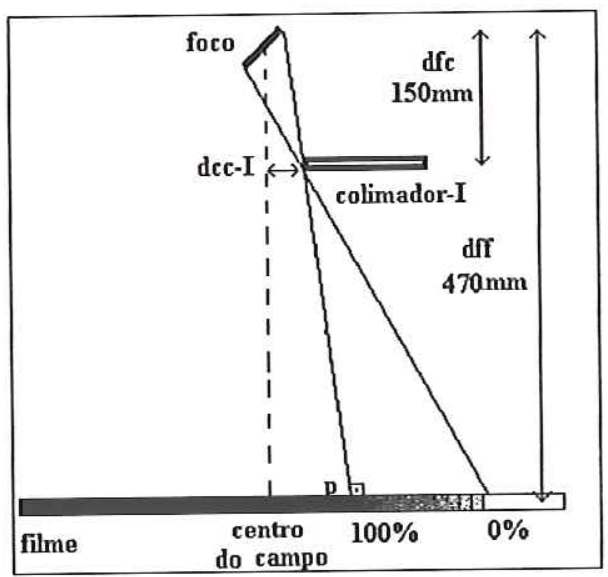

Figura 7. 1. Esquema do sistema com um colimador. 


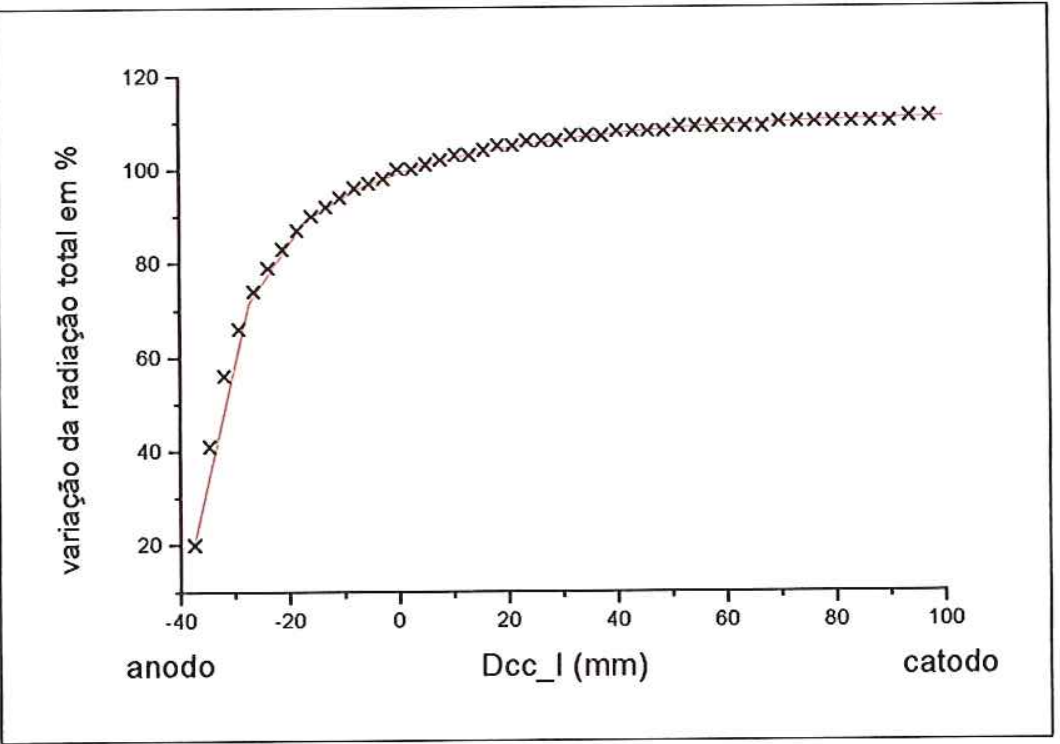

Figura 7. 2. Variação da intensidade de radiação ao longo do eixo catodo-anodo devido ao efeito heel em função da distância $\mathrm{d}_{\mathrm{cc} \_} \mathrm{I}$.

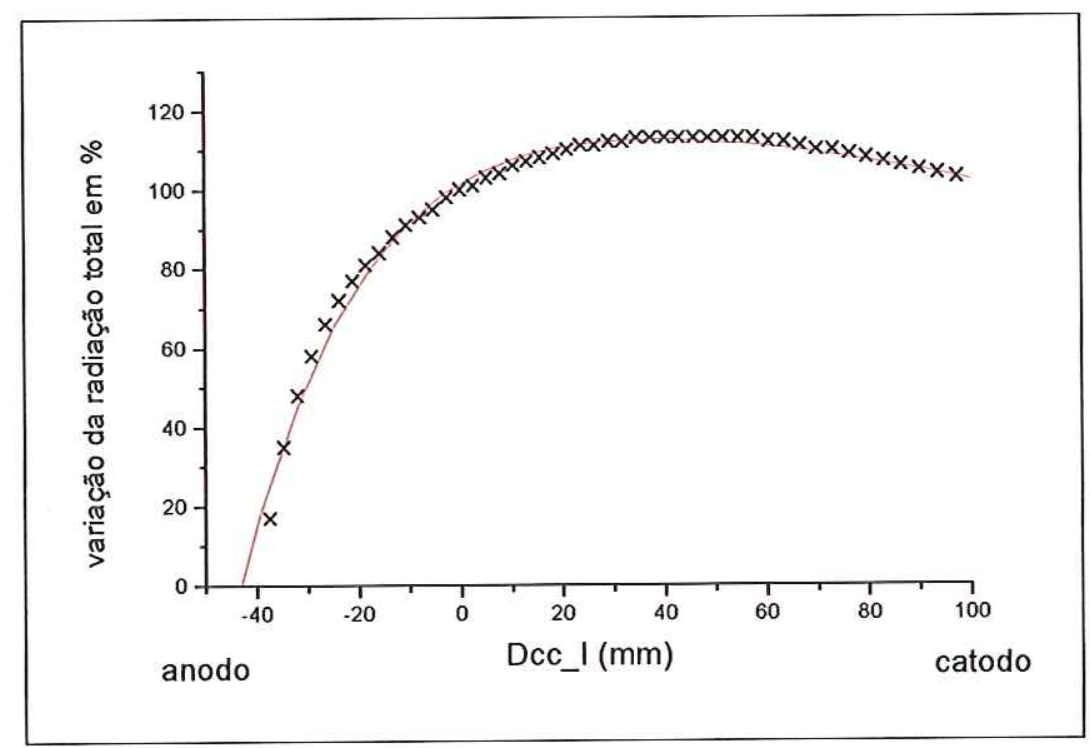

Figura 7. 3. Variação da intensidade de radiação ao longo do eixo catodo-anodo devido ao efeito heel e à lei do inverso ao quadrado da distância.

Na Figura 7.3 o pico máximo da intensidade de radiação ocorre para

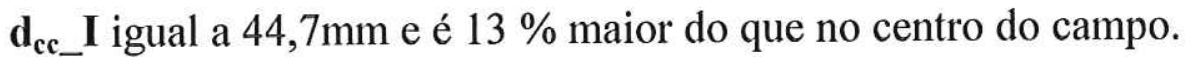

Para o eixo perpendicular ao eixo catodo-anodo, a influência do efeito heel e da distância na intensidade da radiação, é mostrada na Figura 7.4. A 
distância $\mathbf{d}_{\mathbf{c c} \_} \mathbf{I}_{\text {perp }}$ é a distância entre o centro do campo e a extremidade do colimador-I posicionado perpendicularmente ao eixo catodo-anodo. O pico máximo é localizado no centro do campo ( $100 \%$ da intensidade) onde o $\mathbf{d}_{\mathbf{c c} \_} \mathbf{I}_{\text {perp }}$ é igual a zero.

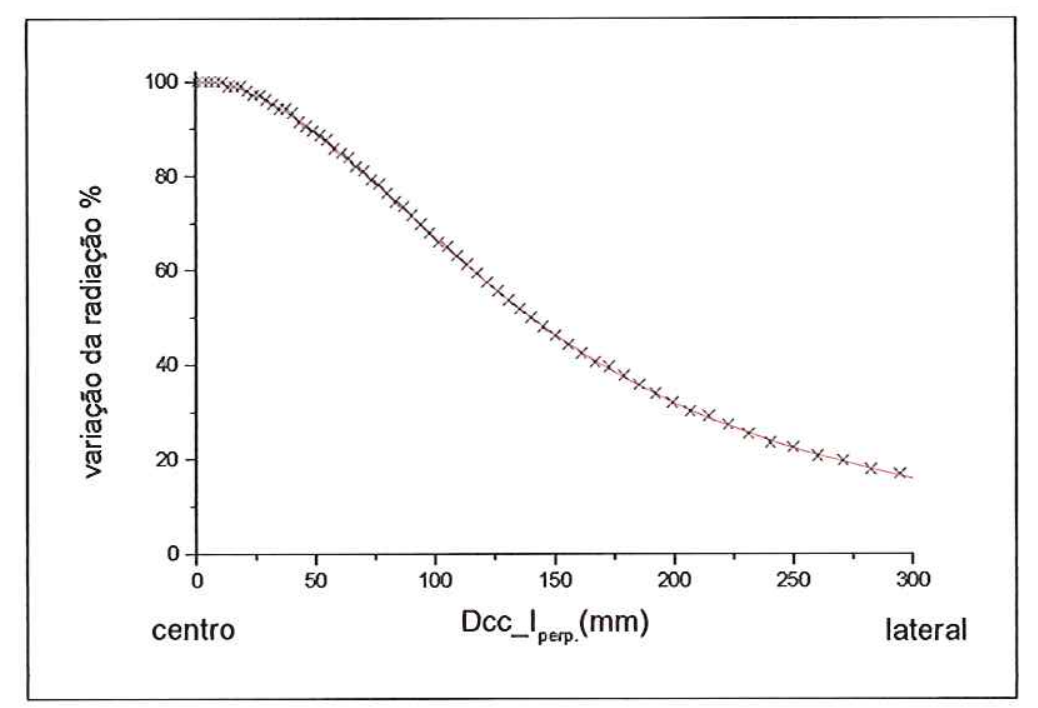

Figura 7. 4. Variação da intensidade de radiação perpendicularmente ao eixo catodo-anodo devido ao efeito heel e à lei do inverso ao quadrado da distância.

Calculamos a densidade óptica (DO) do filme para estas condições. Para validar nosso modelo, realizamos medições experimentais com os mesmos parâmetros utilizados na simulação e medimos as densidades ópticas ao longo do eixo catodo-anodo. Os resultados estão mostrados na Figura 7.5.

Calculamos o desvio entre os resultados simulados e experimentais e encontramos um desvio máximo de 0,048 , ou seja menos de $5 \%$. Os maiores erros ocorrem para valores de densidade acima de 2,4 e são devidos principalmente à curva HD simulada que utilizamos para transformar o número de fótons em densidade que para esses valores não é bem ajustada. Os valores medidos são muito próximos dos simulados o que comprova a validade do modelo escolhido. 


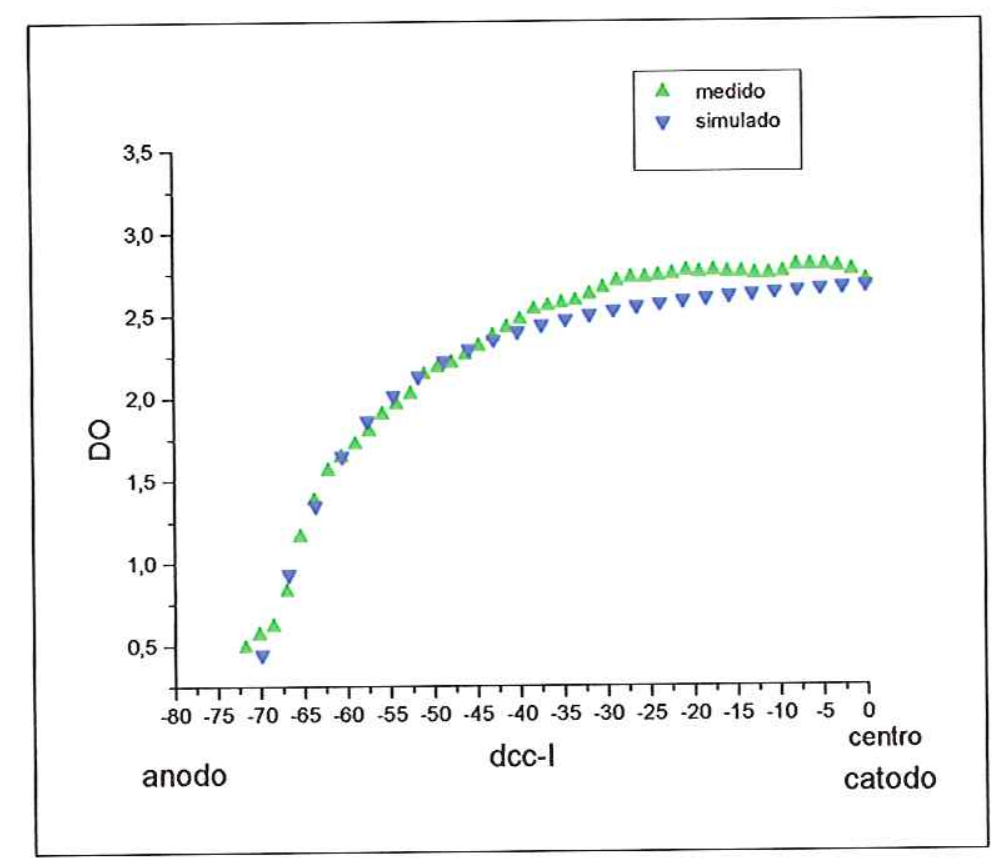

Figura 7. 5. Densidade óptica simulada e medida para o ângulo $d_{c c \_\_}$.

7.3. QUANTIFICAÇÃO COMPUTACIONAL DA RADIAÇÃO ESPALHADA PARA O SISTEMA CONVENCIONAL E VALIDAÇÃO DO MODELO.

\subsubsection{Cálculo da radiação espalhada.}

Calculamos a radiação espalhada por uma espessura de Lucite de $2,5 \mathrm{~cm}$ de espessura em função de $d_{c c \_} I$. A Figura 7.6 mostra a quantidade de fótons primários $\left(I_{p 2}\right)$ e espalhados $\left(I_{s 2}\right)$ para cada posição do colimador. 


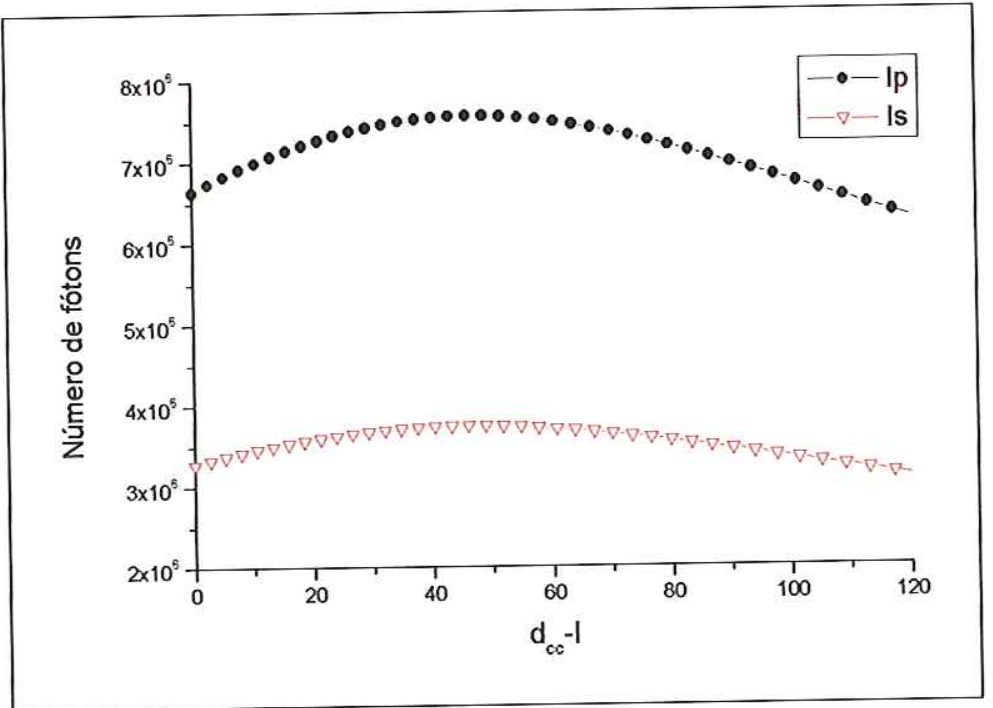

Figura 7. 6. Número de fótons por pixel em função da distância $d_{c c \_}$. Ip é a radiação primária e Is é a radiação espalhada.

Calculamos a quantidade de fótons espalhados que chegam ao filme em relação ao espalhamento total (SST) para as diversas composições dos tecidos da mama e para o Lucite em função da tensão aplicada no tubo. As Figuras 7.7, 7.8, 7.9 e 7.10 mostram resultados obtidos para 0,70 e $100 \%$ de tecidos adiposos e para o Lucite com espessuras entre 1 e $10 \mathrm{~cm}$. As curvas foram aproximadas pela função de SGompez (Origin®) por esta resultar no menor desvio entre a curva ajustada e os pontos (desvio menor que $5 \%$ ).

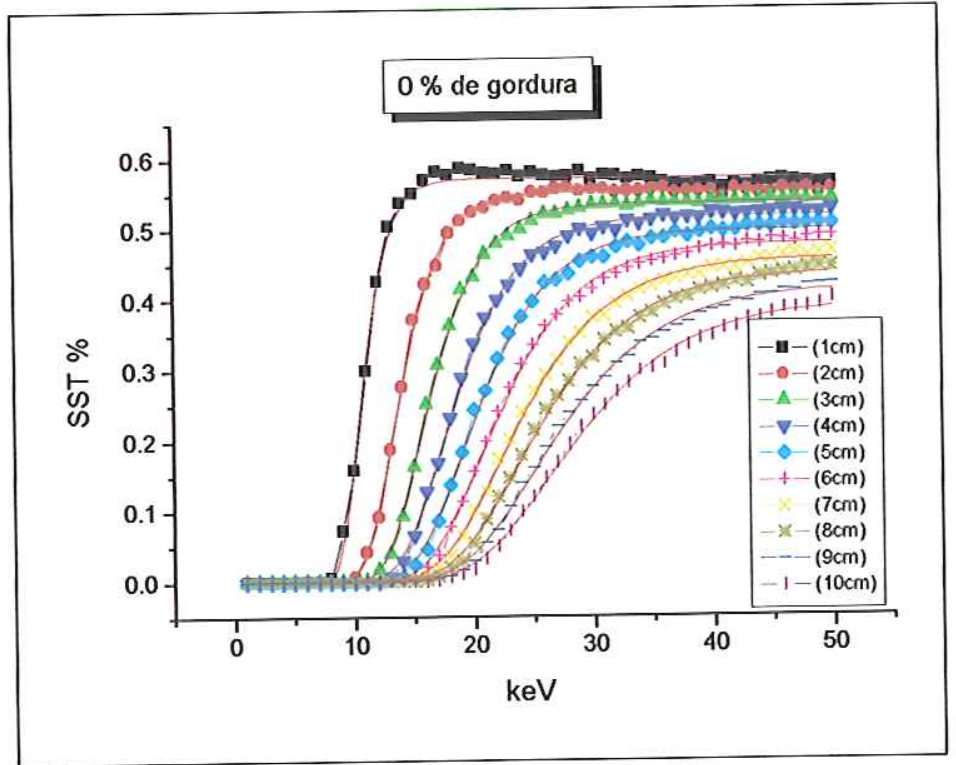

Figura 7. 7. Radiação espalhada SST em função da energia (keV) para mama sem presença de tecido adiposo. 


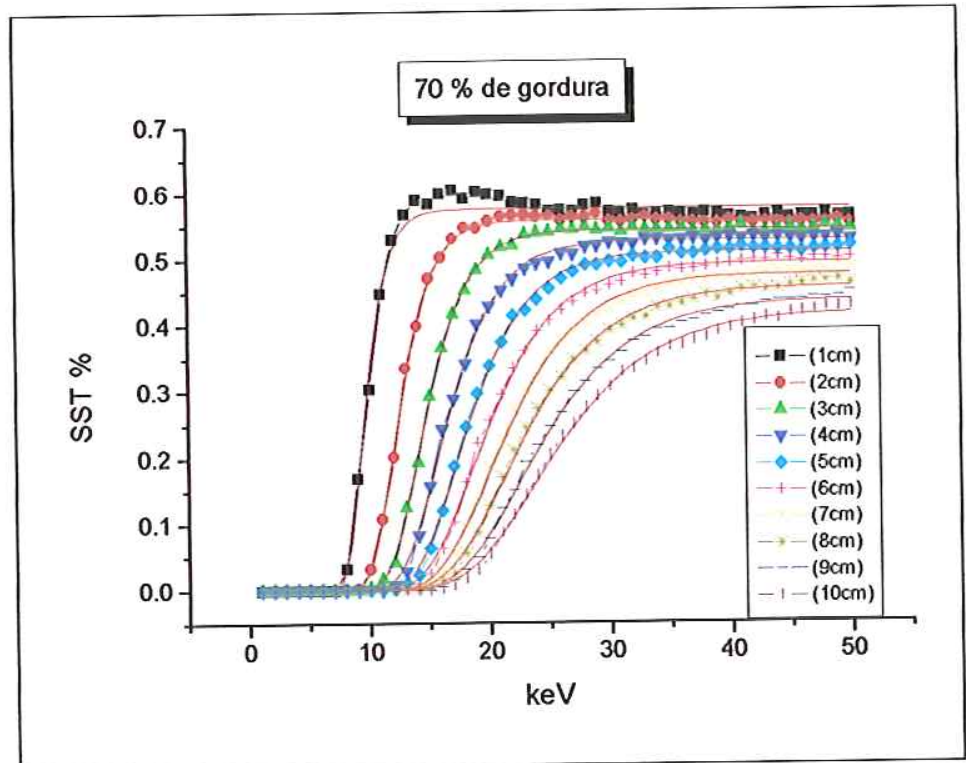

Figura 7. 8. SST em função da energia (keV) para várias espessuras de mama composta de $70 \%$ de tecido adiposo.

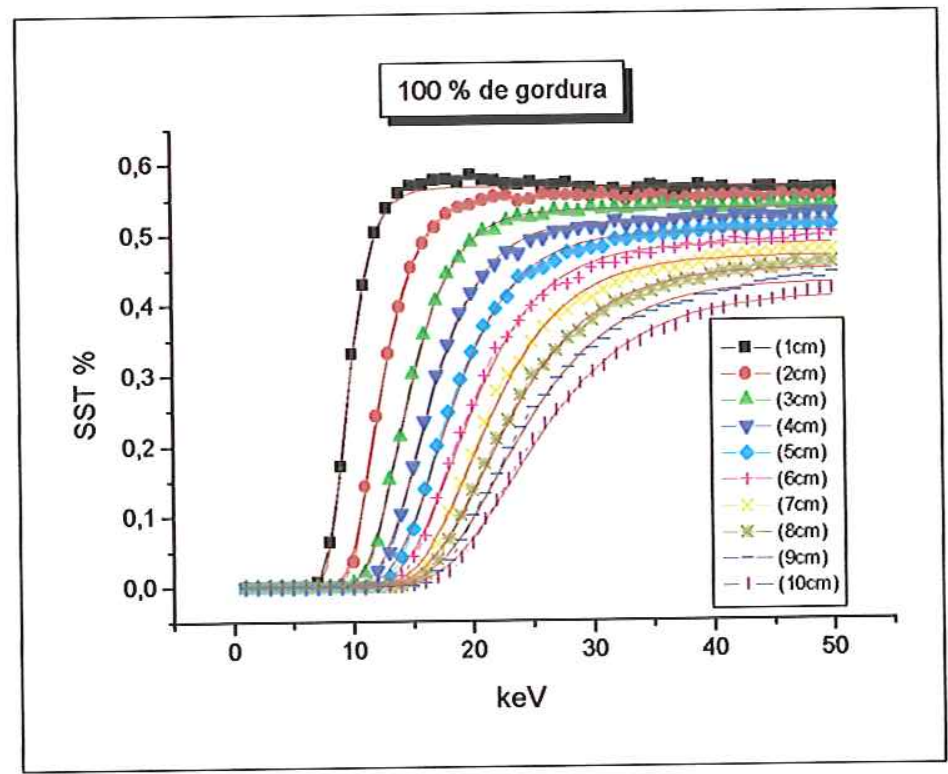

Figura 7. 9. SST em função da energia (keV) para várias espessuras de mama composta unicamente de tecido adiposo. 


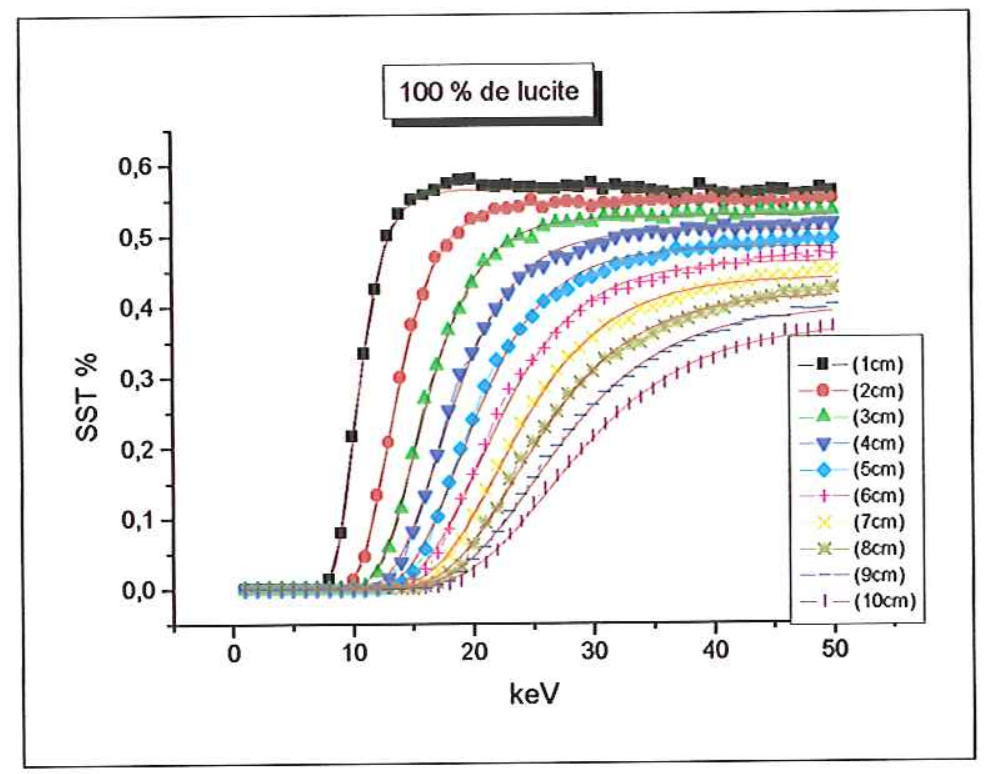

Figura 7. 10. SST em função da energia (keV) para várias espessuras de Lucite.

\subsubsection{Determinação dos coeficientes necessários para o cálculo do SST em função do ângulo de espalhamento $\theta$.}

Através do método de regressão determinamos os coeficientes $\boldsymbol{a}, \boldsymbol{x} \boldsymbol{c}$ e $\boldsymbol{k}$ da equação de SGompez (equação 3.18) para cada energia do espectro de radiação e espessura do material exposto. Essas curvas foram novamente aproximadas por regressão para determinar os seus respectivos coeficientes $A$, $\boldsymbol{B} 1, \boldsymbol{B} 2$ e $\boldsymbol{C}$, apresentados na Tabela 7.1 para a mama e na Tabela 7.2 para o Lucite. Na Tabela 7.1, $\boldsymbol{X}$ representa a fração de tecido adiposo na composição da mama.

Tabela 7. 1. Coeficientes a, xc, k da equação de SGompez para os tecidos da mama.

\begin{tabular}{|c|c|c|c|c|c|c|}
\hline & $\mathbf{A}$ & & B1 & & B2 & C \\
\hline a & $0,5962-6,5854 \mathrm{E}-5^{*} \mathrm{X}$ & $\mathrm{p}^{\prime} \quad 0 \leq \mathrm{X} \leq 100$ & $-0,0192+2,4091 E-5^{*} X$ & $\mathrm{p} / 0 \leq \mathrm{X} \leq 100$ & - & - \\
\hline xc & $8,1117-0,0091^{*} \mathrm{X}$ & $p^{\prime} 0 \leq X \leq 100$ & $\begin{array}{l}2,5702-0,0041^{*} X \\
1,5812+0,0070^{*} X\end{array}$ & $\begin{array}{l}\mathrm{p}^{\prime} 0 \leq \mathrm{X} \leq 90 \\
\mathrm{p}^{\prime} / 90 \leq \mathrm{X} \leq 100\end{array}$ & $\begin{array}{ll}-0,0788+1,4581 E-4^{*} X & p^{\prime} 0 \leq X \leq 90 \\
-0,0229-4,68 E-4^{*} X & p^{\prime} 90<X \leq 100\end{array}$ & - \\
\hline $\mathbf{k}$ & $-0,6489+0,0012^{*} \mathrm{X}$ & $\mathrm{p}^{\prime} \quad 0 \leq \mathrm{X} \leq 100$ & $\begin{array}{l}2,0567-0,0052^{*} \mathrm{X} \\
1,5035+0,0029^{*} \mathrm{X}\end{array}$ & $\begin{array}{l}\mathrm{p}^{\prime} \quad 0 \leq \mathrm{X} \leq 70 \\
\mathrm{p}^{\prime} / 70<\mathrm{X} \leq 100\end{array}$ & 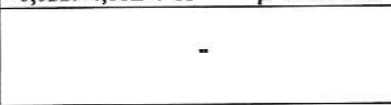 & 0,5 \\
\hline
\end{tabular}


Tabela 7. 2. Coeficientes a, xc, k da equação de SGompez para o Lucite.

\begin{tabular}{|c|c|c|c|c|}
\hline & $\mathbf{A}$ & $\mathbf{B 1}$ & $\mathbf{B 2}$ & $\mathbf{C}$ \\
\hline $\mathbf{a}$ & 0,58926 & $-0,02142$ & - & - \\
\hline $\mathbf{x c}$ & 7,9356 & 2,50115 & $-0,06981$ & - \\
\hline $\mathbf{k}$ & 0,64128 & 2,12137 & - & 0,5 \\
\hline
\end{tabular}

Para todos os coeficientes, o $\chi^{2}$ foi menor que 0,001 , ou seja, a somatória dos erros foi bem menor que os $5 \%(0,05)$ normalmente aceito para este tipo de análise.

A quantidade de fótons espalhados para cada ângulo $\theta, \boldsymbol{S S T}(\theta)$, depende dos coeficientes $\boldsymbol{T o}$, Yo e $\boldsymbol{A}$ aproximados como mostrado na Tabela 7.3, onde $\boldsymbol{D}$ representa a espessura do Lucite.

Tabela 7. 3. Coeficientes To, Yo e $A$ para o Lucite.

\begin{tabular}{|c|c|}
\hline To & $\begin{array}{l}\text { - } \mathrm{t}=5 \mathrm{E}-05^{*} \mathrm{D}^{6}-0,0068 * \mathrm{D}^{5}+0,1961 * \mathrm{D}^{4}-2,4208^{*} \mathrm{D}^{3}+14,733 * \mathrm{D}^{2}-42,668 * \mathrm{D}+58,648 \\
\text { - } \mathrm{a}=-0,0005^{*} \mathrm{D}^{6}+0,0149 * \mathrm{D}^{5}-0,1511^{*} \mathrm{D}^{4}+0,4619^{*} \mathrm{D}^{3}+1,71 * \mathrm{D}^{2}-13,292 * \mathrm{D}+24,0\end{array}$ \\
\hline Yo & $\begin{array}{ll}\text { - } & \mathrm{t}=0,0003^{*} \mathrm{D}^{6}-0,0143^{*} \mathrm{D}^{5}+0,2826^{*} \mathrm{D}^{4}-2,7141^{*} \mathrm{D}^{3}+13,569^{*} \mathrm{D}^{2}-33,909^{*} \mathrm{D}+41,692 \\
\text { - } & \mathrm{a}=-0,0344 \exp (-0,3772 * \mathrm{D})\end{array}$ \\
\hline $\mathbf{A}$ & $\begin{array}{ll}\text { - } & \mathrm{t}=0,0024^{*} \mathrm{D}^{6}-0,0821^{*} \mathrm{D}^{5}+1,0854^{*} \mathrm{D}^{4}-7,0094^{*} \mathrm{D}^{3}+22,769^{*} \mathrm{D}^{2}-34,436 * \mathrm{D}+15,665 \\
\text { - } & \mathrm{a}=6,7361^{*} \mathrm{D}^{6}-217,71 * \mathrm{D}^{5}+2756,2 * \mathrm{D}^{4}-17169 * \mathrm{D}^{3}+54066^{*} \mathrm{D}^{2}-78587 * \mathrm{D}+41457\end{array}$ \\
\hline
\end{tabular}

A porcentagem de radiação espalhada em função do ângulo $\operatorname{SST}(\theta)$, para $25 \mathrm{kVp}$ e $5 \mathrm{~cm}$ de espessura de Lucite está na Figura 7.11. A maior parte dos fótons se encontra na proximidade do eixo de incidência $\left(0^{\circ}\right)$ e decresce seguindo uma função exponencial inversa. 


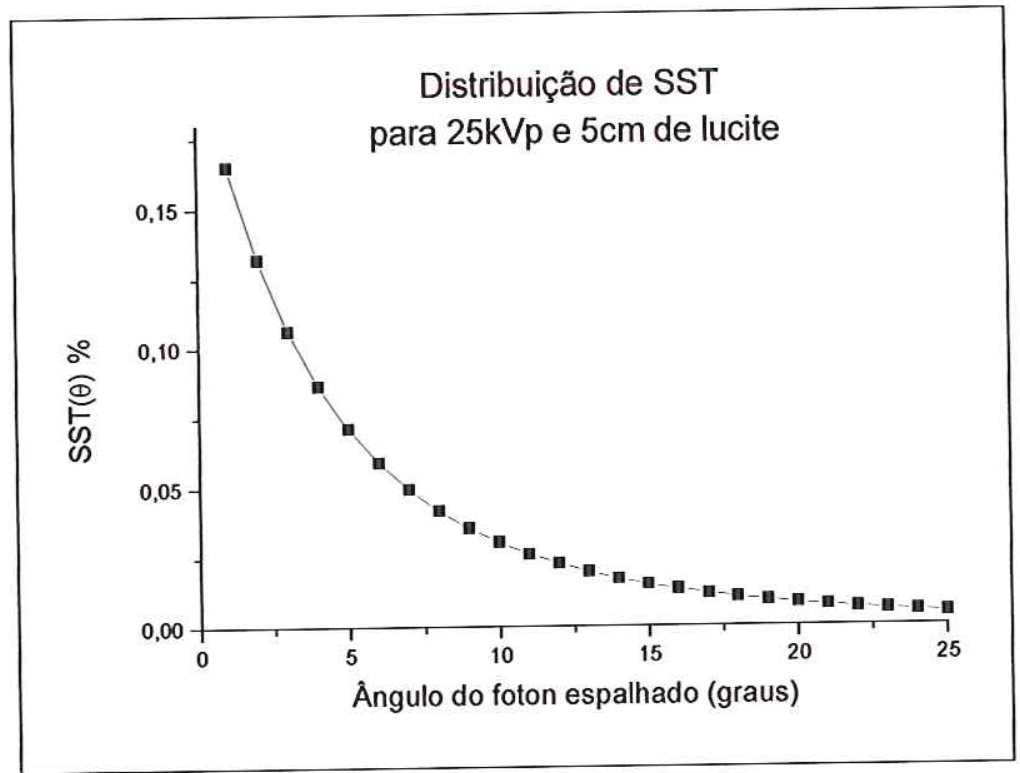

Figura 7. 11. $\operatorname{SST}(\theta)$ para o Lucite de $5 \mathrm{~cm}$ de espessura a $25 \mathrm{kVp}$ em função do ângulo de espalhamento dos fótons.

A incidência de um feixe em um ponto do objeto (Lucite), produz em toda a extensão do material radiografado, um espalhamento $\operatorname{SST}(\theta) \operatorname{com}$ a forma ilustrada na Figura 7.12.

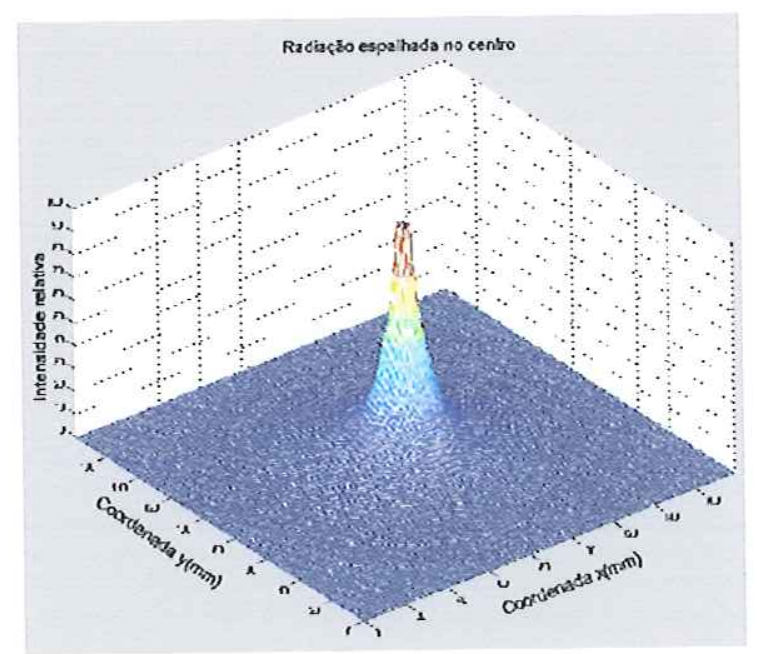

Figura 7. 12. Espalhamento $\operatorname{SST}(\theta)$ provocado por $1 \mathrm{~mm}^{2}$ do Lucite de $5 \mathrm{~cm}$ de espessura com 25kVp. 


\subsubsection{Validação do modelo do espalhamento.}

Simulamos a radiação espalhada com as mesmas condições utilizadas no trabalho de Barnes e Brezovich (BARNES\&BREZOVICH,1978). Esses autores mediram a radiação espalhada em relação à radiação primária (SP) variando a tensão do tubo de raios-X de $27 \mathrm{a} 42 \mathrm{kVp}$, considerando um campo de radiação de $14 \mathrm{~cm}$ de diâmetro e a espessura de um fantoma de Lucite de 3 a $6 \mathrm{~cm}$, para um tubo de raios-X de molibdênio com janela de Berílio(Be) e filtro de alumínio(Al) de $0,5 \mathrm{~mm}$ de espessura. Eles utilizaram o fantoma feito de Lucite porque este possui o mesmo Zeff que uma mama composta de $65 \%$ de gordura e $35 \%$ de tecido glandular. Como o tecido da mama tem densidade de $0,95 \mathrm{~g} / \mathrm{cm}^{3}$ e o Lucite $1,19 \mathrm{~g} / \mathrm{cm}^{3}, 1 \mathrm{~cm}$ de espessura de Lucite corresponde a $1,25 \mathrm{~cm}$ de tecido da mama.

A Figura 7.13 mostra as taxas de espalhamento em função da espessura, obtidas por Barnes e as que simulamos, para $32 \mathrm{kVp}$.

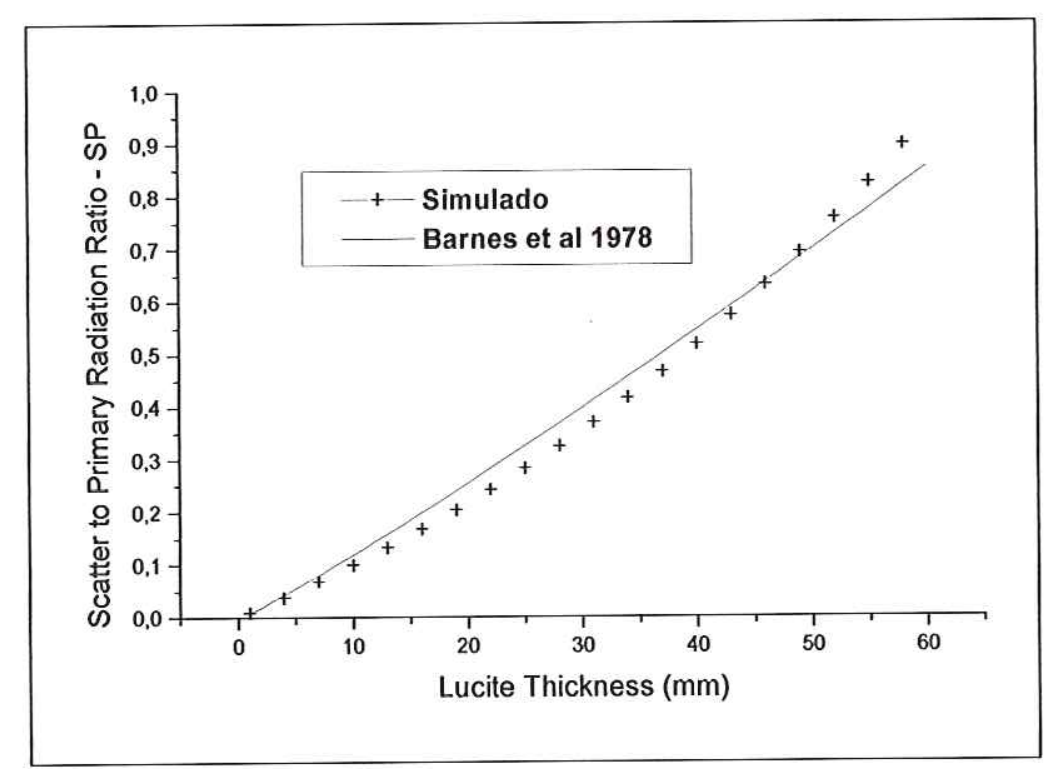

Figura 7. 13. Taxa de espalhamento em relação ao primário (SP) medida feita por Barnes e Brezovich (BARNES\&BREZOVICH,1978) e simulada para espessuras de Lucite de ate $6 \mathrm{~cm}$ com o tubo a $32 \mathrm{kVp}$. 
As duas curvas apresentam uma boa concordância. As diferenças são devidas ao fato que a curva de Barnes e Brezovich foi levantada por regressão linear a partir de 4 medidas experimentais enquanto que, neste trabalho, geramos a curva simulada utilizando a equação de Klein-Nishina (CHAN\&DOI,1983), que contém aproximações.

\subsection{SIMULAÇÃO DO SISTEMA SLIT MODIFICADO}

\subsubsection{O modelo.}

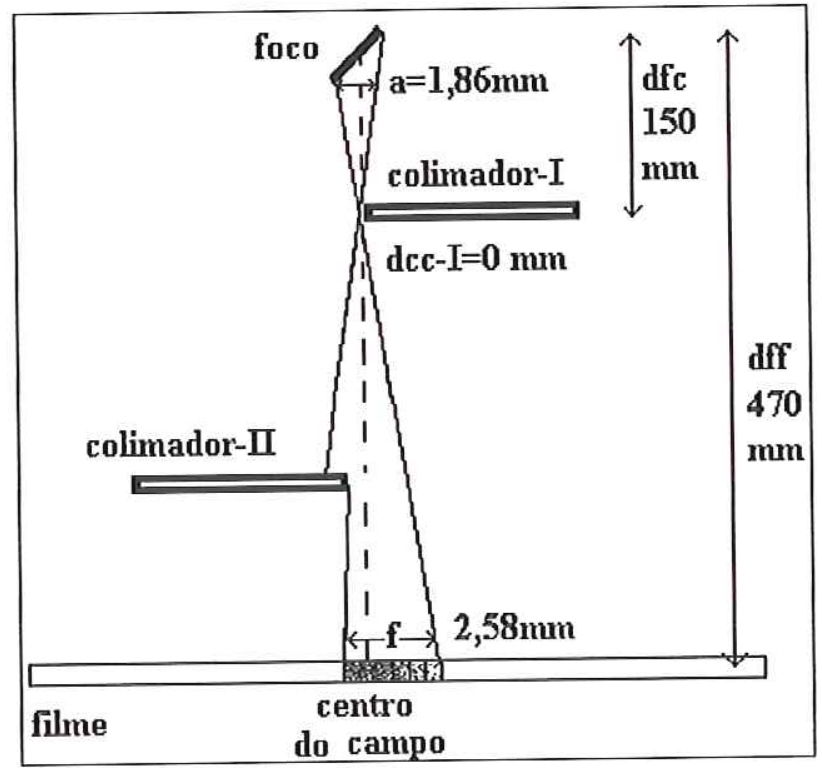

Figura 7. 14. Modelo de feixe colimado para otimizar a aquisição das imagens.

O modelo slit modificado que utilizamos nesta simulação está na Figura 7.14. Para eliminar a grade, colocamos o filme em cima da mesa do mamógrafo. Assim a distância do ponto focal ao filme $\boldsymbol{d}_{f f}$ é de $470 \mathrm{~mm}$ (levando em conta a espessura do chassi). A distância $\boldsymbol{d}_{f c}$ é limitada por um fator físico que é a distância que existe entre o ponto focal e o invólucro do tubo de raios- $\mathrm{X}$ (incluindo a espessura do vidro, a proteção de chumbo e a 
armação metálica). No aparelho mamográfico CGR utilizado ela é de $150 \mathrm{~mm}$. Colocamos o colimador-I nesta distância mínima. Portanto $\boldsymbol{d}_{f c}=150 \mathrm{~mm}$.

Desejaríamos situar o colimador-I para utilizar somente a faixa do campo $f$ onde a radiação é maior, o que ocorre quando $d_{c c_{-}} I$ é igual a $44,7 \mathrm{~mm}$, mas a maioria dos mamógrafos tem o campo de radiação cortado no centro. Portanto como realizamos as medições experimentais com um mamógrafo convencional situamos o colimador no centro do campo de radiação $\left(\boldsymbol{d}_{c c_{-}} \boldsymbol{I}_{I}=0\right)$. Realizamos todos os cálculos para duas posições: a possível, onde $\boldsymbol{d}_{c c_{-} \boldsymbol{I}_{1}}=0,0$ e a ideal onde $\boldsymbol{d}_{c c_{-}} \boldsymbol{I}_{2}=44,7 \mathrm{~mm}$. Para estas duas posições $\beta_{1}$ é igual a $0^{\circ}\left(\boldsymbol{d}_{c c_{-}} \boldsymbol{I}_{I}=0.0 \mathrm{~mm}\right)$ e $\beta_{2}$ é igual a $16,6^{\circ}\left(\boldsymbol{d}_{c c_{-}} \boldsymbol{I}_{2}=44,7 \mathrm{~mm}\right)$.

Deslocamos o colimador-II $\left(\boldsymbol{d}_{\boldsymbol{c} \_\_} \boldsymbol{I}\right)$ ) de modo a variar a abertura da fenda e conseqüentemente a largura do feixe $f$.

Com o comprimento $\mathbf{w}$ do ponto focal de $1,86 \mathrm{~mm}$ no centro do campo $\left(\mathbf{d}_{\mathbf{c c} \_} \mathbf{I}=0.0 \mathrm{~mm}\right)$, pela equação 4.3 o tamanho da faixa $\mathbf{f}_{0}$ é igual a $3,97 \mathrm{~mm}$.

Para $\mathbf{d}_{\mathbf{c c} \_} \mathbf{I}=44,7 \mathrm{~mm}$, $\mathbf{w}$ é igual a $3,05 \mathrm{~mm}$ o que produz uma faixa $\mathbf{f}_{44,7}$ de $6,50 \mathrm{~mm}$ no plano do filme.

$$
\begin{aligned}
& f_{0,0}=w_{0,0} \cdot\left(\frac{d_{f f}}{d_{f c}}-1\right)=1,86 \cdot\left(\frac{470}{150}-1\right)=3,97 \mathrm{~mm} \\
& f_{44,7}=w_{44,7} \cdot\left(\frac{d_{f f}}{d_{f c}}-1\right)=3,05 \cdot\left(\frac{470}{150}-1\right)=6,50 \mathrm{~mm}
\end{aligned}
$$

Diminuímos ou aumentamos esta faixa deslocando o colimador-II na horizontal de acordo com a necessidade do projeto em diminuir a radiação espalhada e/ou o tamanho do ponto focal.

Calculamos para esta faixa $\boldsymbol{f}$ os números de fótons primários (Ip_slit) e espalhados (Is_slit) (Figura 7.14) recebidos pelo pixel $\boldsymbol{p}$ do filme com a posição $\boldsymbol{d}_{c c_{-}} \boldsymbol{I}$ do colimador-I em zero em $\beta_{1}$ e $44,7 \mathrm{~mm}$ para $\beta_{2}$.

Analisamos, o tamanho de ponto focal (a_slit) colimado. Na Figura 7.15 podemos observar que ele aumenta proporcionalmente a largura da faixa 
até alcançar o tamanho máximo determinado pela característica de campo, a saber: $1,89 \mathrm{~mm}$ para $\beta_{1}$ e $3,05 \mathrm{~mm}$ para $\beta_{2}$.

A radiação primária, a radiação espalhada e a taxa de espalhamento $(\boldsymbol{S P})$ em função da largura da faixa estão mostradas nas Figuras 7.16, 7.17 e 7.18. Enquanto que na Figura 7.19 mostramos a taxa de espalhamento em função do tamanho do ponto focal.

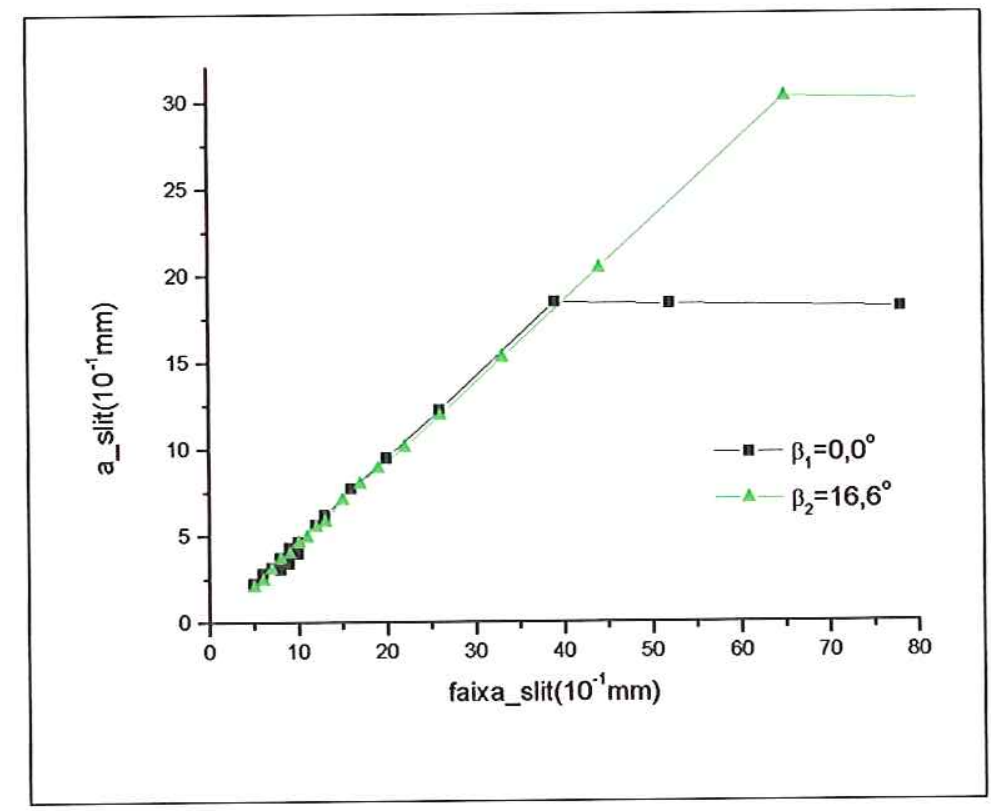

Figura 7. 15. Tamanho do ponto focal em função da largura da faixa de radiação para $\beta_{1}$ e $\beta_{2}$.

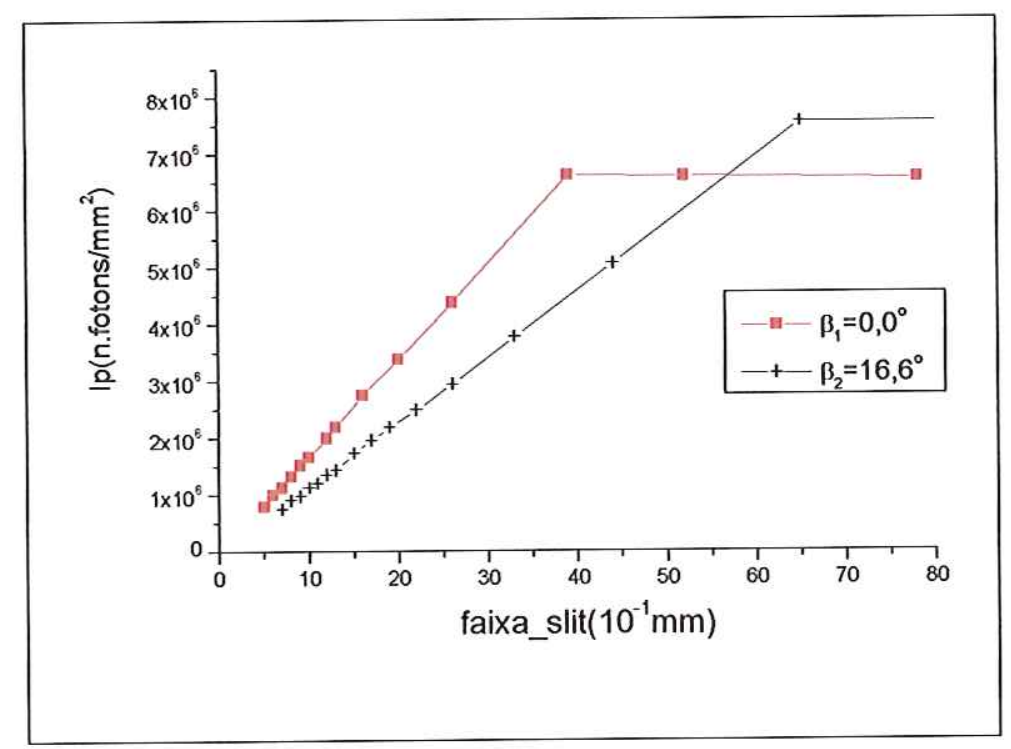

Figura 7. 16. Radiação primária em função da largura da faixa de radiação para a placa de Lucite de $2,5 \mathrm{~cm}$ de espessura em $\beta_{1}$ e $\beta_{2}$. 
Na Figura 7.15 podemos ver que quando a largura da faixa é menor que o tamanho crítico determinado pela equação 4.3 , a saber: $3,97 \mathrm{~mm}$ para $\beta_{1}$ e $6,50 \mathrm{~mm}$ para $\beta_{2}$, a intensidade primária é reduzida. A partir destes valores toda a intensidade primária é recebida pelo pixel o que é mostrada pela saturação das curvas. A intensidade primária de saturação para $\beta_{1}$ é de 6,65E6 fótons/pixel e para $\beta_{2}$ é de 7,52E6 fótons/pixel, isto é, uma diferença de $13,08 \%$ devido ao efeito heel.

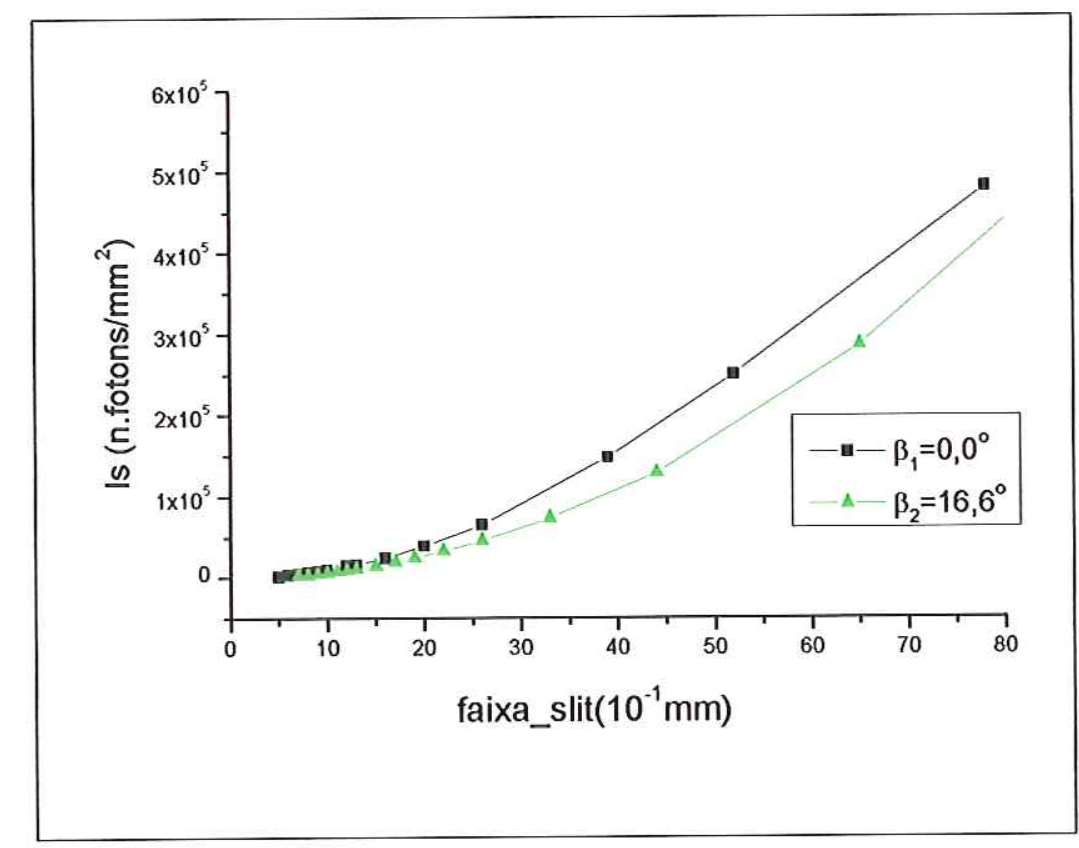

Figura 7. 17. Radiação espalhada em função do tamanho da faixa de radiação para a placa de Lucite de $2,5 \mathrm{~cm}$ de espessura.

Da Figura 7.18 pode-se concluir que quando o slit é posicionado em $\beta_{2}$ $\left(16,6^{\circ}\right)$ a radiação espalhada pelas estruturas mais espessas é mais reduzida em relação a colocação em $\beta_{1}\left(0^{\circ}\right)$ cerca de $32 \%$ menor para faixa de $6,5 \mathrm{~mm}$ e espessura de $2,5 \mathrm{~cm}$.

A partir da faixa de $3,9 \mathrm{~mm}$ o espalhamento aumenta mais rapidamente para todas as espessuras. 


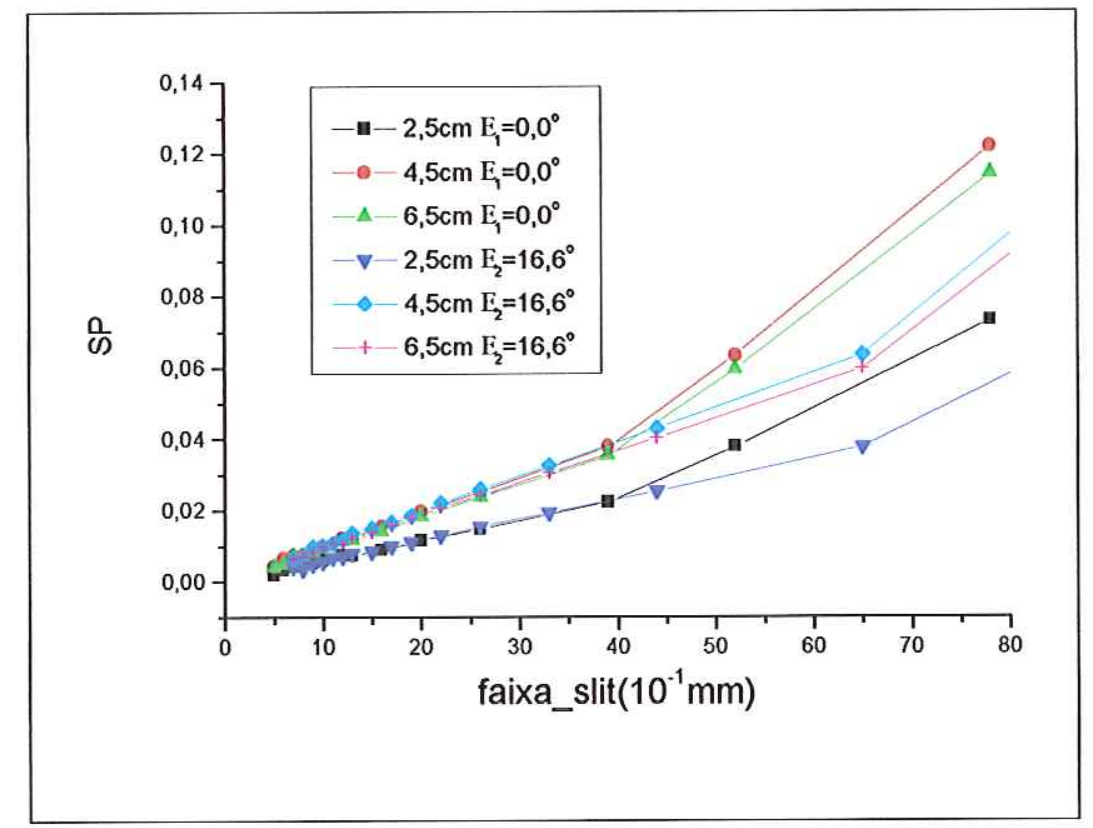

Figura 7. 18. Taxa de espalhamento em função do tamanho da faixa de radiação para espessuras de Lucite de 2,$5 ; 4,5$ e $6,5 \mathrm{~cm}$.

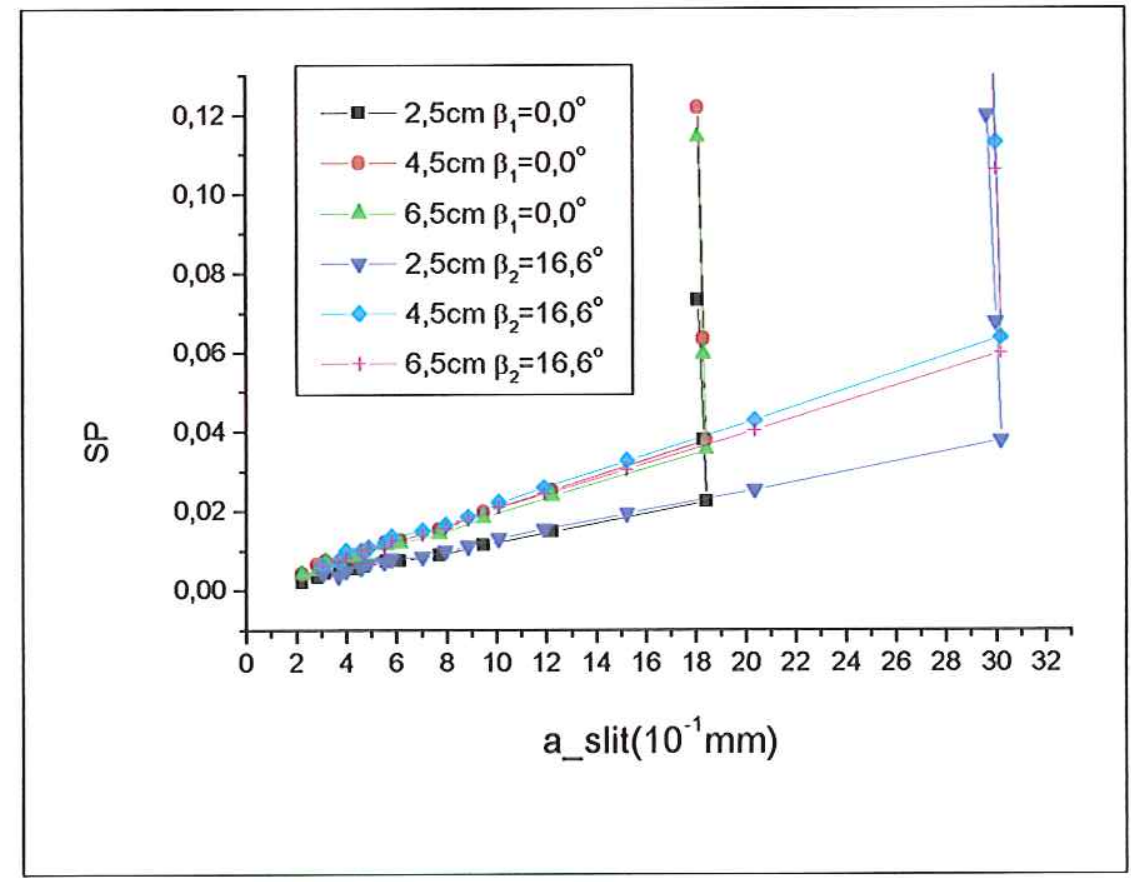

Figura 7. 19. Taxa de espalhamento em função do tamanho do foco a_slit. 
A relação da intensidade que chega no sistema de registro com a intensidade gerada pelo tubo na mesma direção é conhecida como transmissão do sistema. Ela varia em função do tamanho da faixa como mostrada na Figura 7.20. Colocamos no mesmo gráfico os valores das transmissões primária $0,8 \mathrm{e}$ espalhada 0,2 pela grade linear vibratória encontrados na literatura (CHAN\&DOI,1982) para sistema mamográfico.

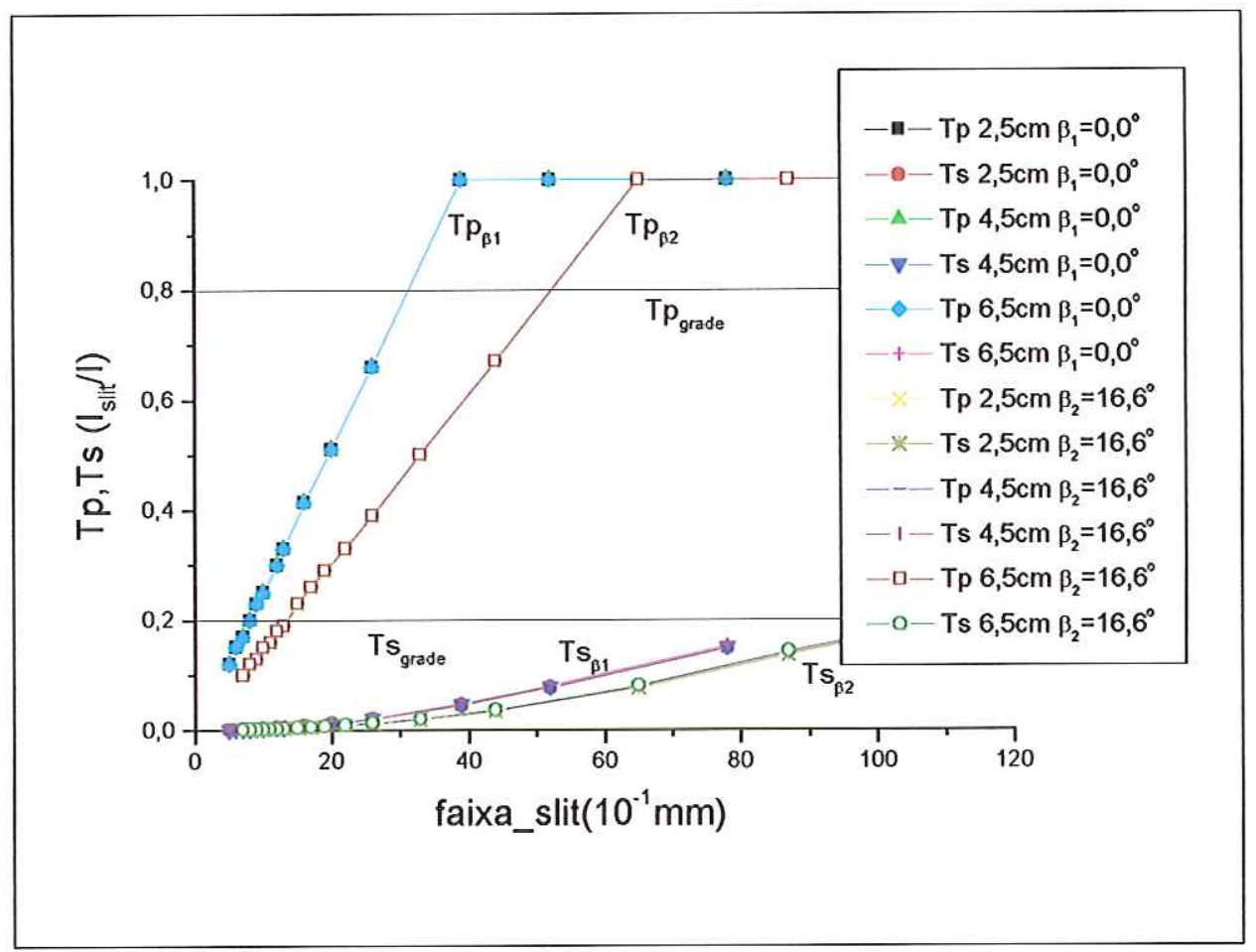

Figura 7. 20. Transmissão primária (Tp) e espalhada (Ts) pela faixa slit. $T \mathbf{p}_{\text {grade }}$ e $T s_{\text {grade }}$ são as transmissões da grade linear vibratória.

Observamos que a transmissão primária é superior a do sistema de grade quando a faixa do slit é maior que $3,1 \mathrm{~mm}$ no centro do campo $\left(\beta_{1}\right)$ e $5,2 \mathrm{~mm}$ para $\beta_{2}$. Para a transmissão espalhada os valores são iguais ao do sistema com grade quando a faixa do slit é de aproximadamente $8,9 \mathrm{~mm}$ para $\beta_{1}$ e $11,2 \mathrm{~mm}$ para $\beta_{2}$, abaixo destes tamanhos as transmissões são menores. Portanto a transmissão primária é melhor no sistema slit quando a faixa for 
maior que 3,1 ou $5,2 \mathrm{~mm}\left(\mathrm{Tp}_{\text {slit }}>\mathrm{T} \mathrm{p}_{\text {grade }}\right)$, e a transmissão espalhada melhora para faixas menores que 8,9 ou $11,2 \mathrm{~mm}$.

Variando a espessura do Lucite de 0,5 a $6,5 \mathrm{~cm}$ levantamos o gráfico da Figura 7.21. As taxas de espalhamento para o modo convencional sem grade, o modo slit e o modo slit modificado aumentam em todos os casos em função da espessura do objeto, mas bem menos no modo slit modificado.

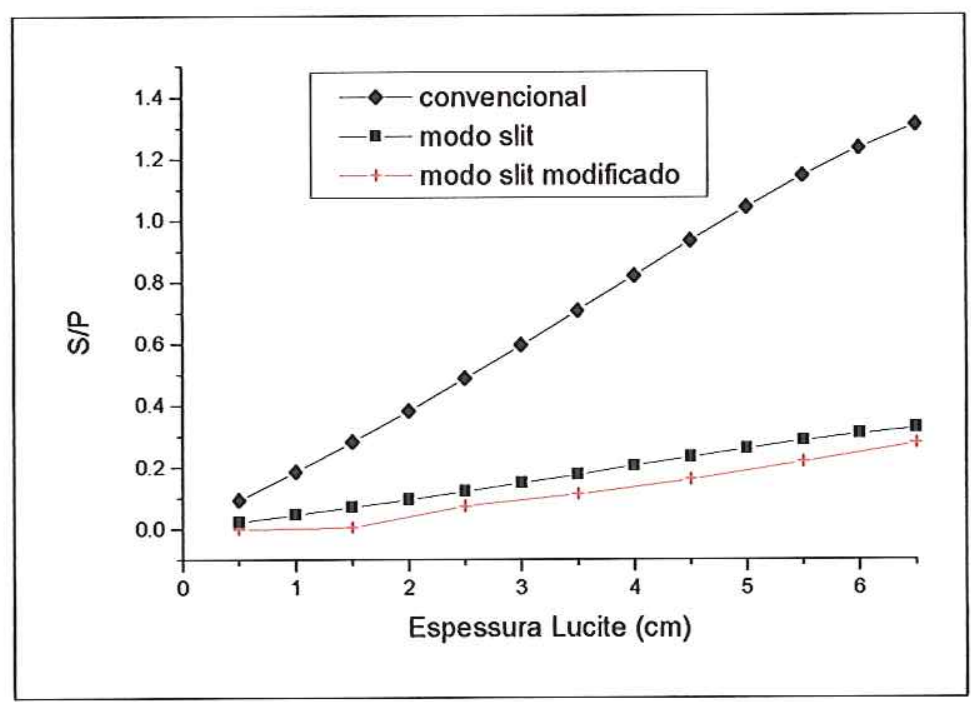

Figura 7. 21. Taxas de espalhamento para o modo convencional sem grade, para o modo slit e para o modo slit modificado em função da espessura do objeto (Lucite) a $25 \mathrm{kVp}$ e abertura de feixe de $10 \mathrm{~mm}$ nos modos slit.

\subsection{DIMENSIONAMENTO DO PROTÓTIPO PARA OTIMIZAR A AQUISIÇÃO DOS MAMOGRAMAS}

\subsubsection{O protótipo ideal.}

Como condição inicial estabelecemos um ponto focal de $0,3 \mathrm{~mm}$ que é o fornecido pelos mamógrafos mais recentes. Para tanto, do gráfico da Figura 7.14 deduzimos que a faixa do slit deveria ser de $0,7 \mathrm{~mm}$. Para esta faixa a intensidade da radiação primária $\mathbf{I}_{\mathbf{p}}$ seria de 1,13E6fótons/pixel (Figura 7.16), 
a intensidade da radiação espalhada $\mathbf{I}_{\mathbf{s}}$ seria de 4,86E3fótons/pixel (Figura 7.17) e a taxa de espalhamento de 0,0043.(Figura 7.18). Estes últimos dados podem ser deduzidos também do gráfico 7.19.

Entretanto no gráfico da Figura 7.20 podemos constatar que para estes valores a intensidade da radiação primária seria muito mais reduzida do que com o sistema grade.

Para não reduzir tanto $\mathbf{I}_{\mathbf{p}}$, as faixas poderiam ser de $3,1 \mathrm{~mm}$ para $\beta_{1}$ e $5,2 \mathrm{~mm}$ para $\beta_{2}$, garantindo uma transmissão primária $\mathbf{T}_{\mathbf{p}}$ de 0,8 igual da grade e uma $\mathbf{T}_{\mathbf{s}}$ de 0,031 para $\beta_{1}$ e 0,050 e para $\beta_{2}$, menor que aquela produzida pela grade. Para estas faixas o foco seria de $1,47 \mathrm{~mm}$ no centro $\beta_{1}$ e $2,42 \mathrm{~mm}$ em $\beta_{2}$. Adotamos um modelo que produz um foco menor de 1,22mm. Escolhemos como parâmetro uma radiação primária de 4,36E6fótons/pixel (Figura 3.17). Neste caso a faixa é de $2,58 \mathrm{~mm}$ no centro do campo, $\mathbf{d}_{\mathbf{c c} \_} \mathbf{I}=0,0$ e $\mathbf{d}_{\mathbf{c c} \_}$II $=2,58 \mathrm{~mm}, \mathrm{Is}=6,41 \mathrm{E} 4$ e $\mathrm{S} / \mathrm{P}=0,0153$.

Para validar o algoritmo simulamos a exposição de uma matriz de esferas virtual no item a seguir.

\subsubsection{Simulação da exposição.}

Para formar a imagem de um objeto no modo convencional é necessária uma exposição $\mathbf{E}_{\mathbf{c o n v}}$ de $5 \mathrm{mAs}$ no centro do campo. Medimos o tempo correspondente $\boldsymbol{t}_{\text {conv. }}$ Ele é de $16,5 \mathrm{~ms}$. No modo slit é necessário percorrer com o feixe colimado uma distância $L_{\text {filme }}$ de $180 \mathrm{~mm}$, relativa ao tamanho lateral de um filme mamográfico.

A faixa $f$ de $2,58 \mathrm{~mm}$ fornece uma $\boldsymbol{T}_{\boldsymbol{p}}$ no modo slit de 0,66 . Com as equações 7.3 e 7.4 calculamos o tempo $\boldsymbol{t}_{\text {slit }}$ como sendo de $1,74 \mathrm{~s}$ e a partir da equação 7.5 encontramos que $\mathbf{E}_{\text {sli }}$ deve ser $528,5 \mathrm{mAs}$. 


$$
\begin{aligned}
& n_{f}=\frac{L_{\text {filme }}}{f}=\frac{180}{2,58}=69,767 \\
& t_{\text {slit }}=t_{\text {conv }} \cdot \frac{n_{f}}{T_{p}}=0,0165 \cdot \frac{69,767}{0,66}=1,74 \mathrm{~s} \\
& E_{\text {slit }}=E_{\text {conv }} \cdot \frac{n_{f}}{T_{p}}=5 \cdot \frac{69,767}{0,66}=528,53 \mathrm{mAs}
\end{aligned}
$$

\subsubsection{Simulação das imagens produzidas pela radiografia} convencional e pelo modo slit.

Simulamos a exposição de raios- $X$ produzida na mamografia convencional com tempo suficiente para escurecer o fundo do filme na imagem final.

Irradiamos uma matriz de esferas virtual de $2,5 \mathrm{~cm}$ de espessura. A Figura 7.22A mostra a radiografia da matriz com espalhamento e a Figura $7.22 \mathrm{~B}$ mostra com detalhe a imagem da esfera posicionada a $3,0^{\circ}$ do centro do campo.

As radiografias simuladas da matriz de esferas utilizando método slit são mostradas na Figura 7.23. A Figura 7.23A representa a radiografia com o espalhamento e a $7.23 \mathrm{~B}$ a imagem da esfera posicionada a $3,0^{\circ}$ do centro do campo.

Na Figura 7.23 podemos verificar que a esfera é mais nítida devido ao espalhamento e ao ponto focal serem menores. O gráfico da Figura 7.24 apresenta os diâmetros das esferas em função da sua localização. Nota-se também que todas as imagens obtidas com o sistema slit tem o mesmo diâmetro o que é uma das características relevantes deste modo de varredura. 


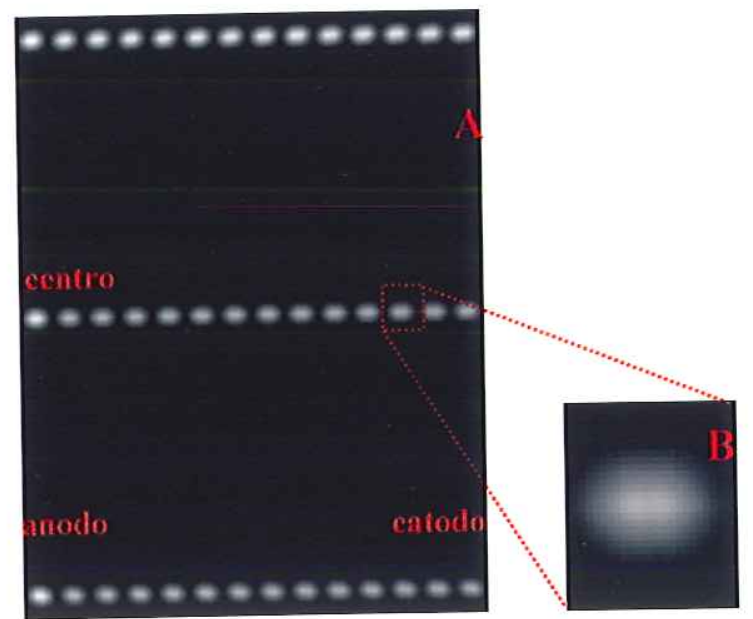

Figura 7. 22. Simulação da radiografia no modo convencional de uma matriz de esferas (A) e imagem da esfera posicionada a $3,0^{\circ}$ do centro do campo (B).

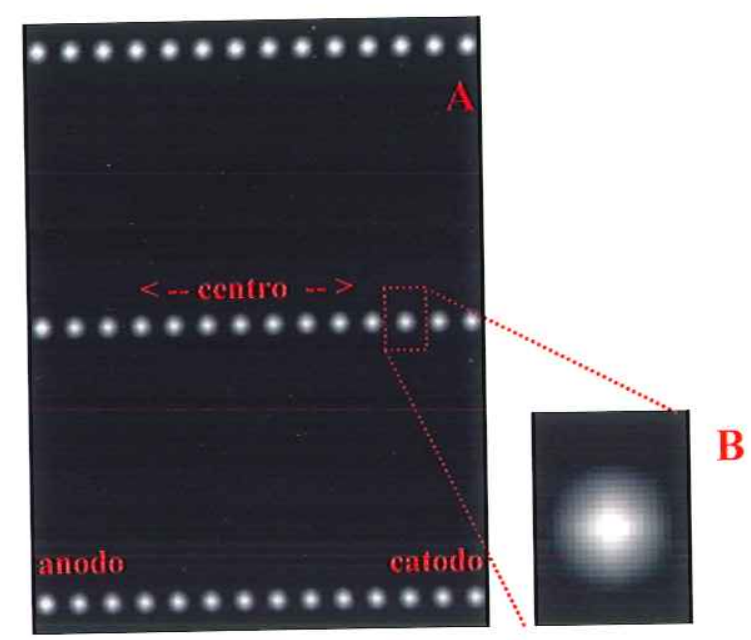

Figura 7. 23. Simulação de radiografia no modo slit modificado (A) e e imagem da esfera posicionada a $3,0^{\circ}$ do centro do campo (B).

Calculamos que a taxa de radiação espalhada (S/P) é de 0,488267, para o modo convencional e de 0,093852 para o sistema slit com o colimador-I posicionado no centro do campo de radiação, ou seja, o sistema slit proporciona uma redução de $80,77 \%$ do espalhamento. 


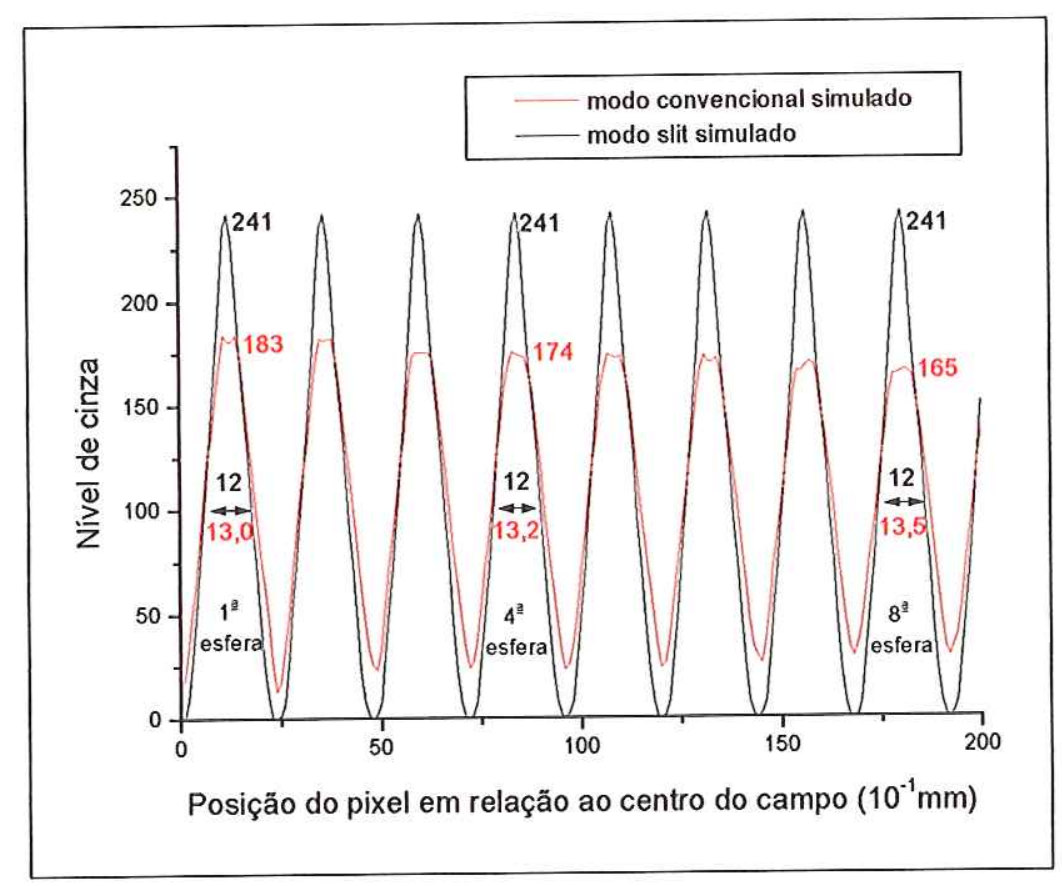

Figura 7. 24. Diâmetros e níveis de cinza máximos das imagens das esferas em função da sua localização.

\subsection{VALIDAÇÃO DO MODELO SLIT MODIFICADO}

\subsubsection{Medições experimentais}

Colocamos o filme a $470 \mathrm{~mm}$ de distância do ponto focal $\left(\mathbf{d}_{\mathbf{f}}\right)$ e posicionamos a matriz de esferas de $2 \mathrm{~mm}$ de espessura na metade desta distância, $235 \mathrm{~mm}$ do ponto focal ( $\left.\mathbf{d}_{\mathbf{f}_{\mathbf{0}}}\right)$ para obtermos magnificação 2 .

Para o modo convencional a exposição foi de $5 \mathrm{mAs}$ e $25 \mathrm{kVp}$.

Para o modo slit posicionamos o dispositivo abaixo do tubo de raios-X o nivelamos e centralizamos, Figura 7.25. Colocamos o colimador-I em $\mathbf{d}_{\mathbf{c} \_} \mathbf{I}$ igual a zero e o colimador-II em $\mathbf{d}_{\mathbf{c c} \_}$II igual a $2,58 \mathrm{~mm}$. Com uma tela fluorescente verificamos se a faixa de radiação é de tamanho desejado de $2,58 \mathrm{~mm}$. 


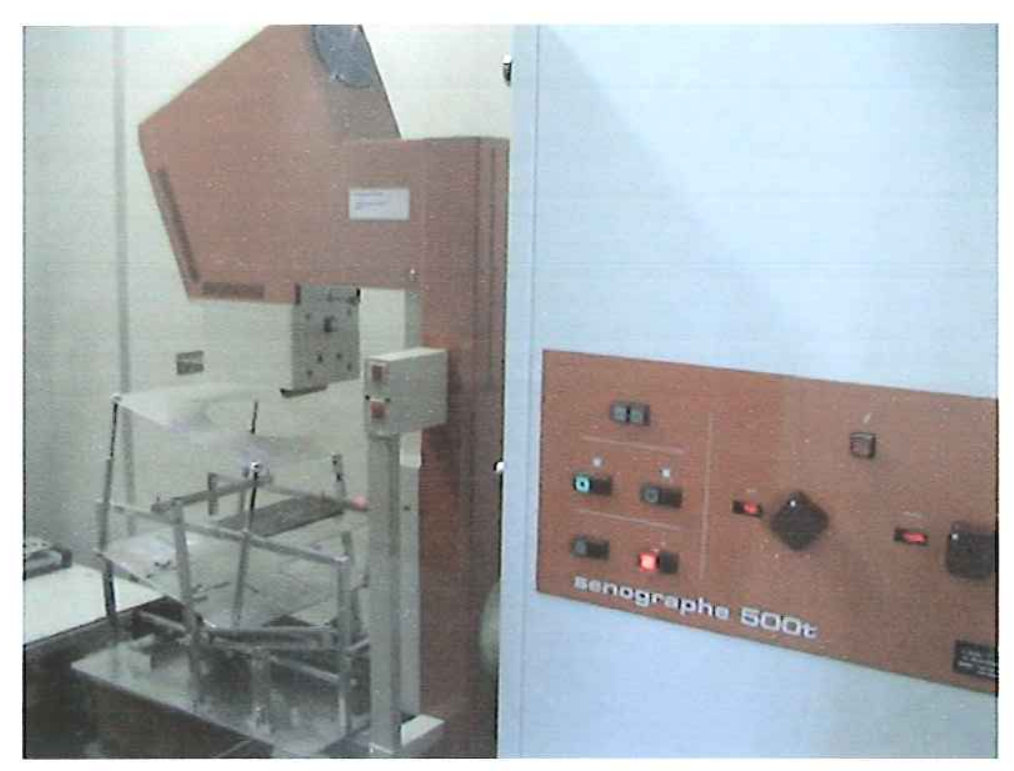

Figura 7. 25. Sistema completo com colimadores no mamógrafo.

A exposição foi de $525 \mathrm{mAs}$ a $25 \mathrm{kVp}$ e o tempo de varredura do dispositivo de $2,49 \mathrm{~s}$. O valor da exposição foi próximo ao calculado, $528,53 \mathrm{mAs}$, porém o tempo de varredura foi muito maior $(2,49 \mathrm{~s}>1,74 \mathrm{~s})$ devido aos tempos gastos para iniciar o movimento (inércia) e para a parada da mesa.

Obtivemos as imagens da Figura 7.26 para o modo convencional e da Figura 7.27 para o modo slit.

$\mathrm{Na}$ imagem referente a mamografia convencional (Figura 7.26), as esferas são menores e mais deformadas devido ao borramento introduzido pelo tamanho maior do ponto focal e pela maior quantidade de radiação espalhada. Nas imagens ampliadas estes fenômenos são mais visíveis. A imagem da esfera no modo convencional ficou reduzida de $30 \%$ em comparação com o tamanho da imagem do modo slit. Para realizar a comparação medimos os diâmetros das duas esferas nas imagens, considerando que todos os pixels com nível de cinza maior que 200 pertencem a esfera. 


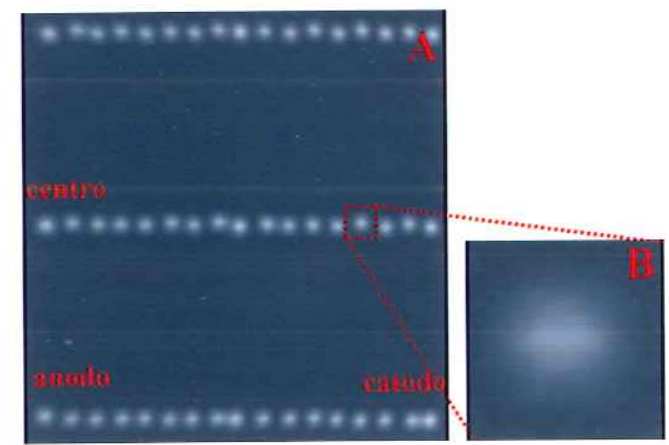

Figura 7. 26. Imagem da matriz com dispositivo mamográfico convencional.

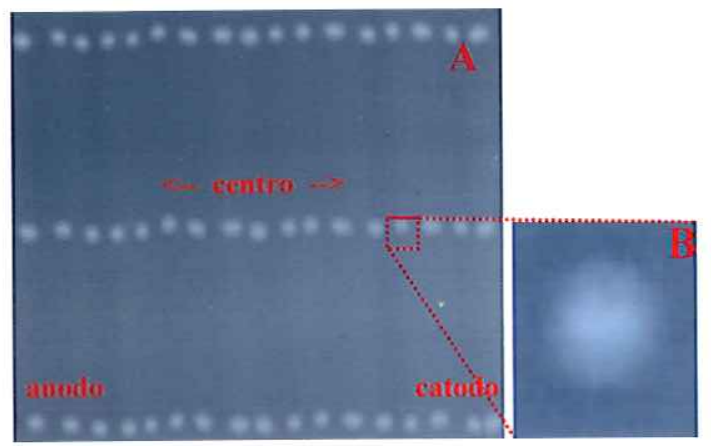

Figura 7. 27. Imagem da matriz com o dispositivo slit modificado.

\subsubsection{Medições do espalhamento e da radiação total}

Utilizando ainda a matriz de esferas de $2 \mathrm{~mm}$ de espessura (Lucite), medimos a intensidade da radiação primária e espalhada para o sistema convencional e slit modificado, e após cálculos obtemos $\boldsymbol{S} / \boldsymbol{P}_{\text {conv }}$ igual a 0,09654 e $\boldsymbol{S} / \boldsymbol{P}_{\text {slit }}$ igual a 0,00331 . Através da simulação calculamos $\boldsymbol{S} / \boldsymbol{P}_{\text {conv }}$ igual a 0,09801 e $\boldsymbol{S} / \boldsymbol{P}_{\text {slit }}$ igual a 0,00355 , ou seja, um desvio entre os valores simulados e medidos de $1,52 \%$ no modo convencional e $7,25 \%$ no modo slit modificado. A redução do $\boldsymbol{S} / \boldsymbol{P}$ no modo slit modificado em relação ao modo convencional é significativa: 96,5\% (equação 7.6). Realizamos várias medições e na média esta redução foi de $95,3 \%$.

$$
\text { Diminuição } \mathrm{S} / \mathrm{P}=100 \cdot\left(\frac{S / P_{\text {conv }}-S / P_{\text {slit }}}{S / P_{\text {conv }}}\right) \%
$$


A relação entre as taxas de transmissão $\mathbf{T}_{\mathbf{p}_{\text {_slit }}}$ e $\mathbf{T}_{\mathbf{s}_{-} \text {slit }}$ simuladas $\left(\mathbf{T}_{\mathbf{p}_{-} \text {slit }} / \mathbf{T}_{\mathbf{s}_{-} \text {sliti }}\right)$ é igual a 30,37. Por outro lado, com os valores simulados de $\boldsymbol{S} / \boldsymbol{P}_{\text {conv }}$ e $\boldsymbol{S} / \boldsymbol{P}_{\text {slit }}$ são iguais a 0,09654 e 0,00331 , encontramos $S / \mathrm{P}_{\text {conv }} / \mathrm{S} / \mathrm{P}_{\text {slit }}$ igual a 29,17 . Verificamos, assim, que os valores de $\mathrm{Tp} / \mathrm{Ts}$ e $\mathrm{S} / \mathrm{P}_{\text {conv }} / \mathrm{S} / \mathrm{P}_{\text {slit }}$ são bem próximos, com um desvio de 3,95\% entre um e outro.

Medimos a radiação total no modo slit modificado de $1,012 \mathrm{mR} / \mathrm{mAs}$ e para o modo convencional de $3,19 \mathrm{mR} / \mathrm{mAs}$. Por simulação estes valores são $1,076057 \mathrm{mR} / \mathrm{mAs}$ para o modo slit modificado e de $3,45 \mathrm{mR} / \mathrm{mAs}$ para o modo convencional, sendo um desvio entre os valores medidos e calculados de $8,15 \%$ (convencional) e 6,32\% (slit). Esses desvios são devidos ao fato que os coeficientes para o cálculo da taxa de espalhamento SST foram obtidos com incrementos de $5,0 \mathrm{~mm}$, com isso os valores calculados para espessura de $2,0 \mathrm{~mm}$ são aproximados. Entretanto tivemos que escolher essa espessura devido às limitações físicas da mesa suporte do dispositivo de varredura, onde a colocação de placas de Lucite acima de $2 \mathrm{~mm}$ provocou trepidações.

\subsection{QUANTIFICAÇÃO DA INFLUÊNCIA DA RADIAÇÃO ESPALHADA SOBRE O DESEMPENHO DOS ALGORITMOS USADOS NOS SISTEMAS CAD.}

7.7.1. Determinação da radiação espalhada por um mamograma

Escolhemos no banco de dados do Fujita Lab/Konica-Aichi Cancer Hospital um mamograma fornecido com as características de exposição e os dados do paciente. Os parâmetros inerentes ao processo de aquisição são $26 \mathrm{kVp}, 35 \mathrm{mAs}$, filtro de Molibdênio (Mo) de 0,03mm, relação de grade de 5:1 
(transmissão Tp pela grade de 0.8 e Ts de 0.17 ), conjunto tela-filme Kodak MIN-R, projeções médio laterais (ML) e scanner Konica LD500. As imagens foram digitalizadas em escala de cinza de 12bits e resolução espacial de $100 \mathrm{~m}$ por pixel.

Como as proporções de tecidos adiposos e glandulares da mama não são conhecidas com precisão, por serem estimativas baseadas em médias, o calculo da proporção de tecido adiposo feito pela equação 3.16 pode não ser exato. Portanto, para minimizar a influência deste erro sobre a avaliação do $\mathrm{CAD}$, escolhemos uma imagem onde o espalhamento é pequeno. Para tanto escolhemos dentro do banco do Fujita Lab a mamografia de uma paciente de 72 anos e espessura da mama comprimida de $1,8 \mathrm{~cm}$. Como o espalhamento diminui quando a espessura da estrutura diminui, esta característica proporciona o menor erro possível se a composição da mama não for exatamente a que prevemos. Calculamos neste caso que a proporção média de tecido adiposo em relação ao tecido fibroglandular é de $80 \%$ utilizando a equação 3.16 .

Simulamos a exposição da mama e calculamos as radiações transmitidas e espalhadas (IRITA et al., 2002). Acrescentamos a mamografia escolhida no banco de dados do Fujita Lab o espalhamento que seria produzido com o aumento da espessura da mama comprimida de 1,8 para $10 \mathrm{~cm}$. Há poucas diferenças visuais entre estas imagens, mas existe uma grande variação da radiação espalhada como mostra o gráfico da Figura 7.28. Neste gráfico verificamos que, por exemplo, a imagem simulada de uma mama com $10 \mathrm{~cm}$ de espessura comprimida, apresentaria $60 \%$ mais radiação espalhada que imagem original com mama de $1,8 \mathrm{~cm}$. 
Taxa de espalhamento em funcão da espessura da mama.

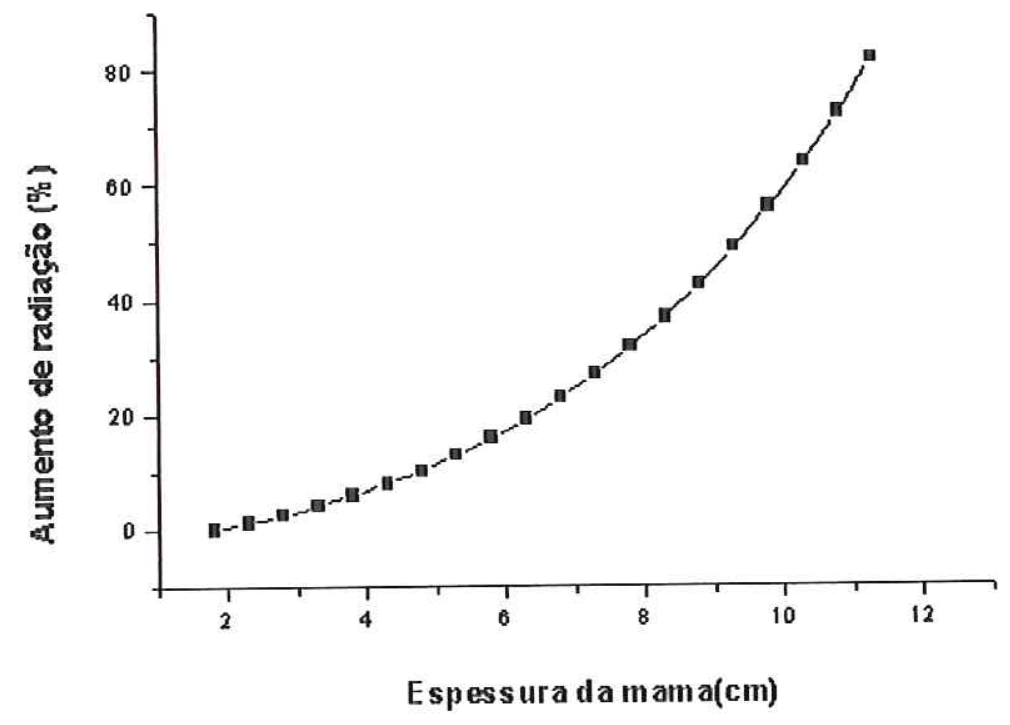

Figura 7. 28. Aumento da radiação espalhada na imagem simulada em função da espessura.

7.7.2 Analisando os resultados do CAD com imagens modificadas

Processamos as imagens tanto a original como as modificadas com o sistema CAD do Fujita Laboratory. Utilizamos parte do sistema CAD que proporciona a deteç̧ão de "clusters" de microcalcificações.

A Figura 7.29 mostra a imagem original, sem nenhum acréscimo de radiação espalhada, onde detectamos, por processamento, 36 microcalcificações (círculos pequenos) e 1 "cluster" de microcalcificações (círculo maior).

Submetemos ao processamento imagens onde aumentamos gradativamente a espessura da mama comprimida de 1,8 a $11,8 \mathrm{~cm}$. 


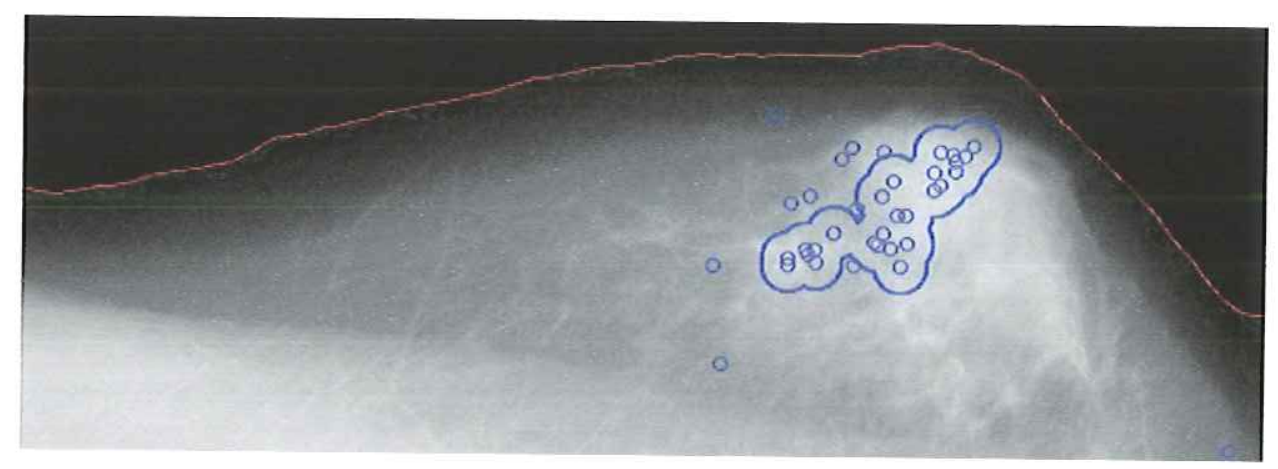

Figura 7. 29. Deteç̧ão de microcalcificações e "cluster" de microcalcificações na imagem original (1,8cm de espessura). As microcalcificações são identificadas pelos pequenos círculos e o "cluster" pelo circulo maior.

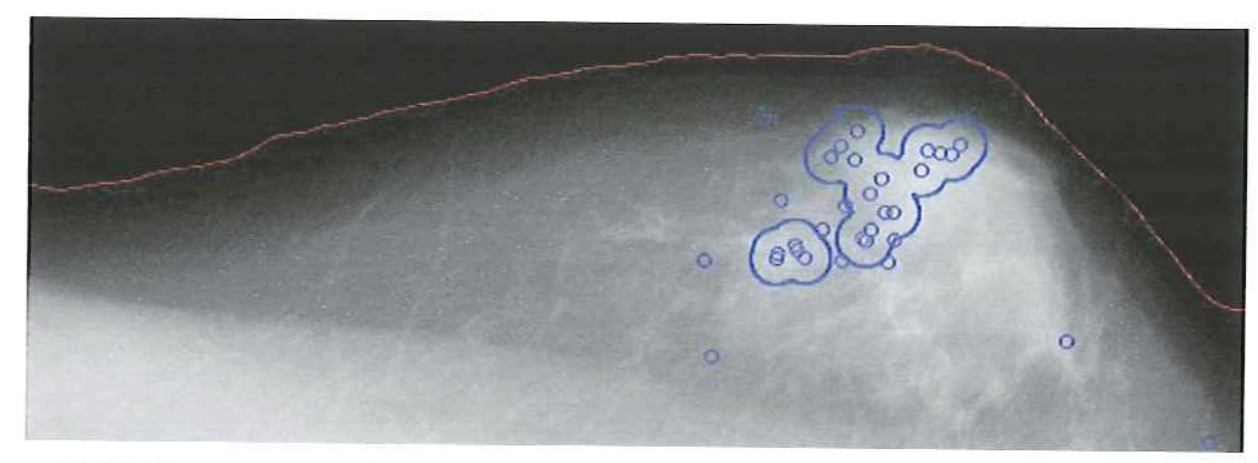

Figura 7. 30. Deteção de microcalcificações e "cluster" de microcalcificações na imagem da mama com $6,8 \mathrm{~cm}$ de espessura.

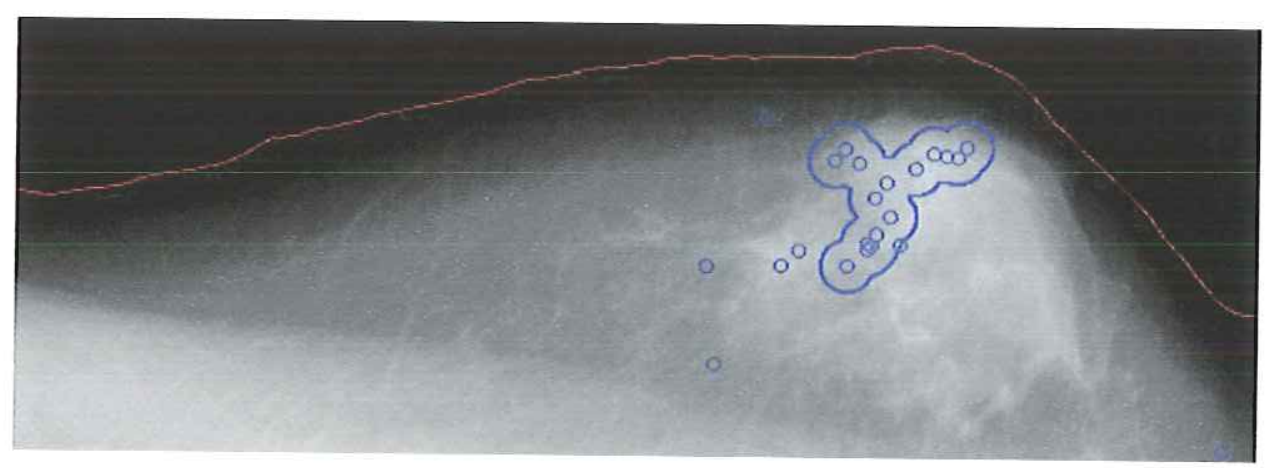

Figura 7. 31. Deteç̧ão de microcalcificações e "cluster" de microcalcificações na imagem da mama com mais de $8 \mathrm{~cm}$ de espessura.

Na Figura 7.30 mostramos o resultado da deteç̧ão para a imagem com aumento de $5 \mathrm{~cm}$ na espessura. Comparando com a Figura 7.29 que apresenta a imagem original, a quantidade de microcalcificações detectadas diminui e houve modificações na quantidade e na forma do "cluster". 
Quando acrescentamos $35 \%$ de radiação espalhada em relação à radiação total original (Figura 7.31) o que corresponde a um aumento de $8 \mathrm{~cm}$ na espessura da mama, 12 microcalcificações não foram detectadas isto é 1/3 destas foram ignorados.

Na Figura 7.32 apresentamos a deteç̧ão das microcalcificações do sistema CAD em função da espessura quando aumentamos gradativamente a espessura da mama comprimida de 1,8 a $11,8 \mathrm{~cm}$. Para avaliar o desempenho do CAD apenas em função do acréscimo de espalhamento, normalizamos os resultados pelo número de deteç̧ões que a imagem original proporcionou (deteç̧ão relativa). Sendo que, valores menores que 1 significam menos microcalcificações detectadas.

Podemos constatar que o desempenho do CAD permanece semelhante para a espessura de mama comprimida de até $3,8 \mathrm{~cm}$, decaindo rapidamente para espessuras maiores. Para a faixa das espessuras de mamas comprimidas consideradas normais, entre 2 e $9 \mathrm{~cm}$, a deteç̧ão mínima foi de 0,65 o que demonstra uma boa eficiência do CAD apesar do aumento da espessura e do conseqüente aumento do espalhamento.

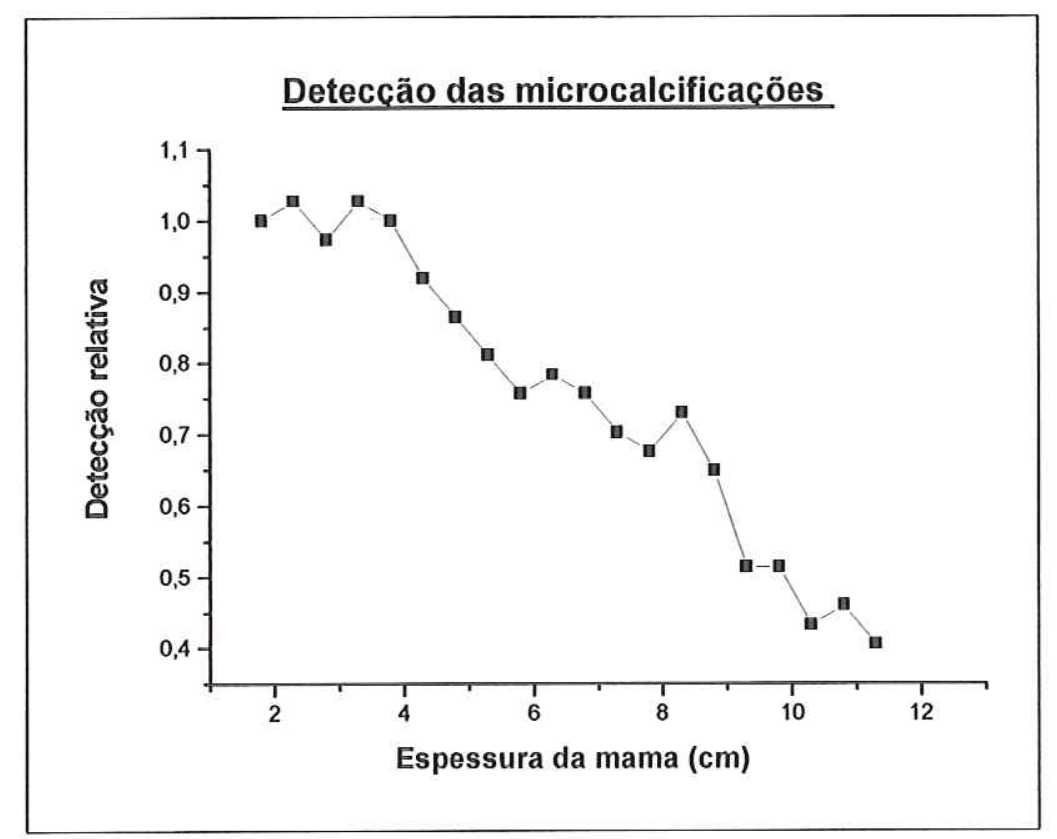

Figura 7. 32. Taxa de deteç̧ão de microcalcificações em função do aumento da espessura da mama. 


\subsubsection{Avaliação do erro}

No modelo, a determinação de $80 \%$ de tecido adiposo para a paciente de 72 anos pode não ser correta. Consideramos possível uma variação de $\pm 10 \%$, ou seja, para o nosso caso uma proporção de tecido adiposo que varia de $70 \%$ a $90 \%$. Portanto, calculamos novamente a taxa de espalhamento para estas novas proporções. No gráfico da Figura 7.33 o erro de $\pm 10 \%$ na estimativa da composição da mama proporciona uma variação da taxa de espalhamento de 0.02974 em relação ao valor calculado para mama de $1,8 \mathrm{~cm}$ de espessura e $80 \%$ de tecido adiposo. Se a espessura é aumentada para $11,8 \mathrm{~cm}$ esta variação chega a 0,61718 .

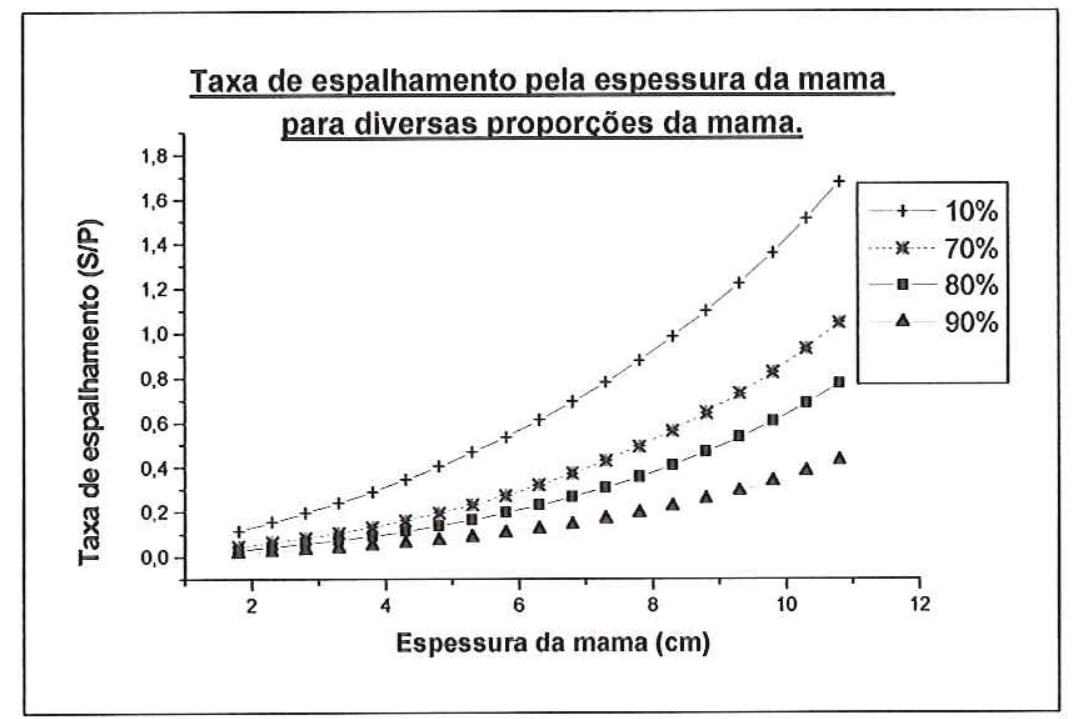

Figura 7. 33. Variação da taxa de espalhamento em função da espessura da mama para as diversas proporções de tecido adiposo.

Avaliamos também o erro que seria cometido se as proporções de tecidos fossem anormais para a faixa etária. Sendo que uma mama pode ter no mínimo $10 \%$ de tecido adiposo e no máximo $90 \%$. Para estas proporções extremas a variação da taxa de espalhamento para mama de $1,8 \mathrm{~cm}$ de 
espessura é de 0,09986. Se a espessura fosse aumentada para $11.8 \mathrm{~cm}$ esta variação poderia chegar a 1,24587.

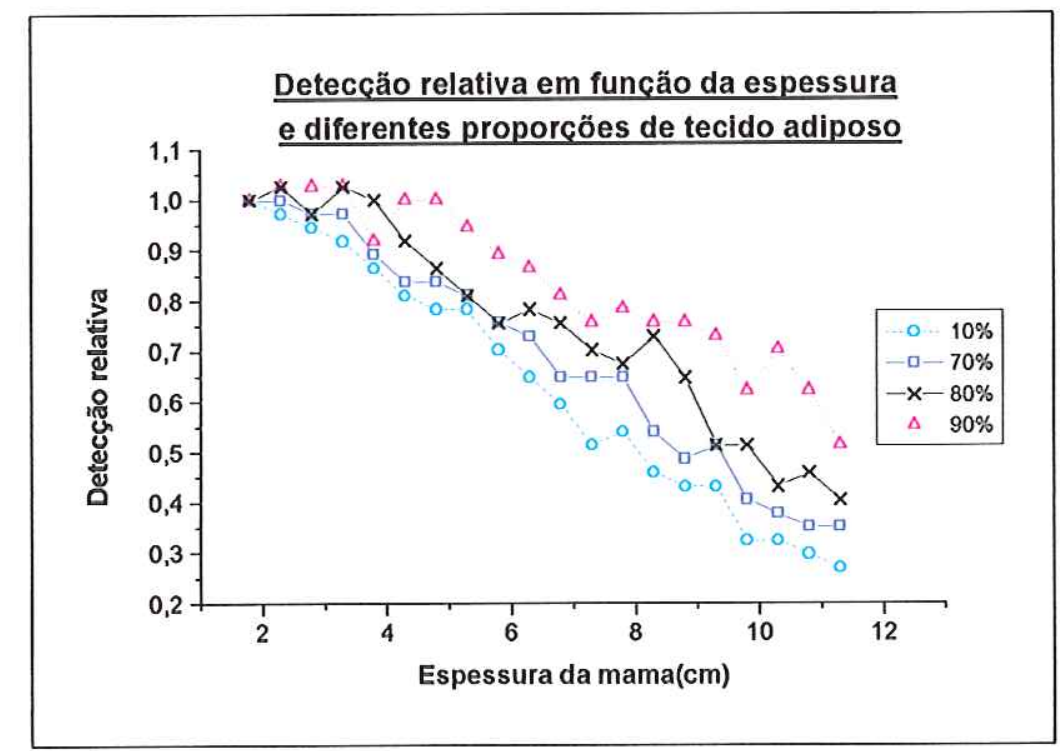

Figura 7. 34. Detecção relativa em função da espessura e proporções de tecido adiposo.

As variações possíveis da proporção do tecido adiposo de $70 \%$ a $90 \%$ não são significativas na detecção do sistema CAD (Figura 7.34), para a espessura de mama de $1,8 \mathrm{~cm}$. Para a mama de $11,8 \mathrm{~cm}$, caso o tecido adiposo seja de $70 \%$ da composição total, a detecção pode ser diminuída de $13,33 \%$ $(0,05406)$ Caso o tecido adiposo seja de $90 \%$ a deteç̧ão pode ser aumentada de $26,66 \%(0,1081)$. 


\section{CAPÍTULO 8. CONCLUSÕES.}

Apresentamos algoritmos que permitem quantificar as radiações espalhadas e projetar novos dispositivos, baseados na tecnologia slit, no intuito de melhorar a aquisição dos mamogramas. Eles também possibilitam a avaliação das melhorias trazidas por novos dispositivos ou por outros sistemas.

Desenvolvemos o protótipo de varredura de feixe de radiação modificando o princípio do método slit. Na literatura o método slit original foi utilizado apenas para diminuir a radiação espalhada. A vantagem do slit modificado é que, além da redução da radiação espalhada, ele possibilita a redução do tamanho do foco. Entretanto esta redução leva a uma diminuição da radiação primária, que é solucionada com o posicionamento do feixe na região onde a intensidade do campo é maior. A escolha da posição no campo de radiação onde a intensidade primária é maior devido ao efeito heel $\left(\beta_{2}=16,6^{\circ}\right)$ foi também calculada pelo algoritmo.

O modelo permite calcular o espalhamento produzido por qualquer configuração, já que podemos variar a geometria de exposição acrescentando ou retirando componentes da trajetória dos fótons no ato da formação de imagem. Esta flexibilidade é muito importante para averiguar a eficiência em reduzir ou não a quantidade de radiação espalhada que seria produzida por novos sistemas de aquisição.

Quantificamos os parâmetros $\left(\boldsymbol{S} / \boldsymbol{P}, \boldsymbol{T}_{\boldsymbol{p}}, \boldsymbol{T}_{\boldsymbol{s}}\right)$ para o sistema slit original e os comparamos aos valores obtidos com grade e com o slit modificado. A 
Tabela 8.1 mostra estes valores para faixa de $2,58 \mathrm{~mm}$ no centro do campo e $25 \mathrm{~mm}$ de espessura de Lucite.

Tabela 8. 1. Tabela comparativa entre os métodos slit original e modificado com método da convencional com grade.

\begin{tabular}{|c|c|c|c|}
\hline$\underline{\text { Parâmetros }}$ & Slit original & Slit modificado & Grade $^{\text {* }}$ \\
\hline $\mathbf{S} / \mathbf{P}$ & 0,0981 & 0,0153 & 0,2000 \\
\hline $\mathbf{T}_{\mathbf{p}}$ & 0,9999 & 0,6600 & 0,8000 \\
\hline $\mathbf{T}_{\mathbf{s}}$ & 0,0399 & 0,0230 & 0,2000 \\
\hline Foco $(\mathbf{m m})$ & 1,8600 & 1,2200 & Variável $^{* *}$ \\
\hline
\end{tabular}

* grade linear vibratório (CHAN\&DOI,1982)

** o foco varia de acordo com a posição no campo de radiação (característica de campo).

Com relação à dose recebida pelo paciente o método slit é superior ao da grade. Com a grade há um aumento de cerca de $25 \%$ na dose em relação a técnica sem redução do espalhamento. No sistema slit a radiação primária é atenuada antes de atingir o paciente (objeto radiografado) e no sistema com grade essa atenuação ocorre após ter passado pelo mesmo, o que implica que toda a dose transmitida não é utilizada para formar a imagem. Em termos de transmissão da radiação pós-paciente a transmissão da radiação primária no slit é sempre total, ou seja, toda radiação primária que sai do paciente atinge o sistema de registro. Portanto, para a mesma intensidade de radiação primária no plano filme é necessário um aumento da dose no modo grade.

Os resultados obtidos com a simulação do espalhamento estão de acordo com o descrito na literatura. Também podemos acrescentar a radiação espalhada desejada a qualquer imagem, sendo que a perda de informação na imagem à medida que aumentamos o espalhamento foi bem representada e o modelo permite que essa perda seja quantificada de imagem para imagem. Essa característica é relevante, pois cada mama possui composição e distribuição de estruturas diferenciadas. Nosso modelo aceita parâmetros que 
variam de acordo com a idade da paciente, a espessura da mama e as características da mamografia digitalizada.

A segunda aplicação dos algoritmos, a avaliação do desempenho de um sistema CAD, mostrou a flexibilidade do modelo e sua relevância na área das imagens médicas.

Os resultados obtidos pelo programa confirmam e quantificam as vantagens que podem ser alcançadas utilizando o método slit e possibilitam esta análise para outras técnicas de exposição radiográfica.

Proposta de trabalhos futuros.

1. Estudar por simulação computacional a influência dos parâmetros físicos dos sistemas radiológicos tais como: $\mathrm{kVp}, \mathrm{mAs}$, distância $\mathbf{d}_{\mathbf{f f}}$, distância $\mathbf{d}_{\mathbf{f o}}$ e magnificação sobre o desempenho dos sistemas CAD.

2. O mesmo estudo pode ser feito simulando o efeito da variação das estruturas radiografadas tais como: relação entre os tecidos adiposo e fibroso no caso da mama ou espessura e características das patologias.

3. A ferramenta desenvolvida que permite controlar a quantidade de espalhamento sobre as imagens seria também útil para estudar a eficácia de algoritmos para remoção deste tipo de ruído.

4. Seria necessário também desenvolver uma interface gráfica amigável, pois os algoritmos foram escritos para serem acionados através de comandos. 


\section{REFERÊNCIAS BIBLIOGRÁFICAS}

AMPLATZ, K; MOORE, R; KORBULY, D (1978). The "Swinging"tube: a new concept. Radiology 128, 783-785.

ANASTASIO,MA et al. (1998). A genetic algorithm-based method for optimizing the performance of a computer-aided diagnosis scheme for detection of clustered microcalcifications in mammograms. Med.Phys. 25(9), 1613-1620.

BARNES G.T.; BREZOVICH I. (1978). The intensity of scattered radiation in mammography, Radiology, vol.126, pp.244-247, Jan..

BARNES G.T., WU X., WAGNER A.J. (1993). Scanning slit mammography, Medical Progress through Technology, vol. 19, pp.7-12.

BARNES,GT; WU,X; SANDERS,PC. (1994). Scanning slit chest radiography: a practical and efficient scatter control design. Radiology 190, 525-528.

BERGER, M. J. et al. (1999). XCOM: Photon Cross Sections Database. National Institute of Standards and Technology, NBSIR 87-3597. Disponível em http://physics.nist.gov/PhysRefData/.

BOONE J.M. (1997). Molybdenum, rhodium, and tungsten anode spectral models using interpolating polynomials with application to mammography. Medical Physics, vol.24, n.12, pp.1862-1874.

BOONE J.M. (1999). A Monte Carlo study of x-ray fluorescence in x-ray detectors, Med Phys, vol 26(6), pp.905-916.

BOYLE,ER; PAK,D; WILLIAMS,JB. (1999). Motion artifact seen on slot-scanning direct digital mammography. AJR 172, 697-701.

CASTANEDA-ZUNIGA,W.R. et al. (1980). Routine magnification lymphangiography with a swing slot X-ray machine. Radiology 137, 231-234.

CHAN H.P., DOI K. (1982). Investigation of the performance of antiscatter grids: Monte Carlo simulation studies. Phys. Med. Biol., vol 27(6), pp.785-803.

CHAN H.P., DOI K. (1983). "Radiation dose in diagnostic radiology: Monte Carlo simulation studies." Med Phys, vol 26(6), pp.905-916.

CHAN,HP; DOI,K (1983a). The validity of Monte Carlo simulation in studies of scattered radiation in diagnostic radiology. Phys. Med. Biol. 28(2), 109-129.

CHAN,HP; DOI,K (1983b). Energy and angular dependence of X-ray absorption and its effect on radiographic response in screen-film systems. Phys. Med. Biol. 28(5), 565-579. 
CHAN,HP; DOI,K. (1985). Physical characteristics of scattered radiation in diagnostic radiology: Monte Carlo simulation studies. Med. Phys. 12(2), 152-165.

CURRY III,TS; DOWDEY,JE; MURRY,R.C. (1990). Christensen's Physics of Diagnostic Radiology. Ed. Lea \& Febiger, Philadelphia, 4th Edition. 1990.

DANCE,DR (1980). The Monte Carlo calculation of integral radiation dose in xeromammography. Phys. Med. Biol. 25(1), 25-37.

DOI, K (1977). Field Characteristics of Geometric Unsharpness Due to the X-ray Tube Focal Spot Med. Phys. - vol 4 (1) - pgs 15-20.

DOI K. et al. (1999). Computer-aided diagnosis in radiology: potential and pitfalls. Eur J Radiol. Aug, 31(2):97-109. Review.

FUJITA H.et al. (1995). Automated Detection of Masses and Clustered Microcalcifications on Mammograms. Proc. of SPIE -The International Society for Optical Engineering, Medical Imaging: Image Processing, 2434, 682-692. 1995.

HIRAKO K. et al. (1995). Development of detection filter for mammographic microcalcifications: A method based on density gradient and triple-ring filter analysis, The Transactions of the Institute of Electronics, Information and Communication Engineers D-II , vol.J78-D-II, pp.1334-1345.

HUBBELL,JH (1975). Atomic form factors, incoherent scattering functions, and photon scattering cross sections. J. Chem. Ref. Data 4(3), 471-538.

HUBBELL J.H.(1999). Review of fóton interaction cross section data in the medical and biological context, Phys Med Biol, vol.44(1), pp.1-22, Jan.

IBRAHIM N. (1997). Automated detection of clustered microcalcifications on mammograms: CAD system application to MIAS database. Phys Med Biol, vo42(12), 2577-2589.

IRITA, R.T. (1999a). Simulação de colimador externo para a melhoria da nitidez de imagens mamograficas, Dissertação (Mestrado) - Escola de Engenharia de São Carlos, Universidade de São Paulo - SEL/EESC/USP, São Carlos. 1999.

IRITA, R.T. et al. (1999b). Simulation of external collimator to enhancement of mammographic image sharpness, Proceedings of European Medical \& Biological Engineering Conference, vol.2, pp.1250-1251, Viena, 04-07 Nov.

IRITA, R.T., FRERE, A.F., FUJITA, H. (2002). Simulation model to analyze the scatter radiation effects on breast cancer diagnosis by CAD system. Proc. of SPIE -The International Society for Optical Engineering, Medical Imaging, v.4682, p.782 - 791.

JAFFE,C; WEBSTER,EW. (1975). Radiographic contrast improvement by means of slit radiography. Radiology 116, 631-635.

JING, Z., HUDA, W., WALKER, J.K. (1998). Scattered Radiation In Scanning Slot Mammography. Med. Phys., v.25 n. 7, 1111-1117.

JONHS,H.E.; CUNNINGHAM,JR. (1983). The Physics of Radiology, 3rd Ed.. Charles C. Thomas Publisher, Springfield, Illinois, USA. 1983.

KALENDER,W. (1981). Monte Carlo calculations of x-ray scatter data for diagnostic radiology. Phys. Med. Biol. 26(5), 835-849.

KALLERGI,M; CARNEY,GM; GAVIRIA,J (1999): Evaluating the performance of deteccion algorithms in digital mammography. Med.Phys. 26(2), 267-275. 
KATO M. et al. (1998). Elimination of false-positive candidates by dynamic thresholding technique in a automated detection of clustered microcalcifications. Gazou Ga-kai , vol.15(3), pp.171-178.

KING,MA (1983): Exposure uniformity considerations in slit radiography. Med. Phys. 10(1), 4-9.

KORBULY,D et al. (1980). Scanography with rotation of the radiographic tube: a new method. Radiology 135, 495-499.

LEE N.A. et al. (1997). Fatty and fibro gladular tissue volumes in the breasts of women 20-83 years old: comparison of X-ray mammography and computer-assisted MR imaging, AJR - American Journal Roentgenol, vol. 168(2), pp 501-506, Feb.

MOORE,R; KORBULY,D; AMPLATZ,K. (1977). Removal of scattered radiation by moving-slot radiography. Applied radiology 1, 85-88.

NEITZEL,U; KOSANETZKY,J; HARDING,G. (1985). Coherent scatter in radiographic imaging: a Monte Carlo Study. Physics Medicine and Biology 30(12), 1289-1296.

NISHIKAWA R.M. (1994). Effect of case selection on the performance of computer-aided detection schemes. Med. Phys. 21 (2) 265-269.

OLIVEIRA, H. J. Q. (1995). Simulação computacional da nitidez de imagens radiológicas para controle de qualidade, Dissertação (Mestrado) - Escola de Engenharia de São Carlos, Universidade de São Paulo - SEL/EESC/USP, São Carlos. 1995.

PEPLOW D.E., VERGHESE K.(1998), "Monte carlo modeling of mammographic Images", Transactions of American Nuclear Society, vol.79, pp.163-164.

ROGERS, D.W.O. et al. (2000). NRC User Codes for EGSnrc. NRC Report PIRS-702, Feb.

SILVA, M.A., FRÈRE, A.F. (2001). Determinação Da Curva H\&D Por Simulação Computacional. Proceedings of II Congreso Latinoamericano de Ingeniería Biomédica, Havana, Cuba, 23-25 Maio.

TESIC, M.M., SONES,RA, MORGAN,DR. (1983). Single-slit digital radiography: Some practical considerations. American Roentgen Ray Society, v.142, 697-702.

VUORINEN,P. (1959). The roentgenographic slit methods. Acta Radiologica 177, 1-88.

YAFFE,MJ. (1993). Direct digital mammography using a scanned-slot CCD imaging system. Medical Progress through Technology, 19, 13-21. 